\title{
2
}

US. Department of Transpontarion. Federal Highwoy Administration

Intelligent

Transportation Systems (ITS)

\section{ITS Benefits: Continuing Successes and Operational Test Results}




\section{Notice}

This document is disseminated under the sponsorship of the Department of Transpcrtation in the interest of information exchange. The United States Government assumes no liability for its contents or use thereof. 
Technical Report Documentation Page

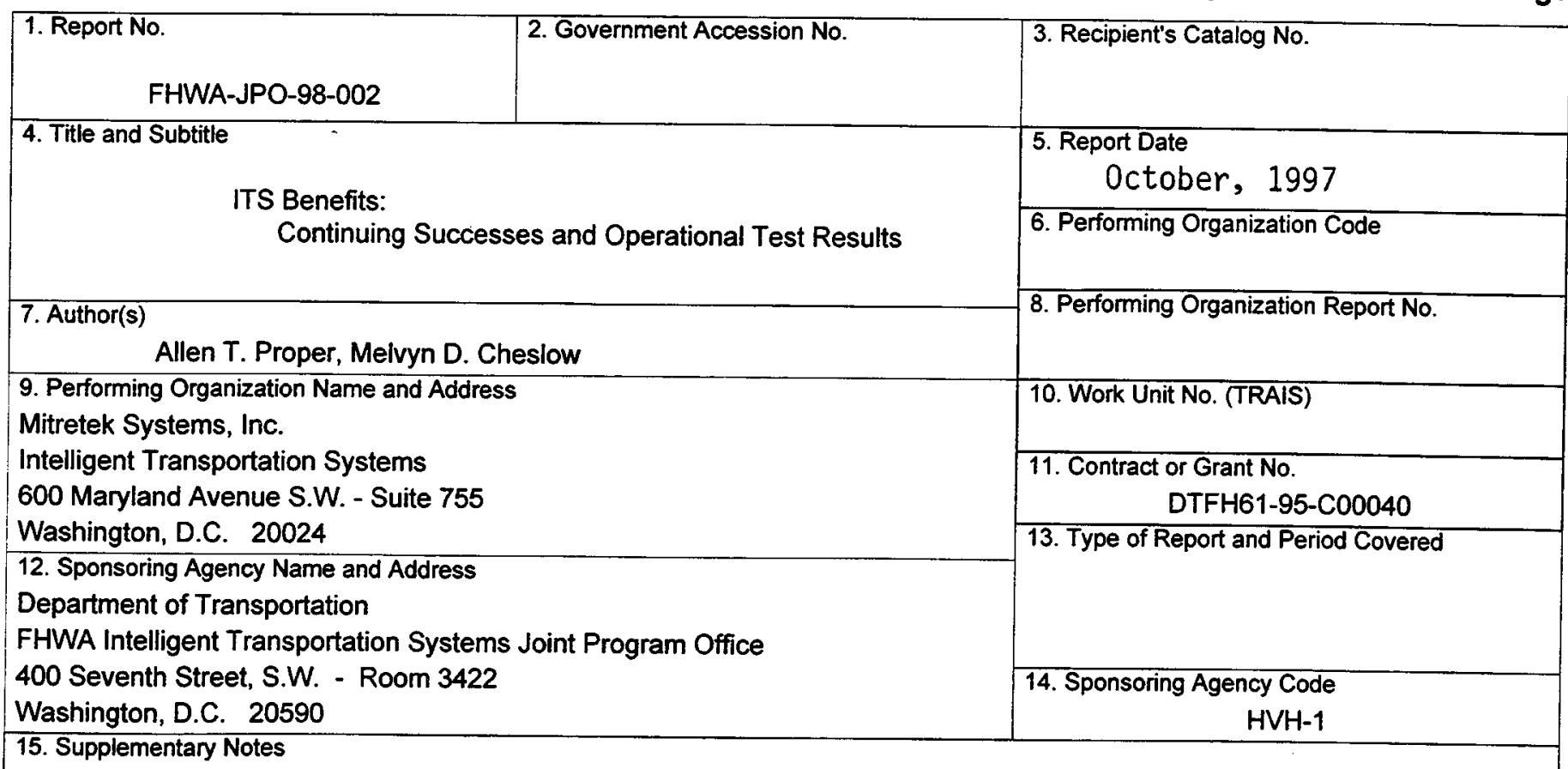

\section{Joe Peters}

\section{Abstract}

This report continues to build upon empirical results from field operations of deployed systems, supplemented with benefits information based upon modeling studies and statistical studies. It differs from previous reports in that results from the federally sponsored ITS field operational tests are explicitly identified.

This report continues the emphasis that has been placed on the use of evaluation results to satisfy the requirements of the Government Performance and Results Act of 1993. Its organization reflects a focus on the use of limited number of key measures of ITS effectiveness. The intent is to focus on a few measures that are robust enough to represent the goals and objectives of the entire ITS program, yet are few enough to be affordable in tracking the progress of the ITS program on a yearly basis. These measures are: Time, Crashes, Fatalities, Throughput, Cost, and Customer Satisfaction. Other important measures include Emissions and Fuel Consumption.

This report is intended to be a reference report. It highlights benefits identified by other authors and refers the reader to information sources. The interested reader is encouraged to obtain source documents to appreciate the assumptions and constraints placed upon interpretation of results. It is the intent of the ITS Joint Program Office to update this report periodically.

\section{Key Words}

Intelligent Transportation Systems(ITS), ITS Infrastructure, ITS Benefits, Benefit to Cost Analysis, ATIS, ATMS, CVO CVISN
18. Distribution Statement

No restrictions. This document is available to the public from.

The National Technical Information Service Springfield, Virginia 22161
19. Security Classif. (of this report) Unclassified
20. Security Classif. (of this page)

Unclassified

\begin{tabular}{|c|c|}
\hline 21. No. of Pages & 22. Price \\
152 & \\
\hline
\end{tabular}




\section{PREFACE}

The Federal Intelligent Transportation Systems (ITS) program, came into being as a result of the Intermodal Surface Transportation Efficiency Act of 1991. In the years since, the ITS field has developed from a collection of ideas and isolated applications of technology into an interrelated program with initial projects already yieiding benefits for the nation's surface transportation system. Since December of 1994, the United States Department of Transportation's (USDOT's) ITS Joint Program Office (JPO) has been actively collecting information on the impact of ITS projects on the operation of the surface transportation network.

The first ITS benefits report sponsored by the JPO was published in August 1995. Between the publication of that report and this report, the ITS program has continued to develop. In January 1996, the Secretary of Transportation announced "Operation TimeSaver" which seeks to install an ITS infrastructure in major US metropolitan areas. In support of the announcement, a second report focused on the benefits of a metropolitan infrastructure implementation. The last report in the series was published in September 1996.

This report continues to build upon empirical results from field operations of deployed systems, supplemented with benefits information based upon modeling studies and statistical studies. It differs from previous reports in that results from the federally sponsored ITS field operational tests are explicitly identified.

This report continues the emphasis that has been placed on the use of evaluation results to satisfy the requirements of the Government Performance and Results Act of 1993. Its organization reflects a focus on the use of a limited number of key measures of ITS effectiveness. The intent is to focus on a few measures that are robust enough to represent the goals and objectives of the entire ITS program, yet are few enough to be affordable in tracking the progress of the ITS program on a yearly basis. These measures are: Time, Crashes, Fatalities, Throughput, Cost, and Customer Satisfaction. Other important measures include Emissions and Fuel Consumption.

This report is intended to be a reference report. It highlights benefits identified by other authors and refers the reader to information sources. The interested reader is encouraged to obtain source documents to appreciate the assumptions and constraints placed upon interpretation of results. It is the intent of the ITS Joint Program Office to update this report periodically.

The JPO will continue to sponsor field operational tests, model deployments, showcase projects and deployment incentives to identify and measure costs and benefits of ITS. Several recent initiatives include the metropolitan and Commercial Vehicle Information Systems and Networks (CVISN) Model Deployment Initiatives (MDI), and the deployment incentive program as part of the proposed extension to the Intermodal Surface Transportation Efficiency Act (ISTEA).

In Fall 1996, the ITS Joint Program Office initiated the Metropolitan MDI program. This program provides for model deployments of the metropolitan ITS infrastructure in the New York/New Jersey/Connecticut, Phoenix, San Antonio, and Seattle metropolitan areas. Model deployments of the Commercial Vehicle Information Systems and Networks (CVISN) are also being initiated. Maryland and Virginia are currently developing a prototype version of CVISN and the following 
states have been announced as deployers of pilot versions of CVISN: California, Colorado, Connecticut, Kentucky, Michigan, Minnesota, and Washington/Oregon. Over the past 12 to 18 months, the metropolitan and CVISN model deployment sites prepared detailed plans for deploying the ITS infrastructure starting in early 1998. Baseline data collection for the evaluation studies began in the third quarter of 1997, and will be followed by at least 12 months of evaluation data collection starting in early 1998 . Within the next two years, a systematic picture of the benefits of Metropolitan and CVISN model deployments will emerge.

New rural field operational tests are expected to be initiated in late 1997 and early 1998. In addition, as the existing field operational tests mature, cost and benefits data from them will be recorded in future reports.

It is anticipated that the next report will contain early results from some of these initiatives as well as additional field operational test results. In addition cost estimates of ITS will be included for the first time. These will include the estimates that have been made for ITS equipment, services, and systems. Generally, the benefit estimates reviewed do not provide this type of detail. Hence, it is expected that in only a few cases will costs estimates be made for the previously available benefit estimates. In addition, new benefit/cost analyses will become available that will augment the results that are presented in Appendix C. For example, the Metropolitan Model Deployment Initiative that is being carried out in several metropolitan areas will provide future benefit/cost results.

To aid the distribution of the information in this report, the full contents will be placed on USDOT's homepage on the internet at www.its.dot.gov/reading/pubs.html

There are also many ITS efforts initiated by states, local governments, and private enterprise. Readers who are aware of important ITS benefits and cost information from these and other sources are encouraged to send reference documents to:

Dr. Joseph Peters

ITS Program Assessment Coordinator ITS Joint Program Office Federal Highway Administration (HVH-1) $4007^{\text {th }}$ Street, SW Washington, DC 20590 


\section{TABLE OF CONTENTS}

PREFACE

TABLE OF CONTENTS

EXECUTIVE SUMMARY

iii

1.0 INTRODUCTION

1.1 GOALS FOR THIS REPORT

1.2 PREVIOUS REPORTS

1.3 DEFINITION OF TERMS

2

1.3.1 Classes of Benefits Data

1.3.2 System Groups 3

1.3.3 A Few Good Measures $\quad 4$

1.3.4 Related System Initiatives 4

1.4 SCOPE AND ORGANIZATION OF REPORT 5

1.5 DATA AVAILABILITY 6

2.0 SAFETY BENEFITS OF ITS

2.1 CRASHES 7

2.1.1 Crash Reduction Benefits of ATIS 9

2.1.2 Crash Reduction Benefits of ATMS 10

2.1.3 Crash Reduction Benefits of CVO 11

2.1.4 Crash Reduction Benefits of AVCSS 11

2.1.5 Crash Reduction Benefits of Integrated Systems $\quad 12$

2.2 FATALITIES 13

2.2.1 Fatality Reduction Benefits of ATIS 13

2.2.2 Fatality Reduction Benefits of CVO 13

2.2.3 Fatality Reduction Benefits of AVCSS 14

2.2.4 Fatality Reduction Benefits of Integrated Systems $\quad 14$ 
3.0 TIME 15

3.1 Time Benefits of ATIS 16

3.2 Time Benefits of ATMS 19

3.3 Time Benefits of APTS 22

3.4 Time Benefits of CVO 22

3.5 Time Benefits of AVCSS 23

4.0 THROUGHPUT 24

4.1 Throughput Benefits of ATIS 25

4.2 Throughput Benefits of ATMS 25

4.3 Throughput Benefits of AVCSS 26

$\begin{array}{ll}5.0 \operatorname{COST} & 27\end{array}$

5.1 Cost Reduction Benefits of ATMS 28

5.2 Cost Reduction Benefits of APTS 28

5.3 Cost Reduction Benefits of CVO 30

5.4 Cost Reduction Benefits of Integrated Systems 32

6.0 CUSTOMER SATISFACTION 33

6.1 Customer satisfaction Benefits of ATIS 33

6.2 Customer Satisfaction Benefits of ATMS 35

6.3 Customer Satisfaction Benefits of APTS 35

6.4 Customer Satisfaction Benefits of CVO 36

6.5 Customer Satisfaction Benefits of Integrated Systems 37

7.0 EMISSIONS AND FUEL CONSUMPTION BENEFTIS OF ITS 38

7.1 Emissions and Fuel Consumption Benefits of ATIS 38

7.2 Emissions and Fuel Consumption Benefits of ATMS 39

7.3 Emissions and Fuel Consumption Benefits of CVO 40

8.0 BIBLOGRAPHY 41 
A.1 TRANSIT SYSTEMS A-3

A.1.1 TravLink A-3

A.2 HIGHWAY SYSTEMS (ATMS/ATIS) A-4

A.2.1 Puget Sound Help Me (PuSHMe) Mayday System A-4

A.2.2 Multi-Jurisdictional Live Aerial Video surveillance A-4

A.2.3 Genesis A-5

A.2.4 Atlanta A-5

A.2.5 Smart Call Box A-6

A.2.6 Travel Demand Management Emissions Detection (TDM-ED) Ada County A-6

A.2.7 CAPITAL A-7

A.2.8 Spread spectrum radio Traffic Interconnect (RTI) A-7

A.2.9 Advance rural Transportation Information and Coordination (ARTIC) A-7

A.3 HIGHWAY SYSTEMS (CVO) A-8

A.3.1 Advantage I-75 A-8

A.3.2 Electronic One-Stop Shopping Operational Tests A-8

A.3.3 Advantage I-75; One-Stop Shopping; Out-of-Service Verification (Wisconsin/Minnesota) A-8

A.3.4 Operation RESPOND A-9

A.3.5 Trilogy A-9

A.4 Bibliography of Appendix A A-10

APPENDIX B: Summary of Results from APTS Operational Test B-1

APPENDIX C: National Analyses of ITS Benefits $\quad$ C-1 


\section{LIST OF FIGURES}

Figure 1 - Range of Measured Crash Reduction Benefits 8

Figure 2 - Range of Measured Travel Time Reduction Benefits 16

Figure 3 - Range of Measured Throughput Improvement Benefits 24

Figure 4 - Range of Measured Improvement in Operating Costs and Productivity 27

Figure B1 - Total APTS System Benefits $\quad$ B-2

\section{LIST OF TABLES}

Table 1 : Summary of ITS Benefits Data Availability 6

Table 2: Summary of Accident Reduction Data for Ramp Meters 8

Table 3 : Summary of Travel Time Benefits Achieved by Ramp Meters 15

Table 4 : Summary of Travel Time Benefits Achieved by Traffic Signal Control 15

Table 5 : Summary of Throughput and Volume Data for Freeway Management Systems

Table A-1 : Operational Tests that Produced Evaluation Results since Spring 1996A-2

Table A-2 : Operational Tests that Should Produce Evaluations in Near Future A-3

Table B-1 : Total APTS System Benefits

B-2 


\section{EXECUTIVE SUMMARY}

The Federal intelligent Transportation Systems (ITS) program came into being as a result of the Intermodal Surface Transportation Efficiency Act of 1991. In the years since, the ITS field has developed from a collection of ideas and isolated applications of technology into an interrelated program with initial projects already yielding benefits for the nation's surface transportation system. Since December of 1994, the United States Department of Transportation's (USDOT's) ITS Joint Program Office (JPO) has been actively collecting information on the impact of ITS projects on the operation of the surface transportation network.

This report continues the process of documenting and publicizing experience with, and prediction of, benefits from ITS in the context of continuing assessment of the ITS program. This benefits review effort is part of a larger effort sponsored by the ITS Joint Program Office to develop benefits knowledge about ITS implementation. This report summarizes major ITS benefits findings while referring the interested researcher to detailed studies or contacts. Each update of this report seeks to improve the completeness and reliability of relevant data, with the ultimate goal being validated results from field measurement for all areas of ITS.

The data collection for ITS benefits review began by focusing on experience with the federally funded Field Operational Tests and other deployed systems providing services similar to ITS user services. The U.S. DOT has funded 84 Field Operational Tests of technologies and operational concepts related to Intelligent Transportation Systems. Although some of these tests began in the early part of the $1990 \mathrm{~s}$, most of them began later in the decade. There has been awareness of the operational test activities for many years, but it has been only recently that significant evaluation results have been produced. Evaluation results from these tests that have been published to date are included in the main body of the current report where appropriate. Results from these test, published within the last year are also included in an appendix. In addition, appendixes that summarize several other ITS related reports, benefit to cost analysis, and ongoing studies have been included in this report.

New sources of benefit information are developing as a result of recent Federal initiatives. These include the Metropolitan Model Deployment Initiatives (MDIs), Commercial Vehicle Information Systems and Networks (CVISN) model deployment initiatives, showcases (e.g., Partners in Motion, Atlanta), and deployment incentives as part of the proposed extension of the Intermodal Surface Transportation Efficiency Act (ISTEA).

Data in this report are organized by key outcome measure, then by groups of systems (ATIS, ATMS, etc.), and finally by class of benefit (measured, anecdotal, and predicted). This report continues the emphasis that has been placed on the use of evaluation results to satisfy the requirements of the Government Performance and Results Act of 1993. Its organization reflects a focus on the use of a limited number of key measures of ITS effectiveness. Known as a "few good measures," these measures are: Time, Crashes, Fatalities, Throughput, Cost, and Customer Satisfaction. This report adopts the groups found in the 1996 edition of Intelligent Transportation Systems (ITS) Projects: Advanced Traveler Information Systems, Advanced Traffic Management Systems, Advanced Public Transportation Systems, Advanced Rural Transportation Systems, Commercial Vehicle Operations, Advanced Vehicle Control and Safety Systems, and Integrated Systems. Benefits data are available from a number of sources that vary in precision, accuracy, and repeatability. Knowledge of benefits described in this report are categorized into the following classes: 
Measured - outcome results from field measurement of benefits through studies, which are the most compelling

Anecdotal - estimates made by people directly involved in field projects, which are also compelling, but less reliable than measured outcomes in terms of quantitative benefits estimates

Predicted -- results from analysis and simulation, which can be useful tools to estimate impact of an ITS deployment when field experience is not available or when projects are not of sufficient scope to determine system impact

The focus of this knowledge is on the term "outcome measure" which is adopted from the Government Performance and Results Act of 1993.

The evaluation of ITS and precursor systems has been an ongoing process. Significant knowledge is available, but gaps in knowledge also exist. Table ES-1 summarizes the availability of benefits knowledge.

Table ES-1: Summary of ITS Benefits Data Availability

\begin{tabular}{|c|c|c|c|c|c|c|c|}
\hline \multirow[b]{2}{*}{ Measure } & \multicolumn{3}{|c|}{ Travel Management } & \multirow[b]{2}{*}{ ARTS } & \multirow[b]{2}{*}{ CVO } & \multirow[b]{2}{*}{ AVCSS } & \multirow[b]{2}{*}{ Integrated } \\
\hline & ATIS & ATMS & APTS & & & & \\
\hline \multirow[t]{2}{*}{ Safety Measure } & $y^{2}=2=$ & $x^{2}$ & $\sqrt{12}$ & 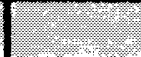 & & : & \\
\hline & Measured & Measured & & & & Measured & Measured \\
\hline \multirow[t]{2}{*}{ Crashes } & Anecdotal & & & & Anecdotal & Anecdotal & \\
\hline & Predicted & & & & & Predicted & \\
\hline \multirow{3}{*}{ Fatalities } & & & & & & & \\
\hline & Anecdotal & & & & & Anecdotal & Anecdotal \\
\hline & & & & & Predicted & & Predicted \\
\hline \multirow{3}{*}{ Time } & Measured & Measured & Measured & & Measured & & \\
\hline & Anecdotal & Anecdotal & Anecdotal & & & & \\
\hline & Predicted & Predicted & & & Predicted & Predicted & \\
\hline \multirow{3}{*}{ Throughput } & & Measured & & & & & \\
\hline & & & & & & & \\
\hline & Predicted & & & & & Predicted & \\
\hline \multirow{3}{*}{ Cost } & & Measured & Measured & & Measured & & \\
\hline & & & & & Anecdotal & & \\
\hline & & Predicted & Predicted & & Predicted & & Predicted \\
\hline \multirow{3}{*}{$\begin{array}{l}\text { Customer } \\
\text { Satisfaction }\end{array}$} & Measured & Measured & Measured & & Measured & & Measured \\
\hline & Anecdotal & & Anecdotal & & & & \\
\hline & & & & & Predicted & & \\
\hline
\end{tabular}


Reducing the number of crashes is an important aspect of improving safety. While the relationships between reduced crashes and other important statistics such as fatalities, injuries, and nonrecurrent delay vary with a number of factors, reducing crashes will tend to improve all of these statistics. Table ES-2 and Figure ES-1 show the percentage reduction in crashes achieved in some operational systems and law enforcement procedures. (Note: MCSAP refers to the Motor Carrier Safety Assistance Program.) While three classes of benefits knowledge are available only measured results are provided in this and subsequent figures. The reader should refer to reference documents cited in the main body of this paper to interpret the conditions under which these ranges are reported. The number of sources used to estimate the ranges of benefits are shown under the axis labels indicating the type of system considered. The high and low estimates are reported in figures for the number of measurements available from reference sources $(\mathrm{N})$.

Table ES-2: Summary of Accident Reduction Data for Ramp Meters

\begin{tabular}{|l|l|r|l|}
\hline \multicolumn{1}{|c|}{ Location } & \multicolumn{1}{|c|}{ State } & $\begin{array}{r}\text { Accident } \\
\text { Reduction }\end{array}$ & \multicolumn{1}{|c|}{ Type } \\
\hline Denver & CO & $5 \%$ & Rear/Side \\
\hline Denver & CO & $50 \%$ & Rear/Side \\
\hline Portland & Oregon & $43 \%$ & Total accidents \\
\hline Minneapolis/ST. Paul & Minn. & $24 \%-27 \%$ & Total accidents \\
& & $38 \%$ & Accident rate \\
\hline Seattle & WA & $39 \%$ & Accident rate \\
\hline Detroit & MI & $50 \%$ & Total accidents \\
& & $71 \%$ & Injuries \\
\hline Long Island & NY & $15 \%$ & Frequency \\
\hline
\end{tabular}
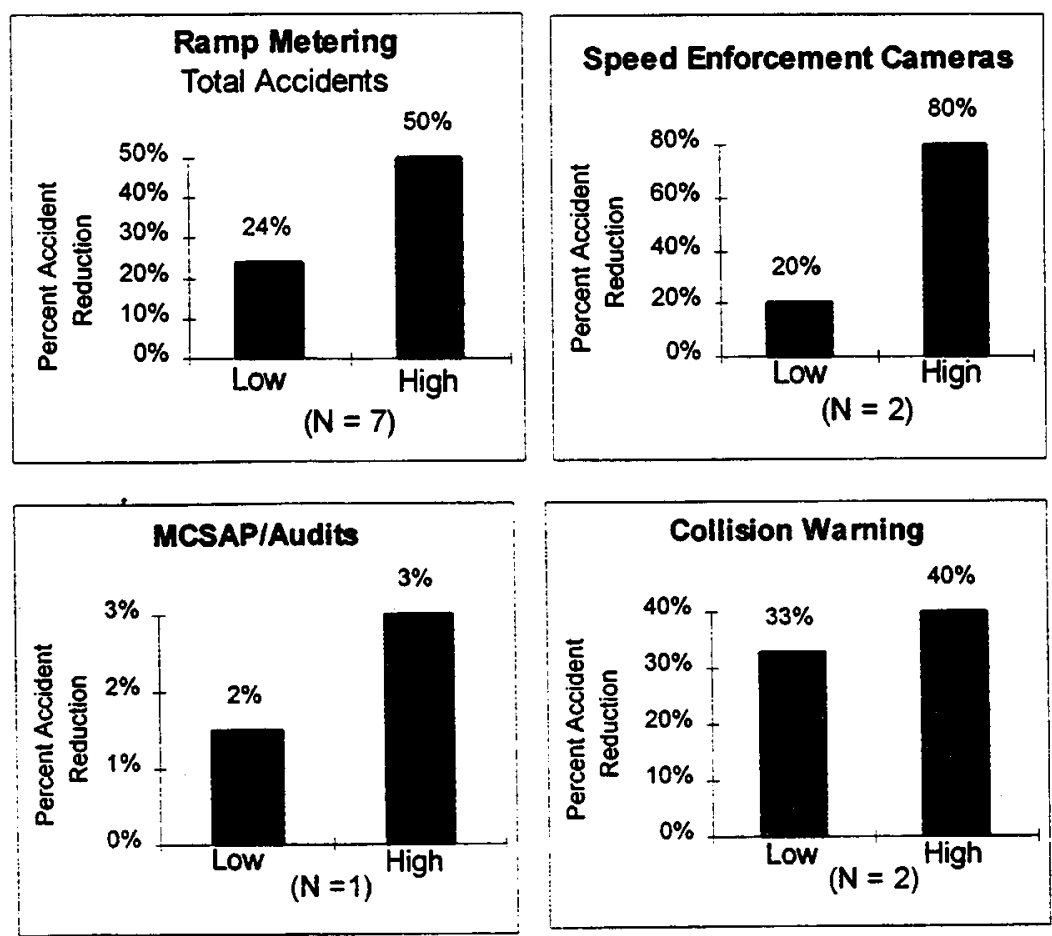

Figure ES-1: Range of Measured Crash Reduction Benefits 
Since a fatality resulting from a crash can be prevented if the crash is avoided, systems that reduce the number of crashes also reduce fatalities. In addition, systems that reduce the severity of the crash, the consequences of the crash, or emergency medical services response times to victims of the crash also reduce the number of fatalities and the extent of injuries. The ITS benefits data on fatality reduction are mostly predicted versus measured in the field due to the long-term nature of fatality reduction efforts.

Reduction in travel time and delay is a major goal of the US DOT's ITS program. The US DOT initiative in this area acquired the theme "Operation TimeSaver." Tables ES-3, ES-4 and Figure ES-2 shows the range of percentage reductions in travel times achieved in some operational systems.

Table ES-3: Summary of Travel Time Benefits Achieved by Ramp Meters

\begin{tabular}{|l|l|r|l|}
\hline \begin{tabular}{l|l|l|}
\hline Location \\
City
\end{tabular} & State & \multicolumn{2}{|l|}{$\begin{array}{l}\text { Travel Time Data } \\
\text { Reduction }\end{array}$} \\
\hline Denver & Type \\
\hline & & $13.1 \%$ & Vehicle Hours \\
& $26.7 \%$ & Travel Time \\
\hline Portland & Oregon & $7.4 \%$ & Travel Time \\
\hline Minneapolis/ST. Paul & Minn. & $26.5 \%$ & Travel Time \\
\hline Minneapolis/ST. Paul & Minn. & $13.8 \%$ & Travel Time \\
\hline Seattle & WA & $47.7 \%$ & Travel Time \\
\hline Denver & CO & $37 \%$ & Travel Time \\
\hline Detroit & MI & $7.4 \%$ & Travel Time \\
\hline Austin & TX & $37.5 \%$ & Travel Time \\
\hline Long Island & NY & $20 \%$ & Travel Time \\
\hline
\end{tabular}

Table ES-4: Summary of Travel Time Benefits Achieved by Traffic Signal Control

\begin{tabular}{|l|l|r|l|}
\hline \begin{tabular}{l|l|} 
Location \\
City
\end{tabular} & State & $\begin{array}{r}\text { Travel Time/Delay Reduction } \\
\text { Reduction }\end{array}$ & Type \\
\hline Los Angeles & CA & $18 \%$ & Travel Time \\
& & $44 \%$ & Delay \\
\hline Toronto & Ontario & $8 \%$ & Travel Time \\
& & $17 \%$ & Delay \\
\hline Abilene & TX & $14 \%$ & Travel Time \\
& & $37 \%$ & Delay \\
\hline ITE Estimate & & $8 \%-25 \%$ & Travel Time \\
\hline
\end{tabular}



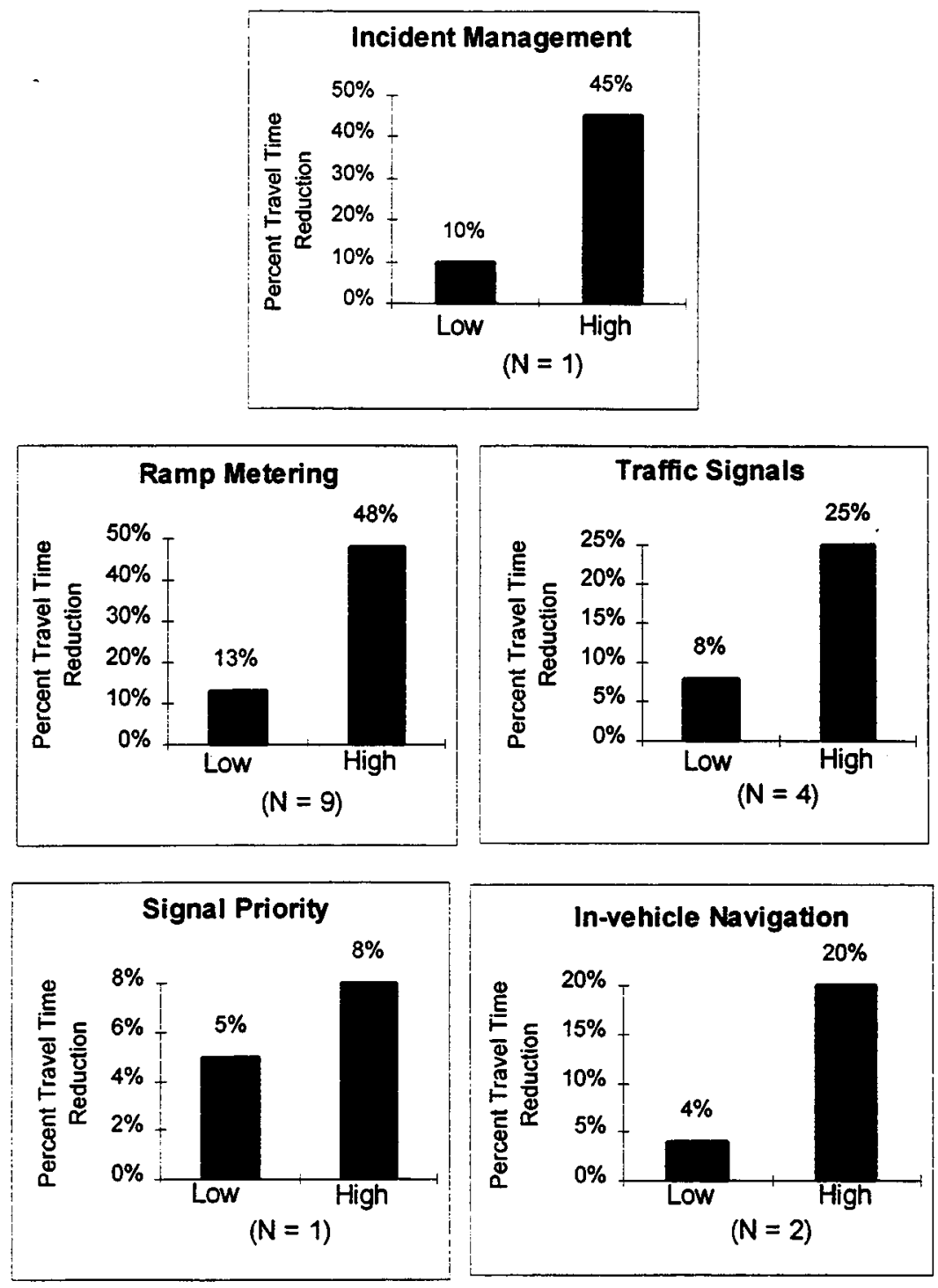

Figure ES-2: Range of Measured Travel Time Reduction Benefits

Many ITS components seek to optimize use of existing facilities and rights-of-way. With these improvements mobility and commerce needs can be met while reducing the need to construct new or expanded facilities. This is done by improving throughput in number of people, number of vehicles, or amount of goods moved per unit of time while maintaining or improving level of service. Although some ITS components address throughput of individual facilities, other components are expected to improve network throughput, which is more difficult both to define and to measure. Table ES-5 and Figure ES-3 show the percentage increases in maximum throughput achieved in some of theses components, or in the case of collision avoidance systems. (Note: ETC refers to Electronic Toll Collection.) 
Table ES-5: Summary of Throughput and Volume Benefits of Freeway Management Systems

\begin{tabular}{|c|c|c|}
\hline $\begin{array}{l}\text { Location } \\
\text { City }\end{array}$ & State & $\begin{array}{l}\text { Throughput/Volume Data } \\
\text { Increase|Type }\end{array}$ \\
\hline Minneapolis/ST. Paul & Minn. & 25\% $\mid$ Volumes \\
\hline Minneapolis/ST. Paul & Minn. & $32 \% \mid$ Volumes \\
\hline Seattle & WA & \begin{tabular}{l|l}
$86 \%$ NB & Volumes \\
$62 \%$ SB &
\end{tabular} \\
\hline Denver & $\mathrm{CO}$ & \begin{tabular}{l|l|l|}
$15.6 \%$ & Volumes \\
\end{tabular} \\
\hline Detroit & $\mid \mathrm{MI}$ & \begin{tabular}{l|l|l|}
$12.5 \%$ & Volumes \\
\end{tabular} \\
\hline San Diego & $\overline{C A}$ & \begin{tabular}{|l|l|}
$8.3 \%$ & Volumes \\
\end{tabular} \\
\hline Austin & $T X$ & \begin{tabular}{l|l}
$7.9 \%$ & Throughput \\
\end{tabular} \\
\hline Long Island & $\sqrt{N Y}$ & \begin{tabular}{l|l|}
$2 \%$ & Throughput \\
\end{tabular} \\
\hline
\end{tabular}
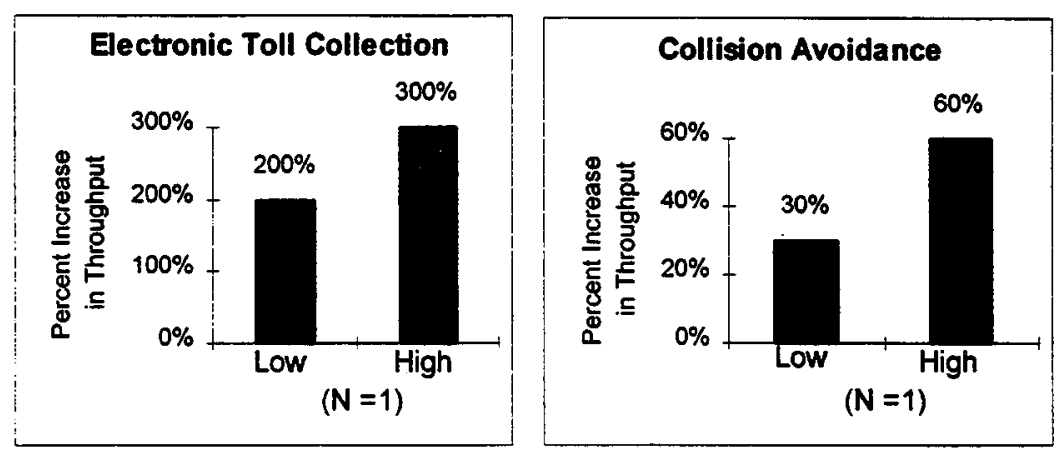

Figure ES-3: Range of Throughput and Volume Improvement Benefits

Implementing ITS requires funding. However, frequently ITS implementation reduces both acquisition and life-cycle costs and allows productivity improvements. Figure ES-4 shows percentage improvement in operating costs and productivity. (Note: AVL refers to Automatic Vehicle Location and CAD refers to Computer-Aided Dispatching.) 

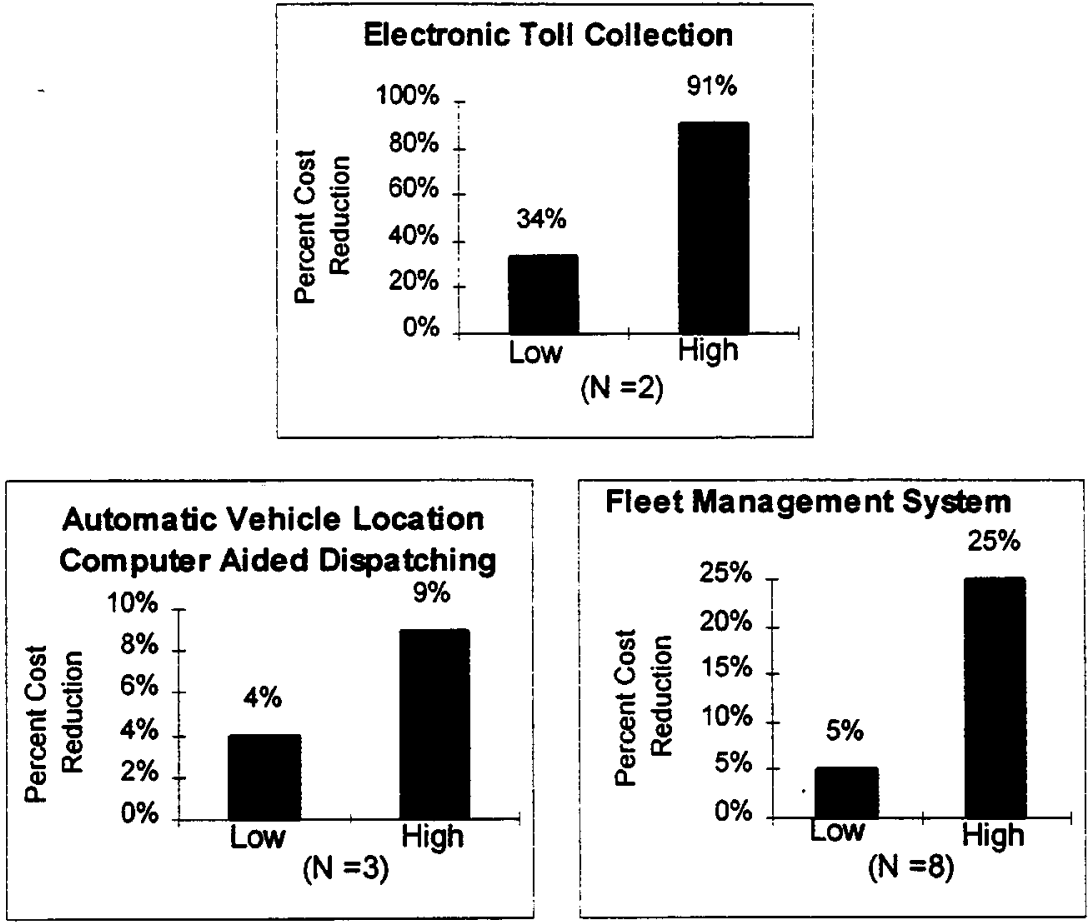

Figure ES-4: Range of Measured Improvement in Operating Costs and Productivity

Customer satisfaction indicates the degree to which consumers are accommodated by transportation service offerings. Although satisfaction is difficult to measure directly (except through qualitative surveys), measures related to satisfaction can be observed including amount of travel in various modes, mode options, and the quality of service as well as the volume of complaints and/or compliments received by service providers. In general, users of ITS products and services are highly satisfied with them.

While the ITS benefit results presented in this report indicate significant areas of positive impact, there is still much to do to fully demonstrate and assess the potential of ITS. The preceding discussion has summarized some benefits of ITS; however, the conditions under which ITS will yield positive results and the magnitude of the resulting improvements are still not well understood. The existing results are still too few in many areas as indicated by the low number $(\mathrm{N})$ of measurements in the preceding figures. Moreover, they vary in magnitude of benefit due to, among other factors, operating conditions, baseline conditions, and maturity of installation. To make further progress, the ITS community needs to gain additional understanding of the results of ITS implementation by obtaining more data to ensure a reliable story can be told and filling in missing data. Additionally, data on cost of installation and operations are sparse and need to be examined more fully. 


\section{SECTION 1}

\section{INTRODUCTION}

The Transportation System of the United States consists of more than 6.3 million kilometers of highways and roads, and 503 public transit operators in 314 urbanized areas. More than 258 million people, 6 million businesses and 86 thousand federal, state and local government agencies produce over 6.3 trillion passenger kilometers of travel and 4.8 trillion ton kilometers of domestic freight. In 1995 Congress designated the near 260,000 kilometer National Highway System. Although this system includes all of the interstates and many other highways, and carries almost half the total highway traffic and most truck and tourist traffic, it consists of less then $4 \%$ of the roadway system in the nation. Of this roadway system, more than $30 \%$ of the roads on the interstate system are rated either "poor" or "mediocre," and more than 125,000 bridges nationwide are near the end of their useful lives ${ }^{1}$.

Over the next ten years travel demand is expected to increase by about $30 \%$. In order to simply maintain congestion at current levels, the U.S. would have to increase the capacity of the transportation system by the same $30 \%$. One option is to increase capacity by increasing the number of lane kilometers. To do this, the U.S. would need to add (in 50 major urban areas) approximately 7,125 new kilometers of roadway every year. Currently, roads are being build at about two-thirds this rate.

A second option is to develop alternatives that increase capacity by improving the efficiency of the transportation system. This option focuses on building fewer lane-kilometers while investing in an Intelligent Transportation Systems (ITS) infrastructure. A twenty year life-cycle cost analysis for 50 major urban areas for the two options indicated that the ITS-based investment (called ITS-plus-build) would "reduce the need for new roads, while saving approximately $35 \%$ of the required investment in urban highways ${ }^{2} . "$

It is clear from this analysis that ITS can be an important factor in addressing our growing transportation needs. There is a continuing need to identify and document the benefits of ITS.

\subsection{GOALS FOR THIS REPORT}

This report continues the process of documenting and publicizing measured, and predicted benefits from Intelligent Transportation Systems (ITS). This benefits review effort is part of an effort sponsored by the ITS Joint Program Office (JPO) of the Federal Highway Administration (FHWA). The purpose of this report is to provide a single location where knowledge about the benefits of ITS implementation is brought together. This report summarizes major ITS benefits findings while referring the interested researcher to detailed studies or contacts for more information. The progression of reports on the topic of ITS benefits seeks to improve the completeness and reliability of relevant data, with the ultimate goal being validated results from field measurement for all areas of ITS. In addition to their direct use in decision-making, field benefits data are an important source of information used in simulation and analysis activities as they add realism to the setting of modeling parameters and verify resuits for statistical analysis work.

\footnotetext{
1 "Transportation: Driving a Thriving Economy," American Association of State Highway and Transportation Officials and the National Governors' Association, May 1997.

${ }^{2}$ McGurrin, M. F., Shank, D. E., "ITS Versus New Roads: A Study of Cost-Effectiveness," in ITS World, July/August 1997.
} 


\subsection{PREVIOUS REPORTS}

Much of the material presented in this report has been published in several previous reports. The first, entitled "Assessment of ITS Benefits - Early Results," presented the initial stories and information related to ITS benefits ${ }^{3}$. The second report, prepared in conjunction with the announcement of the Operation Time Saver initiative, focused on the benefits of only the metropolitan infrastructure elements, with particular emphasis on travel time reductions ${ }^{4}$. The third report, presented at the ITS America Annual Meeting in April 1996, discussed only benefits observed in the field or projected directly from field experience ${ }^{5}$. A fourth report, "Review of ITS Benefits: Emerging Success," was published in September of 1996 , as an update to the original assessment report ${ }^{6}$.

This report is primarily an update to the Emerging Successes report. It contains all the data found in the previous report plus new data that have been collected and submitted by those implementing ITS technologies. In particular, this report contains the available benefits related to many of the ITS field operational tests. The results from these tests that have appeared in the last year are also included as an appendix. This was done so that the most current results from specific field operational tests could be found in a single location.

\subsection{DEFINITION OF TERMS}

Several initiatives have advanced the definition of the ITS program and the way that ITS benefits are being portrayed. These include a summary of ITS projects ${ }^{7}$, the definition of the National ITS Architecture ${ }^{8}$, the Commercial Vehicle Information Systems and Networks (CVISN) ${ }^{9}$, the metropolitan ITS infrastructure initiatives ${ }^{10}$, and the Government Performance and Results Act of $1993^{11}$. This section documents the definition of terms developed in these initiatives because they are used as the foundation for succeeding discussions of ITS benefits.

\subsubsection{Classes of Benefits Data}

Benefits information are available from a number of sources that vary in precision, accuracy, and repeatability. Benefits described in this report are categorized into the following classes:

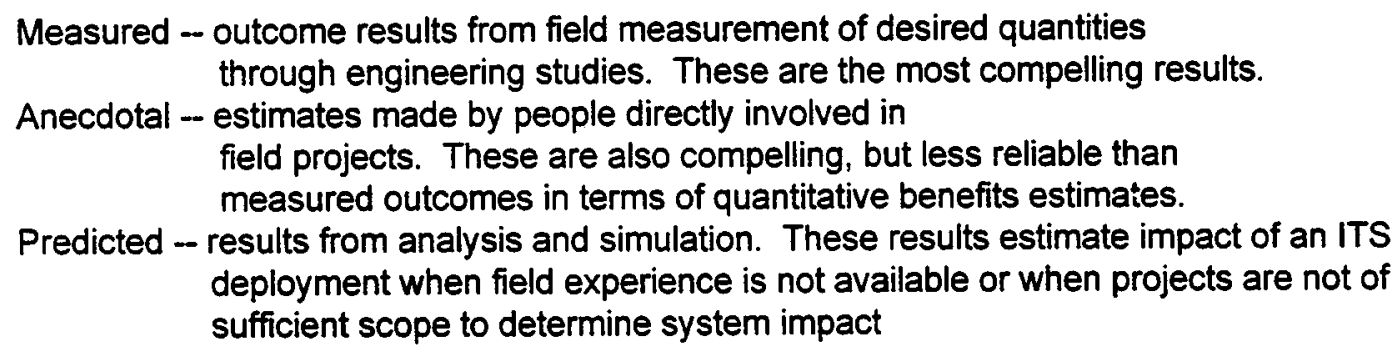

\footnotetext{
3 "Assessment of ITS Benefits -Early Results," US Department of Transportation, FHWA-JPO-96-001,August 1995.

4 "Intelligent Transportation Infrastructure Benefits: Expected and Experienced," US Department of Transportation, FHWA-JPO-96008 , January 1996.

5 "Assessment of ITS Benefits - Results from the Field," ITS America Sixth Annual Meeting, April 1996.

8 "Review of ITS Benefits: Emerging Successes" United States Department of Transportation, FHWA-JPO-97-001

7 "Intelligent Transportation Systems (ITS) Projects," US Department of Transportation, January 1996.

8 "ITS Architecture: Mission Definition," prepared for Federal Highway Administration by the Joint Architecture Team of Loral Federal Systems and Rockwell International, June 1996.

- "Introduction to Commercial Vehicle Information Systems and Networks," prepared for Federal Highway Administration by the Johns Hopkins University Applied Physics Laboratory, Preliminary, January 1996.

10 "Building the ITI: Putting the National Architecture into Action," Federal Highway Administration, FHWA-JPO-96-011, April 1996.

11 Government Performance and Results Act of 1993, Public Law 103-62, $103^{\circ}$ Congress, August 3, 1993.
} 
The focus of this report is on the term "outcome measure" which is adopted from the Government Performance and Results Act of 1993. Outcome measures relate directly to the goals of the ITS program, while output measures (which are grouped with experiential estimates as the anecdotal class) identify results that bear some relationship to the goals, but do not directly measure the degree of achievement of those goals.

\subsubsection{System Groups}

There is an emerging effort to develop a more useful set of system groupings than those used in the past. This effort is based on the observation that there are several different views of the ITS infrastructure, e.g., metropolitan, rural, and commercial vehicle. As this new grouping structure solidifies, future versions of this report will adapt to it. For the time being, the grouping that is used is described below.

This report adopts a grouping method similar to the system groupings found in the 1996 and 1997 editions of Intelligent Transportation Systems (ITS) Projects. This grouping method, which is described in the remainder of this section, has essentially been in existence since 1991.

Travel management systems attempt to efficiently manage the communication between driver, vehicle, and roadway. Transportation control devices, Emergency management and law enforcement are also used to control travel on transportation networks. This report considers Advanced Traveler information Systems (ATIS), Advanced Traffic Management Systems (ATMS), and Advanced Public Transportation Systems (APTS) as travel management techniques.

Advanced Traveler Information Systems (ATIS) provide information to travelers using both highway and transit systems. Transportation network performance before and during travel is transmitted to the traveler using infrastructure-provided equipment as well as personal and vehicle-based devices. En route and pre-trip driver information, route guidance, ride matching, and emergency notifications are examples of ATIS type s'ystems.

Advanced Traffic Management Systems (ATMS) use traffic monitoring, communications, traffic signal control, highway-rail crossing interfaces (HRI), and freeway and incident management systems to manage the demand, operations, safety, and security of the transportation system.

Advanced Public Transportation Systems (APTS) seek to improve operation and encourage use of transit and other shared-ride modes. Technologies in fleet management, traveler information, and electronic fare payment can be used in APTS.

Advanced Rural Transportation Systems (ARTS) provide traveler information and public transportation to travelers in rural areas including mayday, hazard warning, crash avoidance, routing and tourist information for travelers. Information, scheduling, dispatching and sponsor billing for public transportation providers are also being implemented in rural areas. The ARTS group is fundamentally different from the other system groups in that most systems in the ARTS group could also be represented in other groups (i.e., ATIS, ATMS, APTS, CVO, and AVCSS).

Commercial Vehicle Operations (CVO) include the technologies associated with the movement of trucks and buses. The ITS/CVO scope supports the activities that improve the effectiveness of compliance or enforcement of safety regulations. CVO systems also include activities related to roadside safety operations, freight and fleet management, and vehicle operation. CVISN includes information systems owned and operated by state and local governments, carriers, and other stakeholders. CVISN is composed of roadside electronic screening, exchange of safety information between states, and some administrative processes. CVISN does not include the sensor and control elements of CVO. Both CVO and CVISN related benefits are discussed in CVO sections of this paper. 
Advanced Vehicle Control and Safety Systems (AVCSS) will use technology to improve vehicle control and crash avoidance, could eventually include the full implementation automated operation on specified facilities. Assisted braking, lane keeping, collision warning and blind spot detection devices are examples of AVCSS.

Integrated systems incorporate many of the aspects of ATMS, ATIS, APTS, and potentially ARTS into a single facility or coordinated facilities to take advantage of improvements in coordination, communication, and infrastructure investment.

\subsubsection{A Few Good Measures}

In the spring of 1996, FHWA created a list of six measures to be used to analyze the effects of ITS components. These measures, termed a "few good measures," are Crashes, Fatalities, Travel Time, Throughput, User Satisfaction or User Acceptance and Cost. The criteria that was used to choose these measures were acceptance by stakeholders, easily understandable, address all ITS goals, either readily measurable or an 'accepted' surrogate exist that is readily measurable, and when taken together are able to capture a broad range of user services and functions. This report focuses on these measures.

\subsubsection{Related Systems of Systems Initiatives}

Several initiatives are progressing to integrate ITS elements into systems of systems with particular focuses. These initiatives include the National ITS Architecture, Commercial Vehicle Information Systems and Networks (CVISN) infrastructure, and the Metropolitan ITS Infrastructure. The National ITS Architecture is the framework for interconnecting subsystems which together provide the ITS user services thro: gh allocated functionality and defined interfaces. This architecture is open and flexible to prevent unnecessary restriction to implementation choice and to accommodate the varied needs of the public and private sectors. At the same time, the architecture definition must be sufficiently precise to ensure a transportation and communication system design that is both compatible and interoperatible across the nation.

CVISN is the collection of information systems and communications networks that support CVO services. CVISN includes information systems owned and operated by governments, carriers, and other stakeholders. A prototype of CVISN is underway in Virginia and Maryland, and pilot deployments in: California, Colorado, Connecticut, Kentucky, Michigan, Minnesota, and Washington/Oregon.

The metropolitan infrastructure includes core ITS elements that can be implemented in a coordinated fashion to leverage investment enabling technology. Infrastructure components include traffic signal control, freeway management, highway-rail crossing protection, incident management and emergency management services, traveler information, transit management, electronic fare payment, and electronic toll collection. Model Deployment Initiatives to integrate infrastructure components are underway in Seattle, Washington, San Antonio, Texas, Phoenix, Arizona and the New York/New Jersey/Connecticut metropolitan areas. 


\subsection{SCOPE AND ORGANIZATION OF REPORT}

The remaining sections of this report present summaries of ITS benefits grouped by key outcome measures (the few good measures) that have been identified by the United States Department of Transportation (USDOT). Section 2 discusses the two groupings of safety measures. Section 2.1 examines the benefits of ITS and law enforcement related to crashes, and injuries, while methods that reduce the number of fatalities on the transportation system are explored in section 2.2 . Although these measures are highly related, much literature on ITS goes to great lengths to separate these benefits into different groups. However it is recognized that reducing the number of incidents contributes to a reduction in the number of fatalities.

Section 3 looks at the time and delay reduction benefits of ITS. Improvements in throughput and traffic volume are presented in section 4 . Section 5 examines the reductions in operation and maintenance costs. Section 6 discusses the perceptions and effects of ITS on businesses, the general public, and other users in the form of customer satisfaction. Emissions and Fuel Consumption impacts are discussed in section 7.

Within the discussion of each measure, benefits are grouped by system type: Advanced Traveler Iniormation, Advanced Traffic Management, Advanced Public Transportation, Advanced Rural Transportation, Commercial Vehicle Operations, Advanced Vehicle Control and Safety, and Integrated. Each system type for which benefits data are available is discussed in terms of mechanisms by which benefits will accrue followed by examples of measured, anecdotal, and predicted benefits. In areas where no results are available, corresponding sections are omitted.

Since some systems can provide benefits in multiple related areas (e.g., time and throughput), the same reports are sometimes cited in multiple sections. This duplication is deliberate and allows each benefits section to stand alone.

Appendix A contains results available from the field operation tests. These results were placed in the separate appendix so that benefits associated with a specific operational test could easily be found. Appendix $B$ summarizes results from a report prepared for the Federal Transit Administration (FTA) on projected national level benefits from the USDOT's APTS program. Appendix $C$ presents some results from three recent studies, that discuss implementing ITS at a national level. This includes, a recent benefitcost analysis of ITS infrastructure improvements in metropolitan areas. 


\subsection{DATA AVAILABILITY}

The majority of available references demonstrate positive benefits for ITS. This is true both for actual deployments and for analytical studies predicting future benefits. The number of cases reporting negative results has been very small. However, most of the systems that produce negative benefits are carried out primarily to obtain broader societal benefits, or contain other positive benefits that may or may not be measurable.

Table 1 summarizes the availability of benefits data for each system type. Presence of benefits in a cell does not mean that complete benefits information is available. Instead, at least one benefit reference exists in this report for that cell. The remainder of this report presents summary information about the data regarding each system type on a measure-by-measure basis for the key measures. No coverage is given to areas with blank cells. Benefits data attributed to ARTS in the previous report has been move to more relevant sections in this report.

Table 1:- Summary of ITS Benefits Data Availability

\begin{tabular}{|c|c|c|c|c|c|c|c|}
\hline & Travel $\mathrm{M}$ & anageme & ent & & & & \\
\hline Measure & ATIS & ATMS & APTS & ARTS & CVO & AVCSS & Integrated \\
\hline Safety Measu & & & & 8 & & & 49 \\
\hline & Measured & Measured & & & & Measured & Measured \\
\hline Crashes & Anecdotal & & & & Anecdotal & Anecdotal & \\
\hline & Predicted & & & & & Predicted & \\
\hline & & & & & & & \\
\hline Fatalities & Anecdotal & & & & & Anecdotal & Anecdotal \\
\hline & & & & & Predicted & & Predicted \\
\hline & Measured & Measured & Measured & & Measured & & \\
\hline Time & Anecdotal & Anecdotal & Anecdotal & & & & \\
\hline & Predicted & Predicted & & & Predicted & Predicted & \\
\hline & & Measured & & & & & \\
\hline Throughput & & & & & & & \\
\hline & Predicted & & & & & Predicted & \\
\hline & & Measured & Measured & & Measured & & \\
\hline Cost & & & & & Anecdotal & & \\
\hline & & Predicted & Predicted & & Predicted & & Predicted \\
\hline & Measured & Measured & Measured & & Measured & & Measured \\
\hline Customer & Anecdotal & & Anecdotal & & & & \\
\hline Satisfaction & & & & & Predicted & & \\
\hline
\end{tabular}




\section{SECTION 2}

\section{SAFETY BENEFITS OF ITS}

Intelligent Transportation Systems (ITS) address safety issues using several different methods. ITS can reduce the number and severity of crashes by using in-vehicle crash avoidance systems (CAS), lane keeping, and assisted braking. Improved traffic control and enforcement techniques provide a second approach to reducing crashes. Freeway and arterial management systems include techniques such as ramp metering, lane control, and advanced surface street signal control. When installed properly, these devices improve the flow of traffic thereby reducing crash occurrences. Devices such as video speed enforcement and video signal enforcement can also be used to reduce safety violations.

Quicker response for victims of crashes improves medical service, decreasing the chances that a fatality will result. An 8.45 minute reduction in response time can lead to a $11 \%$ reduction of fatality rate ${ }^{12}$. Automatic collision notification devices, rural mayday systems, and incident notification systems alert emergency service providers more quickly to the occurrence of the crash. A faster response to the incident results in restoring traffic flow to normal conditions more quickly and reducing the probability of secondary incidents.

\subsection{CRASHES}

Reducing the number of crashes is an important aspect of improving safety. Despite the current improvements to safety in the nations roadway system, vehicle accidents account for more than $\$ 137$ billion per year in property losses, market productivity losses, and medical cost ${ }^{13}$. While the relationships between reduced crashes and other important statistics such as fatalities, injuries, and non-recurrent delay vary with a number of factors, reducing crashes will tend to improve all of these statistics.

Ramp metering can reduce crashes by reducing the probability of side swipes in merge areas. Also reduced are rear end collisions that occur as vehicles slow to allow others to merge, or because they can not merge. These reductions occur on both mainline lanes as well as on ramps. Table 2 summarizes measured accident reduction statistics available from reference documents in this section. Each statistic is classified by type of accident as described in the referenced documentation.

Advanced technologies in surveillance can be used to enforce traffic laws, thus reducing the probability of accident occurrence. Other operational systems, such as the Motor Carrier Safety Assistance Program (MCSAP) and federal safety audits, can help to remove unsafe vehicles from the roadway. Collision Warning systems, are capable of alerting drivers of possible collisions before they occur. Figure 1 shows the range of percentage reduction in crashes achieved in some operational systems referenced in this document ( $\mathrm{N}=$ the number of measurements).

\footnotetext{
12 Brodsky H. and A. S. Hakkert, "Highway Fatal Accidents and Accessibility of Emergency Medical Services," Soc. Si. Med., Vol. 17 No 11, p 731-740, 1983.

13 "Transportation: Driving a thriving Economy." American Association of State Highway and Transportation Officials and the National Governors' Association, May 1997.
} 
Table 2: Summary of Crash Reduction Data for Ramp Meters

\begin{tabular}{|l|l|r|l|}
\hline \multicolumn{1}{|c|}{ Location } & \multicolumn{1}{|c|}{ State } & $\begin{array}{r}\text { Accident } \\
\text { Reduction }\end{array}$ & \multicolumn{1}{|c|}{ Type } \\
\hline Denver & CO & $5 \%$ & Rear/Side \\
\hline Denver & CO & $50 \%$ & Rear/Side \\
\hline Portland & Oregon & $43 \%$ & Total accidents \\
\hline Minneapolis/ST. Paul & Minn. & $24 \%-27 \%$ & Total accidents \\
& & $38 \%$ & Accident rate \\
\hline Seattle & WA & $39 \%$ & Accident rate \\
\hline Detroit & MI & $50 \%$ & Total accidents \\
& & $71 \%$ & Injuries \\
\hline Long Island & NY & $15 \%$ & Frequency \\
\hline
\end{tabular}
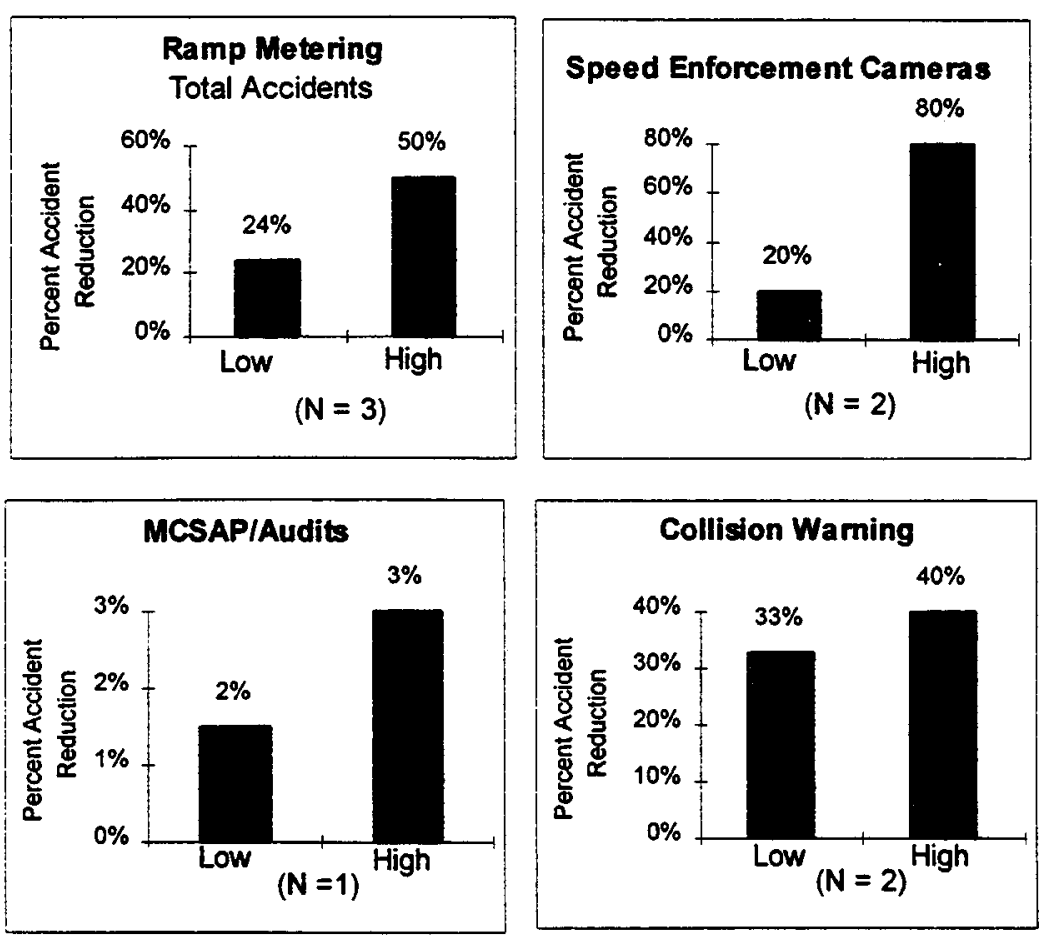

Figure 1: Range of Measured Crash Reduction Benefits 


\subsubsection{Crash Reduction Benefits of ATIS}

Traveler information systems can improve safety primarily by helping drivers avoid situations where risks of crashes are greater due to environmental, roadway, or traffic conditions. Tests to demonstrate such benefits are in the developmental and operational phases. Traveler information is also expected to improve safety by reducing distractions to the driving task. Route finding and navigation activities can result in smoothing the flow of traffic.

\subsubsection{Measured Crash Reduction Benefits of ATIS}

The safety potential for an advanced traffic information system that warns commercial vehicles and other heavy vehicles of a potentially dangerous highway situation is currently being tested. Over the past decade the Washington, DC Capitol Beltway area has experienced several accidents involving truck rollovers at exit and entry ramps. As a result, three sites around the capitol region were selected as ITS operational test sites for a Ramp Rollover Warning System (RRWS). The system alerts drivers to slow down when maximum safe speeds are exceeded. Before the implementation of RRWS there were ten reported rollover truck accidents at these sites between 1985 and 1990. Since implementation in 1993, there have not been any rollover accidents at any of the three sites and average truck speed has been reduced by $11 \mathrm{kph}^{14}$.

\subsubsection{Anecdotal Crash Reduction Benefits of ATIS}

The TravTek project examined the safety aspects of an in-vehicle navigation device that used a moving map display as well as voice directions. While data on accidents and near accidents are not statistically significant, driver workload studies yielded encouraging results. Compared to control conditions of paper maps and road signals, use of both visual and voice displays yielded lower driver workloads in each category of stress, including time stress, visual effort, and psychological stress ${ }^{15}$. TravTek users also perceived that they were safer.

\subsubsection{Predicted Crash Reduction Benefits of ATIS}

The TravTek project used a simulation approach to estimate safety impact. Using the INTEGRATION simulation model, a representation of the Orlando roadway network, and performance parameters obtained during the field studies, analyses were performed to estimate crash risk of motorists using navigation devices compared to motorists without them. In addition, the safety impacts on the entire traffic network (both equipped and unequipped vehicles) were analyzed. Results indicated an overall reduction in crash risk of up to $4 \%$ for motorists using navigation devices, due to improved wrong turn performance and the tendency of the navigation system to route travelers to higher class (normally safer) facilities. Other indications from the TravTek field studies showed that the ability of the navigation system to receive real-time and congestion information provided an advance warning to motorists of potentially unsafe conditions on the route they were traveling, further improving the safety benefits of the system. The simulation revealed a potential for increased safety risk for navigation-system-equipped vehicles when real-time information caused them to divert from a higher class facility to a lower class road (e.g., from a freeway to an arterial). Increased safety risks of up to $10 \%$ were estimated for the equipped vehicles, while the overall network showed a safety neutral to a slight safety improvement when diversion occurred. The network safety improvements were experienced when diversion from congested roadway reduced the level of congestion for the remaining equipped and non-equipped vehicles and helped to smooth traffic flows on those roads.

\footnotetext{
${ }^{14}$ Taylor, B and Bergan, A., "Words of Warning," in ITS: intelligent transport systems, Issue number 10, May/June 1997 ${ }^{15}$ Inman, V., et. al., "TravTek Evaluation: Orlando Test Network Study," FHWA-RD-95-162, Federal Highway Administration, January 1996.
} 


\subsubsection{Crash Reduction Benefits of ATMS}

Traffic management systems reduce accidents primarily by limiting the conflict of streams of traffic either by installing traffic control devices or improving compliance with those devices.

\subsubsection{Measured Crash Reduction Benefits of ATMS}

The first ramp meter was installed on the Eisenhower Expressway in Chicago in 1963. Other early adopters of freeway ramp meters include Detroit, Michigan, Minneapolis, Minnesota, and Los Angeles, California. By 1989, the Federal Highway Administration (FHWA) had enough data to put together a summary of ramp metering practices with quantitative results. As places such as Minneapolis upgrade their ramp metering systems into true Freeway Management Systems, results continue to improve along with coverage, capability, and coordination. While ramp metering systems are designed to improve operation at the merge point and to improve mainline speed and capacity, field experience has demonstrated a significant reduction in accident rate. According to Minnesota DOT Freeway Operations Meeting Minutes from January of 1994, accident rates on 1-35W in Minneapolis before management were 421 per year and are now 308 per year (a $27 \%$ reduction). Annual accident experience on the same freeway after management is 2.11 collisions per million vehicle miles traveled (VMT) compared to 3.40 collisions per million VMT before management was instituted (a $38 \%$ reduction).

A longitudinal study of the ramp metering/freeway management system in the Seattle, Washington area over a six year period ${ }^{16}$ shows that accident rates have fallen consistently to a current level of $62 \%$ compared to the base period. A survey of traffic management centers using ramp metering ${ }^{17}$ reported similar findings. Accidents on freeway systems under freeway management were reduced between $15 \%$ and $50 \%$. While some other freeway improvements were implemented during the study periods, the combination of geometric, vehicle, and operational procedures resulted in significant reduction of accident rate.

The Department of Transport in the United Kingdom recently reported that the number of accidents decreased by $28 \%$ during an 18 month study of variable speed limits on the M25. Speed limits were enforced using cameras, which resulted in a total of 26,000 fines during the lifetime of the project ${ }^{18}$.

Several studies have shown that incident management systems can reduce secondary collisions. However, the reduction in secondary collisions attributable to an incident management program may be difficult to estimate. This is because incident management systems are implemented with coordinated freeway management programs which also reduce collisions. An analysis of the accident statistics on several California arterials and expressways shows that secondary accidents represent an increase in accident risks of over $66 \%{ }^{19}$, without controlling for climatic or other conditions. Another California freeway study ${ }^{20}$ placed the average increase in collision rate at $300 \%$ in congested conditions, with variance due to geometric conditions. The CHART evaluation estimates that the traffic management center, including freeway service patrols, was responsible for a $5 \%$ reduction in the number of accidents during non-recurrent congestion ${ }^{21}$.

\footnotetext{
${ }^{16}$ Henry, K. and Meyhan, O., "6 Year FLOW Evaluation, "Washington State DOT, District 1, January 1989.

${ }^{17}$ Robinson, J. and Piotrowicz, G., "Ramp Metering Status in North America, 1995 Update," Federal Highway Administration, June 1995.

18 "Variable Speed Limits Reduce Accidents Significantly in the UK," in The Urban Transportation Monitor, March 14, 1997.

19 Intelligent Transportation Systems Impact Assessment Framework: Final Report, Volpe National Transportation Systems Center September 1995.

${ }^{20}$ Sullivan, E.C., and Hsu, C. I., "Accident Rates Along Congested Freeways: Final Report," Research Report UCB-ITS-RR-88-6, Institute of Transportation Studies, University of California, Berkeley, CA, 1988.

${ }^{21}$ COMSIS Corporation, "CHART Incident Response Evaluation Final Report," Silver Spring, MD, May 1996.
} 
The use of video surveillance for traffic law enforcement is a more controversial area of potential benefits derived from ITS. A few pilot studies involving red light signal compliance devices are in place in the United States. By using cameras to record violations, San Francisco, California reports a $30 \%$ reduction in violations while Howard County, Maryland, and New York City report $23 \%$ and $20 \%$ reductions. Installation of speed enforcement cameras in London have reduced speed by approximately $10 \%$, accidents from $20 \%$ to as much as $80 \%$, and serious injuries and fatalities by about $50 \%$. An additional benefit is that $98 \%$ of all parties intended for prosecution are not contesting the citations ${ }^{22}$.

Highway-railroad grade crossing systems were recently added as a major component of the metropolitan ITS infrastructure. The need for improvement is indicated by the fact that in 1995, 579 fatalities and 1,894 injuries occurred at grade crossings ${ }^{23}$. Additionally, the occasional spectacular accident including school children or hazardous materials attracts national attention. In 1993, the Los Angeles metro blue line began experimenting with photo enforcement of grade crossings along the 35.4 kilometer blue line. A twomonth demonstration project at Comptom Boulevard resulted in a 92\% reduction in violations. A similar three-month project at Alondra Boulevard resulted in a $78 \%$ reduction. Fort Mead, Florida also reports a $50 \%$ reduction in violations despite the fact that citations cannot be issued. Similarly, Jackson, Mississippi reported a $60 \%$ violation reduction at a major intersection ${ }^{24}$.

\subsubsection{Crash Reduction Benefits of CVO}

Using in-vehicle, deskside, and roadside ITS in commercial vehicle operations can directly reduce the number of crashes by improving the identification of drivers and vehicles that are at high risk. While these automated CVO systems are not fully in place yet, experience with existing programs indicates significant potential benefits. The improvements in traffic flow near weigh stations and enforcement areas with the implementation of CVO systems may also contribute to a reduction in crashes.

\subsubsection{Anecdotal Crash Reduction Benefits of CVO}

An early information network in Oregon enabled an increase of $90 \%$ in number of weighins and $428 \%$ in number of safety inspections between 1980 and 1989 while staff increased by only $23 \%{ }^{25}$. While these are not direct measures of desired outcomes, the link between inspections and reductions in crashes is intuitive.

\subsubsection{Crash Reduction Benefits of AVCSS}

There are a number of vehicle control systems available that are designed to reduce the likelihood of crashes. These systems either test the facility of the driver, improve the awareness of the driver, or take direct control of the vehicle in certain circumstances in order to assist in avoiding the crash. Initial devices that improve the awareness of the driver are currently available as commercial products and are beginning to report benefits.

\footnotetext{
${ }^{22}$ Harris, J. and Sands, M., "Speed Camera Advances," Traffic Technology International, Spring 1995.

${ }^{23}$ National Transportation Statistics 1997, USDOT Bureau of Transportation Statistics, U.S. Government Printing Office, Washington, DC, December 1996.

24 "Photo Enforcement Proves Very Effective," in Urban Transportation Monitor, Vol. 9, No. 5, March 17,1995.

${ }^{25}$ Krukar, M. and Evert, K., Integrated Tactical Enforcement Network (Automated Enforcement Facilities in Oregon), Presented at the National Traffic Data Acquisition Technologies Conference, Austin, TX 17-20, August 1990.
} 


\subsubsection{Measured Crash Reduction Benefits of AVCSS}

Collision warning devices and blind spot detectors are becoming available as commercial products. Transport Besner Trucking Co. has installed an Eaton-Vorad collision warning device on $100 \%$ of its 170 truck fleet. Internal studies found that the combination of the device with a safety training program has reduced accidents by 33\% (Daniel Lareau, Transport Besner Trucking Company, telephone interview, February 1995 verifying information in "Freightliner to Offer Collision Warning on New Truck Line," Inside ITS, Vol. 5, No. 23, November 20, 1995). The Greyhound accident experience using an earlier model product yielded a reduction of $20 \%$ in a deployment equipping half of the fleet, which could extrapolate to a $40 \%$ reduction in accidents for full equipage ${ }^{26}$.

\subsubsection{Predicted Crash Reduction Benefits of AVCSS}

Automated Highway System (AHS) related products can have safety benefits prior to full implementation of AHS segments. Based on data from Minnesota ${ }^{27}, 60 \%$ of rural freeway accidents are susceptible to reduction using lane keeping and collision avoidance technologies. These types of collisions include runoff-the-road, accounting for $34 \%$ of accidents, and animal hits. A national reduction of $40 \%$ in these accidents could account for an annual reduction of 19,000 accidents including 190 fatal accidents nationally accounting for an estimated cost savings of $\$ 225$ million. Applying the same type of analysis to urban areas shows the most common types of accidents to be rear end $(50 \%)$, run-off-the-road $(22 \%)$, and side swipe (13\%). These also are amenable to correction with less than full implementation of AHS. Assuming a reduction of $35 \%$ of these accidents, 52,000 fewer collisions could be expected to occur on a national basis, including 100 fatal accidents.

\subsubsection{Crash Reduction Benefits of Integrated Systems}

\subsubsection{Measured Crash Reduction Benefits of Integrated Systems}

The San Antonio TransGuide system became operational in 1995. Consisting of approximately 42 kilometers of freeway around San Antonio, Texas it includes Variable Message Signs, lane signal control, video surveillance and loop detectors. A before and after analysis of the TransGuide system reports a $15 \%$ decrease in injury related accident occurrence. As a result, this translates to an annual benefit of $\$ 3.3$ million. Incident response time improved by $21 \%$ for major accidents and $19 \%$ for minor accidents without any significant change in staffing levels for assistance personne $\left.\right|^{28}$. A second report documents some other improvements including a $35 \%$ reduction in total accidents, $30 \%$ reduction in secondary accidents, $40 \%$ reduction in weather related accidents, and a $41 \%$ reduction in accident rate per million vehicle miles of trave? .

\footnotetext{
${ }^{26}$ Renforth, James D., Director - Safety Services of Greyhound Lines, Inc., letter to Paul Bouchard, President, VORAD Safety Systems, February 1994.

${ }^{27}$ AHS Precursor Analyses, Activity Area A, Urban and Rural AHS Analysis, Battelle, BRW, and Transportation Research Center, 1994.

${ }^{28}$ Henk, R. H. et al, "Before-and-After Analysis of the San Antonio TransGuide System Phase 1,"

$76^{\text {th }}$ annual meeting , Transportation Research Board, Washington, D.C, Paper No. 971027, January 1997.

${ }^{29}$ Henk, R. H. et al, "Before-and-After Analysis of the San Antonio TransGuide system," paper submitted for the Third World Congress on Intelligent Transport Systems, July 1996.
} 


\subsection{FATALITIES}

Since a fatality resulting from a crash can be prevented if the crash is avoided, systems that reduce the number of crashes also reduce fatalities. In addition, systems that reduce the severity of the crash, the consequence of the crash, or emergency medical service response times to victims of the crash also reduce the number of fatalities and the extent of injuries. The following sections discuss the reduction of injuries and fatalities and do not reiterate the benefits related to reducing just the number of crashes.

\subsubsection{Fatality Reduction Benefits of ATIS}

In addition to helping avoid crashes, information in the form of traffic conditions and route guidance provided to emergency service providers can reduce the time between a request for service and the arrival of the service at the required location.

\subsubsection{Anecdotal Fatality Reduction Benefits of ATIS}

Automatic Vehicle Location (AVL), Computer Aided Dispatch (CAD), and navigation systems are being installed in fire, police, and emergency vehicles. While quantitative evaluations are rare, a collection of anecdotal evidence is becoming available. A crash in Muskogee County, Oklahoma, involving a car and a school bus, resulted in the need for medical attention. The fog that contributed to the collision would have also delayed an ambulance and made location of collision difficult from a helicopter. However, the helicopter, equipped with a GPS receiver, located the crash scene using location information provided by a Highway Patrol officer on the scene using a handheld GPS. The helicopter was then able to complete the rescue ${ }^{30}$. The AVL system installed by the Schaumburg, Illinois police department has been reported to enable dispatch of backup to officers who failed to report location information and dispatch of assistance to an incapacitated officer ${ }^{31}$.

\subsubsection{Fatality Reduction Benefits of CVO}

Although crash statistics indicate that commercial vehicle drivers are involved in fewer accidents per mile traveled than the average vehicle, the larger number of miles driven on an annual basis and the increased risk of injury when crashes do occur result in high levels of responsibility on the part of the commercial vehicle operator and regulator.

\subsubsection{Predicted Fatality Reduction Benefits of CVO}

Analysis using empirical data to estimate the impact of ITS applications in CVO implementation of fatal involvements found a potential reduction of $14 \%$ to $32 \%{ }^{32}$. The analysis considered experience relating total miles traveled, percentage of rural travel, and inspection practices to fatality rate. The impact was estimated based on hypothetical usage of CVO services and changes in inspection practices due to ITS CVO implementation.

\footnotetext{
30 "GPS Aids in Oklahoma Bus Crash," Earth Observation Magazine, April 1996.

${ }^{31}$ Pilant, L., "Automated Vehicle Location," The Police Chief, September 1995.

${ }^{32}$ Evanco, W., "The Impact on Fatal Involvements of Commercial Vehicle Operation ITS Services," Mitretek Systems, Inc., January 1997.
} 


\subsubsection{Fatality Reduction Benefits of AVCSS}

The same vehicle control systems that reduce the likelihood of crashes, reduce the severity of crashes by reducing the vehicle speed at the time of the crash and therefore the energy of the collision. Pre-crash restraint deployment systems are expected to reduce injuries and fatalities by protecting vehicle passengers better than current technology. Devices that automatically notify emergency service providers that a crash has occurred are expected to reduce fatalities by summoning medical help more quickly.

\subsubsection{Anecdotal Fatality Reduction Benefits of AVCSS}

In a Stuttgart, Germany test of an on-board crash notification system, simulated emergency calls have shown a decrease in time for medical help to arrive from 14 minutes to 8 minutes for urban crashes and from 21 minutes to 12 minutes for out-of-town crashes. The $43 \%$ drop in response time corresponds to a $12 \%$ increase in the chance of survival for an occupant involved in the crash ${ }^{33}$. For comparison purposes, US response times for fatal accidents average 10.1 minutes in urban areas and 19.6 minutes in rural areas $^{34}$.

\subsubsection{Fatality Reduction Benefits of Integrated Systems}

Incorporation of multiple services into a single center is expected to provide benefits in operational and organizational arenas. While few quantitative results are available from such centers, individual occurrences as well as the continued development of such centers indicate benefits will be perceptible.

\subsubsection{Anecdotal Fatality Reduction Benefits of Integrated Systems}

The San Antonio TransGuide facility opened in the summer of 1995. The value of an integrated facility was demonstrated in the week before the center opened when an industrial plant fire erupted within view of freeway video surveillance. Based on the visibility afforded at TransGuide, the fire was accessed and fought more effectively, possibly saving the lives of several firefighters. Both local police and fire were convinced of the wisdom of their investment in collocation with traffic management at the TransGuide facility.

\subsubsection{Predicted Fatality Reduction Benefits of Integrated Systems}

According to analysis based on data from the Fatal Accident Reporting System, similar to the rural analysis reported in a preceding section reduction of incident notification times on urban interstates from the current average of 5.2 minutes to 2 minutes would result in a reduction in urban interstate fatalities of $15 \%$, or a national total of 365 lives annually if all urban interstates nationwide were under such a program ${ }^{35}$. A reduction to three minutes would reduce fatalities by 246 annually nationwide, or $11 \%$. For comparison, the San Antonio TransGuide Project has an incident detection goal of two minutes ${ }^{36}$.

\footnotetext{
33 "Stuttgart STORMS Ahead," Intelligent Transport Systems, Issue No. 2, Kent, UK Autumn 1995.

34 National Highway Traffic Safety Administration, "Traffic Safety Facts 1994," DOT-HS-808-292, August 1995.

${ }^{35}$ Evanco, W., "The Impact of Rapid Incident Detection on Freeway Accident Fatalities," Mitretek Systems, Inc., WN96W0000071, June 1996.

${ }^{36}$ McGowan, P. and Irwin, P., "TransGuide Transportation Guidance System: Technology in Motion," Texas DOT, November 1995.
} 


\section{SECTION 3}

\section{TIME}

Reduction in travel time and delay is a major goal of many ITS components. In 1996, the Secretary of Transportation termed this initiative of the US DOT, "Operation Time Saver." Time and delay benefits also include reducing the variability of travel time and increasing the reliability of destination arrival time. It should be noted that reduction in non-recurrent or unexpected delay, such as incidents, make up much of the time saved for travelers. Tables 3 and 4 summarize travel time benefits available for Ramp Meters and Traffic Signal control that have been reported in referenced documents. Figure 2 shows the range of percentage reductions in travel times achieved in some operational systems. The reader should refer to reference documents to interpret the conditions under which these ranges are reported.

Table 3: Summary of Travel Time Benefits Achieved by Ramp Meters

\begin{tabular}{|c|c|c|c|}
\hline $\begin{array}{l}\text { Location } \\
\text { City }\end{array}$ & State & $\begin{array}{l}\text { Travel Time } \\
\text { Reduction }\end{array}$ & $\begin{array}{l}\text { e Data } \\
\text { |Type }\end{array}$ \\
\hline Denver & CO & \begin{tabular}{l|}
$13.1 \%$ \\
$26.7 \%$
\end{tabular} & $\begin{array}{l}\text { Vehicle Hours } \\
\text { Travel Time }\end{array}$ \\
\hline Portland & Oregon & $7.4 \%$ & Travel Time \\
\hline Minneapolis/ST. Paul & Minn. & $26.5 \%$ & Travel Time \\
\hline Minneapolis/ST. Paul & Minn. & $13.8 \%$ & Travel Time \\
\hline Seattle & WA & $47.7 \%$ & Travel Time \\
\hline Denver & $\mathrm{CO}$ & $37 \%$ & Travel Time \\
\hline Detroit & $\mathrm{MI}$ & $7.4 \%$ & Travel Time \\
\hline Austin & TX & $37.5 \%$ & Travel Time \\
\hline Long Island & NY. & $20 \%$ & Travel Time \\
\hline
\end{tabular}

Table 4: Summary of Travel Time Benefits Achieved by Traffic Signal Control

\begin{tabular}{|l|l|r|l|}
\hline $\begin{array}{l}\text { Location } \\
\text { City }\end{array}$ & State & $\begin{array}{r}\text { Travel Time/Delay Reduction } \\
\text { Reduction }\end{array}$ & Type \\
\hline Los Angeles & CA & $18 \%$ & Travel Time \\
& & $44 \%$ & Delay \\
\hline Toronto & Ontario & $8 \%$ & Travel Time \\
& & $17 \%$ & Delay \\
\hline Abilene & TX & $14 \%$ & Travel Time \\
& & $37 \%$ & Delay \\
\hline ITE Estimate & & $8 \%-25 \%$ & Travel Time \\
\hline
\end{tabular}



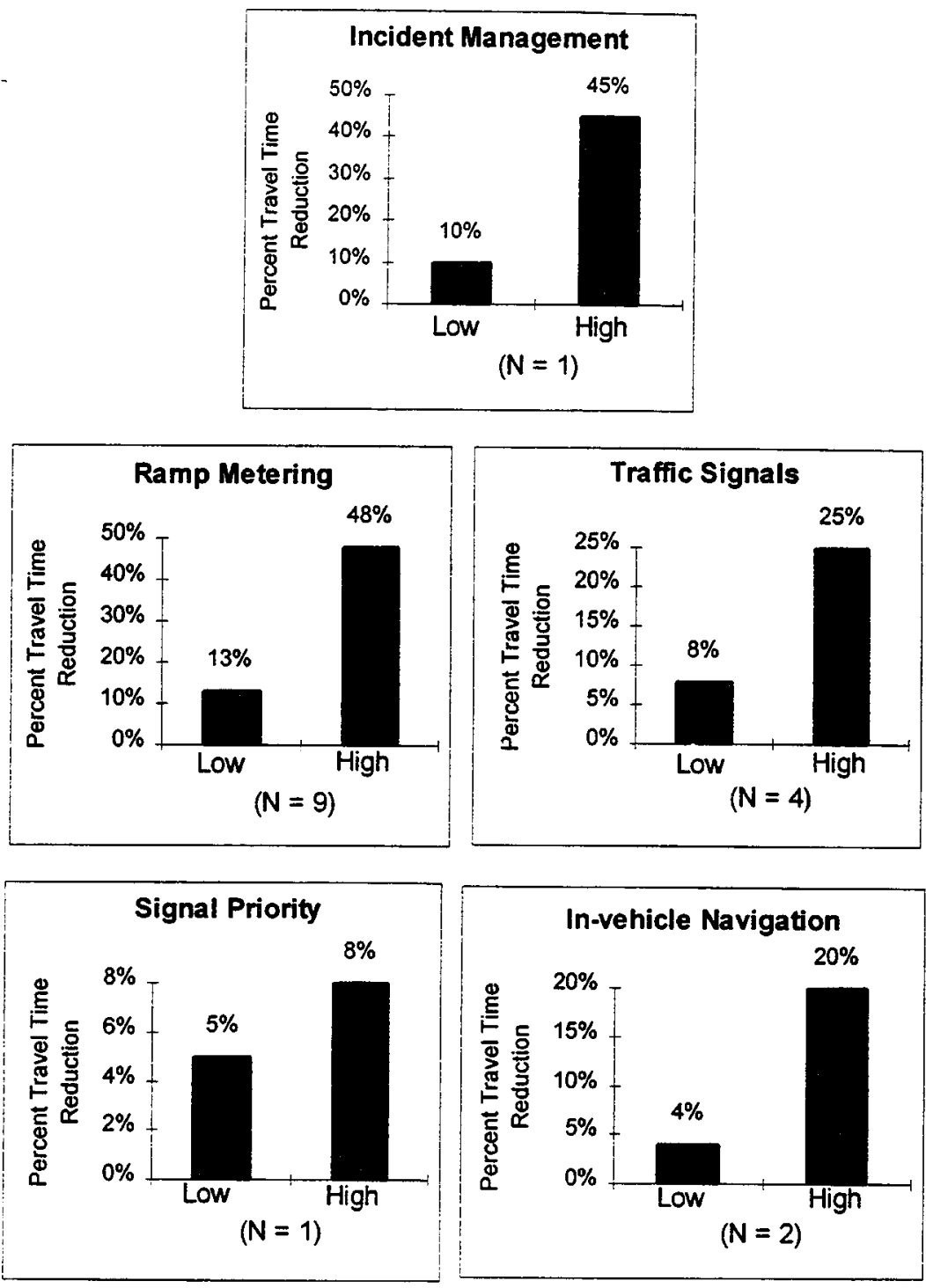

Figure 2: Range of Measured Travel Time Reduction Benefits

\subsection{Time Benefits of ATIS}

Advanced Traveler Information Systems can reduce travel times by giving travelers the information needed to select the most appropriate route, mode, or departure time for a given trip. With this information individual travelers can make selections that reduce their travel time while reducing the total network delay. Traveler information is particularly beneficial in situations when travelers are unaware of travel conditions on the highway network. These conditions could include incidents or bad weather. Even under normal conditions, these types of systems can benefit travelers who are unfamiliar with the area. ATIS can also be used to predict expected destination arrival time by route choice, mode of travel, and time of departure. 


\subsubsection{Measured Time Benefits of ATIS}

The Information for Motorists (INFORM) program is an integrated corridor management system on Long Island, New York providing information via variable message signs (VMS), control using ramp meters serving parallel expressways, and some signal coordination on arterials. The program stretches back to concept studies in the early 1970's and a major feasibility study performed from 1975 to 1977 . The implementation progressed in phases starting with VMS's, followed by ramp meters in 1986 and 1987 and completed implementation by early 1990 . Estimates of delay savings due to motorist information ${ }^{37}$ reach as high as 1900 vehicle-hours for a peak period incident and 300,000 vehicle-hours in incident related delay annually.

In-vehicle navigation devices can benefit users in terms of travel time and route finding. Field Operational Test experience is producing data that suggest system benefits when wider deployment appears. The TravTek test in Orlando found that for unfamiliar drivers, wrong turn probability decreased by about 33\% and travel time decreased by $20 \%$ relative to using paper maps, while travel planning time decreased by $80 \%{ }^{38}$. The TravTek yoked driver study demonstrated a travel time benefit from the use of the system for route planning and route guidance. A savings of $80 \%$ was observed for trip planning ${ }^{39}$. The ADVANCE project in the Northwest suburbs of Chicago tested the time effects of dynamic route guidance using a yoked vehicle study on an arterial network with limited probe data. The aggregate data set demonstrated that motorists could reduce travel time by $4 \%$ under normal or recurring conditions: However, there was a small sample size and relatively high standard deviation ${ }^{40}$. It did appear that the dynamic route guidance concept, as implemented in ADVANCE, can detect some larger delays and help drivers avoid them. The Pathfinder project implemented an in-vehicle navigation and motorist information system including access to real-time traffic information. The project was implemented in the Los Angeles area. The evaluation ${ }^{41}$ stated that the Pathfinder navigation system delivered meaningful user benefits including fewer travelers failing to follow their desired route. Since in-vehicle systems operate in a complex environment, specific results vary with conditions and options selected.

\subsubsection{Anecdotal Time Benefits of ATIS}

The two municipalities of Redondo Beach and Hermosa Beach, California are the first to implement the FleetMaster fleet management system. The system is installed in half of the 40 police vehicles and utilizes a GPS-based, real-time, system for automatic vehicle location (AVL). The system allows dispatchers to know, at all times, the exact location of patrol cars to arrange for the immediate backup of officers. It is anticipated that the FleetMaster system will save $25 \%$ of the time required to provide police and emergency service response to crimes and traffic incidents ${ }^{42}$.

\footnotetext{
${ }^{37}$ Smith, S. and Perez, C., "Evaluation of INFORM - Lessons Learned and Application to Other Systems," Conference Paper Presented at $71^{\text {st }}$ TRB, January 1992.

${ }^{38}$ Inman, V. et al., "TravTek Evaluation Orlando Test Network Study," FHWA-RD-95-162, Federal Highway Administration, January 1996.

${ }^{39}$ Inman, V., et al, "TravTek Evaluation Yoked Driver Study", FHWA-RD-94-139, Federal Highway Administration, October 1995.

${ }^{40}$ Schofer, J. et al., "Formal Evaluation of the Targeted Deployment," Vol. II, Appendix J, Northwestern University Transportation Center, July 1996.

${ }^{41}$ Pathfinder Evaluation Report, Prepared for California Department of Transportation, JHK \& Associates, Pasadena, CA, February 1993.

42 "Tracking Patrol cars in California,", in ITS: intelligent transport systems, June 1996.
} 
Studies also indicate that travelers are interested in receiving traffic information and are willing to react to avoid congestion and delay. In focus groups for the Atlanta, Georgia, Advanced Traveler Information Kiosk Project ${ }^{33}, 92 \%$ - $98 \%$ of participants found the current information on accidents, alternate routes, road closures, and traffic congestion to be useful and desirable. A survey in Marin County, California, showed that if regular commuters had been presented with alternate routes including travel time estimates, $69 \%$ would have diverted and would have saved an average of 17 minutes ${ }^{44}$. A pilot project in the Netherlands found a $40 \%$ increase in route diversions based on traffic information provided to the 300 vehicles equipped with FM sideband data receivers ${ }^{45}$.

According to studies related to INFORM, drivers will divert from $5 \%$ to $10 \%$ of the time when passive (no recommended actions) messages are displayed and twice that when messages include recommendation to divert. Convenient alternate routes also have a major impact on diversion. Drivers will start to divert several ramps prior to an incident, with typically $3 \%$ to $4 \%$ of drivers using an individual exit ramp. This represents an increase in ramp usage of $40-70 \%$. Surveys performed in the Seattle, Washington, and Boston, Massachusetts, areas indicate that $30 \%-40 \%{ }^{46}$ of travelers frequently adjust travel patterns based on travel information. Of those who change travel patterns, about $45 \%$ change route of travel and another $45 \%$ change time of travel; an additional $5 \%-10 \%$ change travel mode.

\subsubsection{Predicted Time Benefits of ATIS}

Simulations performed for the Architecture program using an urban scenario also produced encouraging indication of potential ATIS benefits. On a network experiencing periodic saturation, with congestion causing increases of up to a factor of 3 from free flow travel time, drivers with in-vehicle traffic information experience an $8 \%-20 \%$ advantage in travel time. As the network becomes loaded, but before congestion significantly affects travel time, the advantage to drivers with in-vehicle traffic information is smaller. For experienced commuters, the simulation predicts an aggregate travel time benefit of $7 \%-12 \%$. Benefit to longer trips is nfore significant in both absolute and relative terms than benefit to shorter trips, consistent with a greater opportunity for advantageous diversion. The simulations were performed using an ATIS market penetration level of $5 \%$. A separate simulation study predicted that pretrip information on roadway conditions could result in a system-wide delay reduction of $21 \%$ when a capacity reducing incident occurs, other travel options are present, and pre-trip information is universally available ${ }^{47}$.

Simulation studies based on the Detroit Metropolitan area ${ }^{48}$ examined the effects of pre-trip route selection under incident conditions. This study demonstrated that $90 \%$ of the benefit associated with en-route guidance could be obtained by receiving route travel time information before the start of a trip. This study also showed that for every 1.6 kilometers of trip length, time saved for those equipped with pre-trip route selection increased by 12 seconds.

\footnotetext{
43 "Advanced Traveler Information Kiosk Project: Summary Report - Focus Groups," Catherine Ross and Associates, Inc., undated. ${ }^{44}$ Khattak, A., Kanafani, A., and Le Colletter, E., "Stated and Reported Route Diversion Behavior: Implications on the Benefits of ATIS," University of California - Berkely, UCB-ITS-PRR-94-13, 1994.

45 Broeders, W.P.B., "RDS/TMC as Traffic Management Tool and Commercial Product," Proceedings of the Second World Congress on Intelligent Transportation Systems, Yokohama, Japan, November 1995.

${ }^{46}$ Air Quality Benefit Study of the SmarTraveler Advanced Traveler Information Service, Tech Environmental, Inc., July 1993.

${ }^{47}$ Glassco, R., et al, "Studies of Potential Intelligent Transportation Systems Benefits Using Traffic Simulation Modeling,: Mitretek Systems, MTR 96W0000054, June 1996.

48 Glassco, R., et al, "Studies of Potential Intelligent Transportation Systems Benefits Using Traffic Simulation Modeling: Volume 2," Mitretek Systems, MTR 1997-31, June 1997.
} 


\subsection{Time Benefits of ATMS}

Advanced Traffic Management Systems reduce travel time by improving the flow of traffic both in incident and nonincident conditions. By using improved communications and control techniques, traffic management can reduce delay in uncongested situations, adjust control devices to improve utilization of available capacity and thereby increase throughput in congested situations. A key part of ATMS, incident management systems are capable of responding more quickly to incidents, and help to restore full capacity, thereby decreasing delay effects.

\subsubsection{Measured Time Benefits of ATMS}

Incident management programs show concrete promise of reducing the $50-60 \%$ of delay associated with traffic congestion attributable to incidents. The Institute of Transportation Engineers (ITE) has estimated $10 \%-45 \%$ decreases in travel time during congested times using incident management programs included in freeway management systems ${ }^{49}$.

Before the implementation of an Autoscope automated incident detection system along the Gowanus Expressway in Brooklyn, New York, the average time to clear an incident was 1.5 hours. Since the installation of 20 CCTV cameras, the video images of incidents are now sent directly to operators who determine the severity of the conditions. The time required to detect and clear vehicle breakdowns has been reduced to 19 minutes, while the average time to clear all types of incidents has been reduced to 31 minutes $^{50}$ (a $66 \%$ reduction).

In preparation for the 1996 Olympic Games, Atlanta Georgia added several ITS capabilities to assist in moving visitors and vehicles in an extremely crowed area. Improved interagency coordination was developed based on the capabilities of a regional ATMS program. The mean time between the first report of an incident and incident verification was reduced from 4.2 minutes to 1.1 minutes, a reduction of $74 \%$. Mean time beiween incident verification and automated generation of incident response was reduced from 9.5 minutes to 4.7 minutes (50\%). The mean time between incident verification and clearance of traffic lanes was reduced from 40.5 minutes to 24.9 minutes (38\%). The maximum time between incident verification and clearance of traffic lanes was reducas from 6 hours 15 minutes to 1 hour 28 minutes, a $60 \%$ reduction $^{51}$.

The Maryland CHART program is in the process of expanding to more automated surveillance with lane sensors and video cameras. The evaluation of the initial operation of the program shows a benefit/cost ratio of 5.6:1, with most of the benefits resulting from a $5 \%$ (2 million vehicle-hours per year) decrease in delay associated with non-recurrent congestion ${ }^{52}$. Freeway service patrols, which began prior to the emergence of ITS technologies, but are being incorporated into traffic management centers, significantly reduce the time to clear incidents, especially minor incidents. The Minnesota Highway Helper Program ${ }^{53}$ reduces the duration of a stall (the most frequent type of incident, representing $84 \%$ of service calls) by 8 minutes. Based upon representative numbers, annual benefits through reduced delay total $\$ 1.4$ million for a program that costs $\$ 600,000$ to operate.

\footnotetext{
${ }^{10}$ Meyer, M., ed., A Toolbox for Alleviating Traffic Congestion, Institute of Transportation Engineers, Washington, DC, 1989.

50 "Under Detection," in ITS: intelligent transport systems, Issue number 10, May/June 1997.

51 Booz Allen \& Hamilton,"1996 Olympic and Paraolympic Event Study," Final Report, May 1997.

52 COMSIS Corporation, "CHART Incident Response Evaluation Final Report," Silver Spring, MD, May 1996.

53 Minnesota Department of Transportation, "Highway Helper Summary Report - Twin Cities Metro Area, Report \# TMC 07450 0394, July 1994.
} 
Freeway management systems and ramp meters show good results in reducing travel times on congested roadway segments. According to a longitudinal study of the ramp metering/freeway management system in the Seattle, Washington area over a six year period ${ }^{54}$, freeways in the area show a growth in traffic volume of $10 \%$ to $100 \%$ along various segments of $1-5$ while speeds have remained steady or increased up to $20 \%$. The improvements have occurred while average delays caused by ramp meters have remained at or below 3 minutes. Average freeway speeds on Minnesota's 1-494 near Minneapolis, have risen from $30 \mathrm{mph}$ to almost $50 \mathrm{mph}$ while peak period demand increased between 2.9 and $7.2 \%$. Also, the net results indicate a vehicle delay reduction between 11 and 93.1 vehicle hours during peak periods for 7 ramp meters included in the study ${ }^{55}$. In studies comparing 1987 to 1990 flows in the areas of the INFORM system, measuring benefits from ramp metering in combination with motorist information, freeway speeds increased $13 \%$ despite an increase of $5 \%$ in VMT for the PM peak ${ }^{56}$. The relative merits of ramp metering and motorist information can not be discerned from the available data. The number of detectors showing speeds of less than $30 \mathrm{mph}$ decreased $50 \%$ for the AM peak. Average queue lengths at ramp meters ranged from 1.2 to 3.4 vehicles, representing $0.1 \%$ of vehicle hours traveled. A survey of traffic management centers using ramp metering ${ }^{57}$ reported similar findings of speed increases of $16 \%$ $62 \%$ and travel time improvements of up to $48 \%$, while demand increased $17 \%-25 \%$.

Traffic signal system improvements are frequently implemented with reduction of travel time as a primary goal. The Automated Traffic Surveillance and Control (ATSAC) Program in Los Angeles, California, largely a computerized signal control system, reported an $18 \%$ reduction in travel time, a $16 \%$ increase in average speed, and a $44 \%$ decrease in delay ${ }^{58}$. The city of Toronto, Ontario, Canada, evaluated the SCOOT computerized signal control system on two corridors and the central business district network, totaling 75 signals $^{59}$. During an evaluation performed over a two-month period comparing the SCOOT implementation to a "best effort" fixed timing plan, SCOOT resulted in a $8 \%$ decrease in travel time as well as a $17 \%$ decrease in delay. The City of Abilene, Texas, installed a closed-loop computerized signal system. Their report ${ }^{60}$ indicates an overall decrease in travel time of $14 \%$, a decrease in delay of $37 \%$ and an increase in travel speed of 22\%. Phase I of a Texas state program called Traffic Light Synchronization (TLS) involving 44 cities, has installed arterial and network signal system projects affecting 2,243 of the approximately 13,000 traffic signals in the state. An additional 73 systems were installed in Phase II. TLS analysis shows a benefit/cost ration of $62: 1^{61}$, with a majority of the benefits being travel time reduction. ITE estimates of reduction in travel time from traffic signal improvements range from $8 \%$ to $25 \%{ }^{62}$.

Portland, Oregon ${ }^{63}$ has integrated a bus priority system with the traffic signal system on a major arterial. By allowing buses to either extend green time or shorten red time by only a few seconds, the bus travel time was reduced by between $5 \%$ and $8 \%$. In addition to the travel time savings, this approach allows the use of fewer vehicles to serve that route.

\footnotetext{
${ }^{54}$ Henry, K. and Meyhan, O., "6 Year FLOW Evaluation," Washington State DOT, District 1, January 1989.

55 "Partners in Motion, 494 Transportation Corridor: ICTM Project, Interim Report \#1," Prepared for ICTM Evaluation Committee by HNTB Corporation, undated.

${ }_{58}$ Smith, S. and Perez, C., "Evaluation of INFORM - Lessons Learned and Application to Other Systems, "Conference Paper Presented at $71^{\text {st }}$ TRB, January 1992.

${ }^{57}$ Robinson, J. and Piotrowicz, G., "Ramp Metering Status in North America, 1995 Update," Federal Highway Administration, June 1995.

${ }^{58}$ City of Los Angeles Department of Transportation, "Automated Traffic Surveillance and Control (ATSAC) Evaluation Study," June 1994.

s9 Siemens Automotive, USA, "SCOOT in Toronto," Traffic Technology International, Spring 1995.

${ }^{60}$ Orcutt Associates, "Evaluation Study, Buffalo Gap Road, Abilene Signal System," prepared for the City of Abilene, Texas, 1994.

${ }^{61}$ Benefits of the Texas Traffic Light Synchronization Grant Program I; Volume I, TxDOT/TTI Report \# 0258-1, Texas Department of Transportation, Austin, Texas, October 1992.

62 Meyer, M., ed., A Toolbox for Alleviating Traffic Congestion, Institute of Transportation Engineers, Washington, DC, 1989.

63 Kloos, W., et al., "Bus Priority at Traffic Signals in Portland: The Powell Eoulevard Pilot Project," ITE Compendium of Technical Papers, July 1994.
} 


\subsubsection{Anecdotal Time Benefits of ATMS}

The City of Richardson, Texas tied the operator of the city's towing concession into the roadway surveillance network with an investment of roughly $\$ 200$. Using the information provided by the camera, the tow truck dispatcher can position appropriate equipment near the collision site prior to the request for service from the police department. This reduces the response time for incident clearance by 5-7 minutes on average and greatly improves the ability to send appropriate equipment that can handle the active incident (Pamela Hadnot, City of Richardson internal memorandum, December 1995).

ETC can greatly improve throughput on a per-lane basis compared with manual toll collection techniques. On the Tappan Zee Bridge toll plaza, a manual toll lane can accommodate 400-450 vehicles per hour while an electronic lane peaks at 1000 vehicles per hour ${ }^{64}$.

\subsubsection{Predicted Time Benefits of ATMS}

The incident management program of the TranStar system covers 127 miles of the Houston freeway network. An analysis of major freeway incidents within the TranStar system demonstrated a savings of 30 minutes. This same analysis supports a 5 minute average savings for all types of incidents. Together these result in an annual estimated delay savings of 572,095 vehicle-hours with an economic value of $\$ 8.4$ million. In 1996, there were seven occurrences where video surveillance was used to determine if HOV restrictions could be lifted. It was estimated that 12,910 vehicles were able to save between 13.5 to 27 minutes over those vehicles remaining in the queue for a total estimated cost savings of $\$ 42,500$ to $\$ 85,100^{65}$.

Simulation and analysis have predicted that traffic adaptive signal controls could further reduce delays and emissions compared to the currently implemented systems under certain conditions. In simulations performed for the National ITS Architecture Program using non-proprietary adaptive algorithms, delay reduction of well over $20 \%$ were observed when traffic patterns deviated from predicted levels ${ }^{66}$.

Simulation of a network based on the Detroit Commercial Business District ${ }^{67}$ indicated that adaptive signal control for detours around an incident reduced delay by $60 \%$ to $70 \%$ for affected paths. Additionally, by providing alternative routing possibilities $52 \%$ of those choosing an alternative rather than the detour benefited. Using the same network under non-incident conditions, it was demonstrated that a synchronized, actuated signal control system reduced travel times between $25 \%$ to $41 \%$. The highest savings occurred for high traffic volume paths. Over all paths, $91 \%$ had some benefit and $65 \%$ benefited over $20 \%$.

\footnotetext{
64 Lennon L., "Tappan Zee Bridge E-Z Pass System Traffic and Environmental Studies," Compendium of Technical Papers, $64^{\text {th }}$ ITE Annual Meeting, Institute of Transportation Engineers, 1994.

65 "Estimation of Benefits of Houston TranStar," Prepared by Parsons Transportation Group in cooperation with Texas Transportation Institute, February 7, 1997.

${ }^{66}$ Glassco, R, et al, "Studies of Potential Intelligent Transportation System Benefits Using Traffic Simulation Modeling," Mitretek Systems, MP96W0000101, June 1996.

${ }^{67}$ Glassco, R, et al., "Studies of Potential Intelligent Transportation System Benefits Using Traffic Simulation Modeling: Volume 2," Mitretek Systems, MTR 1997-31, June 1997.
} 


\subsection{Time Benefits of APTS}

Advanced Public Transportation Systems can reduce travel time both by improving the operation of the vehicles and the overall operation of the transportation network. Vehicle management systems improve schedule adherence resulting in a reduction in passenger wait time and improvement in transfer coordination. To the extent that travel demand can be accommodated with higher occupancy vehicles, the transportation network is less congested, resulting in reduced travel time for both transit passengers and other vehicles.

\subsubsection{Measured Time Benefits of APTS}

For nearly a decade, transit properties have been installing and using automatic vehicle location (AVL) systems based on signpost, triangulation, LORAN, and, more recently, GPS technologies ${ }^{68}$. The most direct improvement enabled by transit management systems relates to schedule adherence. The Mass Transit Administration in Baltimore, Maryland, reported a 23\% improvement in on-time performance by AVL-equipped buses. The Kansas City Area Transportation Authority in and around Kansas City, Missouri, improved on-time performance by $12 \%$ in the first year of operation using AVL, compared to a $7 \%$ improvement as the result of a coordinated effort between 1986 and 1989 . Preliminary results from Milwaukee, Wisconsin, indicate a $28 \%$ decrease in the number of buses more than one minute behind schedule ${ }^{69}$.

\subsubsection{Anecdotal Time Benefits of APTS}

AVL systems continue to be deployed rapidly. A recent study found 22 U.S. Transit systems operating more than 7,C00 vehicles under AVL supervision and another 47 in various stages of procurement. The new procurements represent a tripling of the number of deployed systems, with most new systems using a GPS-based location process ${ }^{70}$ Five Canadian operators are using AVL on fleets totaling 3700 buses, including a 2300 -vehicle fleet in Toronto ${ }^{71}$. Fleet management systems with vehicle location capability are producing benefits in productivity, security, and travel time. In addition, several operators have reported incidents where AVL information assisted in resolving disputes with employees and patrons.

\subsection{Time Benefits of CVO}

Implementations of ITS commercial vehicle operational services may reduce both travel time and regulatory time. Travel time of commercial vehicles may be reduced, by removing the need to stop at inspection stations, and reducing processing times at ports of entry. Time required to acquire credentials and perform inspections could also be reduced with electronic communications and automated monitoring tools. Dispatch systems reduce time and telephone charges required to communicate with dispatch centers. CVO services may also assist in improving the arrival reliability of just-in-time deliveries.

\footnotetext{
${ }^{68}$ Jones, W. ITS Technologies in Public Transit: Deployment and Benefits, USDOT ITS Joint Program Office, November 1995.

${ }^{69}$ Giugno, M., Milwaukee County Transit System, July 1995 Status Report.

${ }^{70}$ Casey, R., and Labell, L., "Advanced Public Transportation Systems Deployment in the United States,: USDOT Federal Transit Administration, August 1996.

${ }^{71}$ Casey, R. et. al., Advanced Public Transportation Systems: The State of the Art - Update '96, USDOT Federal Transit Administration, January 1996.
} 


\subsubsection{Measured Time Benefits of CVO}

The Commercial Vehicle Operations (CVO) area continues to be viewed as a potential early winner for the ITS program. Use of advanced vehicle monitoring and communication technologies by motor carriers have demonstrated considerable time savings ${ }^{72}$. Schneider of Green Bay Wisconsin, reported a $20 \%$ increase in loaded miles. Schneider also reported that the elimination of driver check-in telephone calls saves approximately two hours per day, resulting in a driver salary increase of $\$ 50$ per week, with a primary benefit of improved customer senvice. Trans-Western Ltd. of Lerner, Colorado, reports that their fleet management system for improved driver relations, noting that drivers are able to drive 50 to 100 additional miles per day. Frederick Transport of Dundas, Ontario, Canada, estimates an increase of $20 \%$ in loaded miles, a reduction of $\$ 30$ out of $\$ 150$ per month in telephone charges and a $0.7 \%$ greater load factor. Best Line of Minneapolis, Minnesota, estimates a $\$ 10,000$ per month saving since 300 drivers previously lost about 15 minutes each day waiting to talk with dispatchers.

\subsubsection{Predicted Time Benefits of CVO}

A simulation study demonstrated ITS capabilities that could be used to improve the effectiveness of a hypothetical advanced truck weigh station ${ }^{73}$. The study examined the delay effects of increased transponder usage of trucks as arrival rates to the station varied. Truck equipped with transponders where permitted to bypass the station thereby saving $100 \%$ non-equipped truck delay. As transponder usage increased, queue lengths behind scales decreased, thus also decreasing the delay experienced for non-equipped trucks. Savings for non-equipped trucks varied as a function of average inter-arrival time, time required at the scale, and percent of trucks equipped with transponders. For an average inter-arrival time of 20 seconds and a weigh time of 25 seconds, non-equipped vehicles saved approximately 30 seconds for a $20 \%$ transponder equipage and a $60 \%$ transponder equipage resulted in an average 8 minutes saved at the station.

\subsection{Time Benefits of AVCSS}

Improved vehicle control can reduce travel time by allowing increased speeds and increased throughput at improved levels of safety. As sophistication of vehicle control systems progresses and user confidence grows, significant speed increases are possible. Vehicle control systems indirectly aid in reducing nonrecurrent congestion by reducing the number of incidents.

\subsubsection{Predicted Time Benefits of AVCSS}

In a preliminary analysis performed for the Automated Highway System program, capacity increases of $300 \%$ for platooned operations and $200 \%$ for non-platooned compared to current freeway operation have been predicted. Analysis based on the Long Island Expressway and the Capital Beltway near Washington $D C$, predicted that capacity improvements could reduce travel time by $38 \%$ to $48 \%{ }^{74}$.

\footnotetext{
72 Hallowell, S., and Morlok, E., "Estimating Cost Savings From Advanced Vehicle Monitoring and Telecommunication Systems in Intercity Irregular Route Trucking," Department of Systems, University of Pennsylvania, Philadelphia, PA, January 1992

${ }^{73}$ Glassco, R., et al, "Studies of Potential Intelligent Transportation Systems Benefits Using Traffic Simulation Modeling: Volume 2," Mitretek Systems, MTR 1997-31, June 1997.

${ }^{74}$ Stevens, W. et al., "Summary and Assessment of Findings From the Precursor Analysis of Automated Highway System," The MITRE Corporation, WN95WO000124, October 1995.
} 


\section{SECTION 4}

\section{THROUGHPUT}

Many ITS components seek to optimize use of existing facilities and rights-of-way so that mobility and commerce needs can be met while reducing the need to construct new facilities or expand rights-of-way. This can be done by increasing the number of people, number of vehicles, or amount of goods moved per unit of time while maintaining or improving level of service. Although some ITS components address throughput of individual facilities, other components seek to improve network throughput, which is more difficult both to define and to measure. Table 5 presents a summary of measured increases of throughput and volume for data referenced in this document. Figure 3 shows the reported percentage increases in maximum throughput achieved in ETC systems, and collision avoidance systems.

Table 5: Summary of Throughput and Volume Benefits of Freeway Management Systems

\begin{tabular}{|l|l|r|l|}
\hline \begin{tabular}{l|l|} 
Location \\
City
\end{tabular} & State & $\begin{array}{r}\text { ThroughputVolume Data } \\
\text { Increase }\end{array}$ & Type \\
\hline Minneapolis/ST. Paul & Minn. & $25 \%$ & Volumes \\
\hline Minneapolis/ST. Paul & Minn. & $32 \%$ & Volumes \\
\hline Seattle & WA & $86 \%$ NB & Volumes \\
& & $62 \%$ SB & \\
\hline Denver & CO & $15.6 \%$ & Volumes \\
\hline Detroit & MI & $12.5 \%$ & Volumes \\
\hline San Diego & CA & $8.3 \%$ & Volumes \\
\hline Austin & TX & $7.9 \%$ & Throughput \\
\hline Long Island & NY & $2 \%$ & Throughput \\
\hline
\end{tabular}
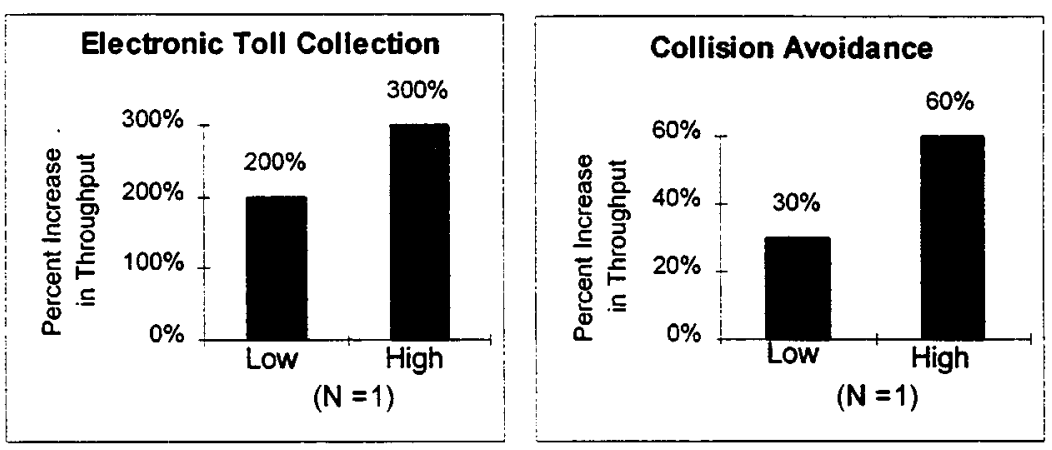

Figure 3: Range of Throughput Improvement Benefits 


\subsection{Throughput Benefits of ATIS}

Traveler information systems can increase the throughput of existing facilities by informing travelers to make better decisions. Information regarding incidents and congestion allows drivers to reroute onto less congested facilities. Information can also lead travelers to increase utilization of shared ride modes such as carpools or transit. This effect leads to the average occupancy of the vehicles on the network increasing. Route guidance information will reduce the distance traveled due to poor navigation. Although studies relating traveler information to decreased travel time give an indication of increased throughput, no direct quantitative estimates of these network improvements are currently available.

\subsubsection{Predicted Throughput Benefits of ATIS}

Simulations using data collected during the TravTek test predicted an increase in throughput. Using constant average trip duration as a surrogate for maintaining level of service, a market penetration of $30 \%$ for dynamic route guidance results in the ability to handle $10 \%$ additional demand ${ }^{75}$.

\subsection{Throughput Benefits of ATMS}

Traffic management systems improve throughput by improving the flow of traffic both in incident and nonincident conditions, similar to the manner by which travel time is decreased. By using improved communication and control techniques, traffic management can adjust control devices to improve utilization of available capacity in congested or incident situations and can respond more quickly to incidents to restore full capacity.

\subsubsection{Measured Throughput Benefits of ATMS}

Freeway management systems including both ramp meters and incident management programs are designed to improve the operation performance of freeways. The Seattle, Washington study ${ }^{76}$ showed a growth in traffic of $10 \%$ to $100 \%$ along various segments of $1-5$ while speeds have remained steady or increased up to $20 \%$. Other ramp metering installations have reported increases in peak throughput of $8 \%-22 \%$ with steady or increased travel speeds ${ }^{77}$.

\footnotetext{
${ }^{75}$ Van Aerde, M., and Rakha, H., "TravTek Evaluation: Modeling Study," FHWA-RD-95-090, Federal Highway Administration, March 1996.

${ }^{76}$ Henry K. and Meyhan, O., "6 Year FLOW Evaluation," Washington State DOT, District 1, January 1989.

${ }^{77}$ Robinson, J. and Piotrowicz, G., "Ramp Metering Status in North America, 1995 Update," Federal Highway Administration, June1995.
} 


\subsection{Throughput Benefits of AVCSS}

Improved vehicle control systems are expected to increase throughput by reducing required headway. Indirectly, it is expected that vehicle control systems can aid in increasing throughput by reducing the number of incidents.

\subsubsection{Predicted Throughput Benefits of AVCSS}

In preliminary analyses performed for the Automated Highway System, throughput increases of $300 \%$ for platooned operation and $200 \%$ for nonplatooned automated control compared to non-automated freeway segments have been predicted ${ }^{78}$. Less complete implementations, termed evolutionary representative system configurations, with rear-end collision warning or collision avoidance can show less dramatic capacity increases. Analyses indicate increases of $30 \%$ with collision warning in uniform vehicles to $60 \%$ with collision avoidance in vehicles differing in braking capacity ${ }^{79}$.

\footnotetext{
${ }^{78}$ Stevens, W. et al., "Summary and Assessment of Findings from the Precursor Analyses of Automated Highway System," The MITRE Corporation, WN95W0000124, October 1995.

79 "Precursor Systems Analyses of Automated Highway Systems: Volume Four - Lateral and Longitudinal Control Final Report," prepared by University of Southern California Center for Advanced Transportation Technologies under subcontract to Raytheon Company for Federal Highway Administration, February 1995.
} 


\section{SECTION 5}

\section{COST REDUCTION BENEFITS}

ITS implementation frequently reduces operating costs and allows productivity improvements. In addition, ITS options may have lower acquisition costs compared to traditional transportation improvement options. They may also have lower life-cycle cost due to operating cost and productivity improvements. Figure 4 shows percentage improvement in operating cost.
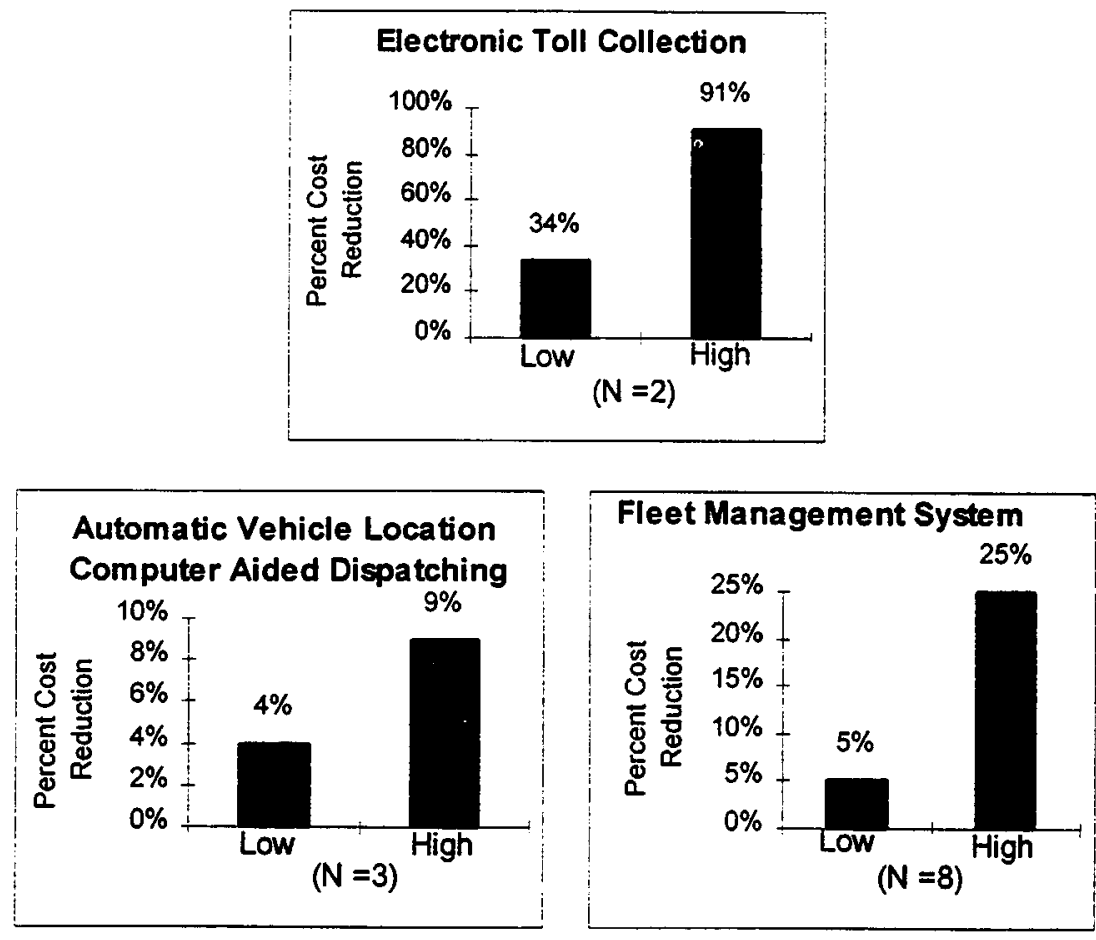

Figure 4: Range of Measured Improvement in Operating Costs and Productivity

Investments in improving transportation systems have typically resulted in more than a two dollar return for every dollar invested. In fact, a recent study involving the Philadelphia transit system showed that the economic cost of rehabilitating the system is ten times less then the cost of terminating service ${ }^{80}$. Some of the cost savings reported in this section are directly realized by the transportation systems, while others are societal savings.

\footnotetext{
so "Transportation: Driving a Thriving Economy," American Association of State Highway and Transportation Officials and the National Governors' Association, May 1997.
} 


\subsection{Cost Reduction Benefits of ATMS}

\subsubsection{Measured Cost Reduction Benefits of ATMS}

Deployment of ETC is occurring at a rapid pace and is being driven by cost savings to the operator. The Oklahoma Turnpike has been operating ETC in the Pike Pass program since 1990. Statistics from the Turnpike in a flyer indicate a $91 \%$ savings ${ }^{81}$ :

Annual cost to operate automated lane $-\$ 15,800$

Annual cost to operate an attended lane $-\$ 176,000$

\subsubsection{Predicted Cost Reduction Benefits of ATMS}

The incident management program of the TranStar system covers 127 miles of the Houston freeway network. An analysis for freeway incidents within the TranStar system estimated an annual delay savings of 572,095 vehicle-hours with an economic value of $\$ 8.4$ million. The ramp metering program on the $1-10$ Katy Freeway of the TranStar system reports daily savings of 2,875 vehicle hours resulting in a $\$ 37,030$ benefit to Houston commuters. In 1996, there were seven occurrences where video surveillance was used to determine if HOV restrictions could be lifted. It was estimated that 12,910 vehicles were able to save between 13.5 to 27 minutes over those vehicles remaining in the queue for a total estimated cost savings of $\$ 42,500$ to $\$ 85,100^{82}$.

The six month pilot Courtesy Patrol Program in Denver, Colorado is estimated to have reduced the cost of traffic delay by $\$ 0.8-\$ 1.0$ million for the morning period, and by $\$ 0.90-\$ 0.95$ million in the evening. This assumes a time value of $\$ 10$ per hour. Program costs varied between the tow truck operators between $\$ 29$ to $\$ 38$ per truck-hour, which results in a benefit to cost ratio of $10.5: 1$ to $16.9: 1^{83}$.

\subsection{Cost Reduction Benefits of APTS}

Application of ITS technologies is expected to reduce the cost of transit operations by improving productivity of staff and utilization of faciiities and equipment.

\subsubsection{Measured Cost Reduction Benefits of APTS}

The use of AVL/CAD systems has demonstrated significant productivity improvements to transit operators. After an extended analysis of travel times, Kansas City, Missouri, was able to reduce up to $10 \%$ of the equipment required for some bus routes. This allows fewer buses to serve those routes with no reduction in customer service. The result was a savings in both operating expense and capital expense by actually removing these buses from service and not replacing them. The productivity gain of eliminating seven buses out of a 200 bus system allowed Kansas City to amortize their investment in AVL in two years. Other transit systems have reported reductions in fleet size of $4 \%$ to $9 \%$ due to efficiencies of bus utilization ${ }^{84}$.

81 "Pike Pass Facts," Oklahoma Turnpike Commission flyer, 1995

82 "Estimation of Benefits of Houston TranStar," Prepared by Parsons Transportation Group in cooperation with the Texas Transportation Institute, February 7, 1997.

${ }^{83}$ Cuciti P., and B Janson., "Incident Management via Courtesy Patrol: Evaluation of a Pilot Program in Colorado," $74^{\text {th }}$ annual Meeting of the Transportation Research Board, Washington DC, Transportation Research Record, 1995.

${ }^{84}$ Jones, W., ITS Technologies in Public Transit: Deployment and Benefits, USDOT ITS Joint Program Office, November 1995. 
The Winston-Salem Transit Authority in Winston-Salem, North Carolina, evaluated effects of a computeraided dispatch and scheduling (CADS) system on the operation of a 17 bus fleet ${ }^{85}$. While the client list grew from 1,000 to 2,000 over a 6-month period and vehicle miles per passenger trip grew $5 \%$, operating expenses dropped $2 \%$ per passenger trip and $9 \%$ per vehicle mile. These productivity improvements occurred at the same time as service improvements including institution of same day reservations, which grew to account for $10 \%$ of trips, and a decrease in passenger wait time of over $50 \%$.

While much of the literature regarding electronic fare payment discusses technical capability and patron convenience, some indications of benefits to the transit property are accumulating. Reductions in data collection costs range from an estimated $\$ 1.5$ million in Manchester, UK to a predicted $\$ 5$ million in Ventura, California, in addition to improved data accuracy ${ }^{86}$. New York estimates the increase in ridership due to electronic fare payment to be worth $\$ 49$ million. New Jersey Transit estimates annual cost reduction of $\$ 2.7$ million in cash handling, while Atlanta estimates $\$ 2$ million in savings ${ }^{87}$.

Public transportation providers in rural areas can produce cost efficiencies by increasing ridership. The computer-assisted dispatching system in Sweetwater County, Wyoming, which allows same-day ride requests to be accepted, has contributed to an increase in ridership from 5,000 passengers monthly to 9,000 monthly without increasing the dispatch staff and a reduction of operational expense of $50 \%$ over a 5-year period on a per passenger mile basis ${ }^{88}$.

\subsubsection{Predicted Cost Reduction Benefits of APTS}

Analysis of benefits accruing to the transit industry from APTS technologies predicts that current and planned deployments at US transit properties will yield benefits totaling between $\$ 3.8$ billion and $\$ 7.4$ billion in discounted 1996 dollars over the next ten years. In approximate terms, $44 \%$ of the total results are from transit management systems, $34 \%$ are from electronic fare payment systems, $21 \%$ are from automated traveler information systems, and $1 \%$ of the total benefit is from computer-aided dispatching in demand-responsive transit application ${ }^{89}$.

Public transportation providers in rural areas can coordinate travel needs among various providers. The Potomac and Rappahannock Transportation Commission operates demand-responsive transit to serve transit needs and commuter rail stations in the suburban fringe of the Washington, DC, metropolitan area. The service also meets requirements of the Americans with Disabilities Act. Compared to a fixed route service and complementary para transit service, the demand-responsive system is estimated to produce a $40 \%$ reduction in total $\cos t^{\circ}$. Use of coordinated para transit with a dispatch system including AVL, which can coordinate trips among up to five agencies, has the potential to reduce fraud in Medicaid transportation by $\$ 11$ million annually in the State of Florida ${ }^{91}$.

\footnotetext{
${ }^{85}$ Stone, J., "Winston-Salem Mobility Management: An Example of APTS Benefits, " NC State University, 1995.

${ }^{86}$ Dinning, M., "Benefits of Smart Cards in Transit," The Volpe Center September 1995.

87 Jones, W., ITS Technologies in Public Transit: Deployment.and Benefits, USDOT ITS Joint Program Office, November 1995.

${ }^{88}$ Casey, R., "The Benefits of ITS Technologies for Rural Transit," The Volpe Center, presented at the Rural ITS Conference, September 1996.

${ }^{89}$ Goeddel, D., "Benefits Assessment of Advanced Public Transportation Systems (APTS)", prepared for Federal Transit Administration by Volpe National Transportation Systems Center, July 1996.

${ }^{\circ 0}$ Farwell, R., "Evaluation of OmniLink Demand Driven Transit Operations: Flex-Route Services," SG Associates, Annandale, Virginia, presented at the European Transport Forum, 1996.

${ }^{91}$ Ride Solutions, "Operational Strategies for Rural Transportation," Florida Coordinated Transportation System, undated
} 


\subsection{Cost Reduction Benefits of CVO}

ITS applications to commercial vehicle operations can reduce cost to both the regulators and the motor carriers by automating paperwork completion and improving the productivity of employees and utilization of facilities and equipment. Improved enforcement of regulation, especially weight regulations can reduce infrastructure maintenance and replacement costs.

\subsubsection{Measured Cost Reduction Benefits of CVO}

The CVO area continues to be viewed as a potential early winner for the ITS program. Productivity improvements reported by motor carriers (in a 1992 study) using advanced vehicle monitoring and communications technology provide an indication of the magnitude of these benefits. For intercity irregular-route trucking, Telesat Canada estimates use of its system will increase loaded mileage $9 \%$ to $16 \%$ and reduce operating cost \$.12 to \$.20 per truck mile. Schneider of Green Bay, Wisconsin, reports that the elimination of driver check-in telephone calls saves approximately two hours per day resulting in a driver salary increase of $\$ 50$ per week. Trans-Western Ltd. of Lerner, Colorado notes that drivers are able to drive 50 to 100 additional miles per day, and driver turn-over has decreased from $100 \%$ to $30 \%$. Frederick Transport of Dundas, Ontario, Canada, a reduction of $\$ 30$ (from $\$ 150$ per month) in telephone charges, a $0.7 \%$ greater load factor and a $9 \%$ increase in total miles. Best Line of Minneapolis, Minnesota, estimates a $\$ 10,000$ per month savings since 300 drivers previously lost about 15 minutes each day waiting to talk with dispatchers. Mets of Indianapolis, Indiana, performed tests that showed vehicle utilization increased by $13 \%$. In addition, United Van Lines of Fenton, Missouri, claims that the ability to track and recover stolen vehicles is expected to reduce theft insurance premiums ${ }^{92}$.

Additional results are provided in an ATA Foundation 1992 survey ${ }^{93}$ of 69 trucking companies operating in an urban area. More than half of the 69 companies surveyed use CAD systems. Productivity gains resulted from an increase in the number of pickups and deliveries per truck per day, ranging from $5 \%$ to more than $25 \%$, with most gains being clustered in the $10-20 \%$ range. The use of two-way text communication systems yielded driver time savings of 30 minutes per day because of the reduced time spent locating and using telephones.

\subsubsection{Anecdotal Cost Reduction Benefits of CVO}

Anecdotal evidence that fleet management provides benefits is continuing to accumulate. The Automated Mileage and Stateline Crossing Operational Test (AMASCOT) has generated significant interest from carriers, manufacturers, and regulators. Although the AMASCOT evaluation did not calculate cost savings during the operational phase, carriers involved in the test estimated a potential to reduce costs by $33 \%$ to $50 \%$ for International Fuel Tax Agreement (IFTA) and International Registration Plan (IRP) reporting ${ }^{94}$. State processing and audit staffs were receptive to potential changes in processing requirements. These staffs were also optimistic about the ability of such a system to improve accuracy, productivity, and compliance for both carriers and states ${ }^{95}$.

\footnotetext{
92 Hallowell, S., and Morlok, E., "Estimating Cost Savings From Advanced Vehicle Monitoring and Telecommunication Systems in Intercity Irregular Route Trucking.," department of Systems, University of Pennsylvania, Philadelphia, PA, January 1992.

${ }_{93}$ ATA Foundation, Inc., "A Survey of the Use of Six Computing and Communications Technologies in Urban Trucking Operations," Alexandria, VA, 1992.

${ }^{94}$ Maze, TH., et al,. "Automated Mileage and Stateline Crossing Operation Test Part 1 - Evaluation Summary," May 1, 1996.

${ }^{95}$ Center for Transportation Research and Education, "Automated Mileage and Stateline Crossing Operational Test Evaluation

Summary," Final Report, Federal Highway Administration, May 1996.
} 
Commercial vehicle regulators will also experience financial benefits due to implementation of ITS.

Improvements in administrative efficiency, avoidance of infrastructure investment, and improvements in highway data collection will reduce cost while increased compliance will increase revenues and reduce damage to highways in addition to improving safety. The HELP/Crescent Project on the West Coast evaluated the applicability of four technologies for screening transponder equipped vehicles. The technologies included automatic vehicle identification, weigh-in-motion, automatic vehicle classification, and integrated communications systems and database. The benefits data are developed as a projection of experience from the project and from other databases rather than direct measurement by the project. ${ }^{96}$ Impact of hazardous material incidents could be reduced $\$ 1.7$ million annually per state. Estimates of reductions in tax evasion range from $\$ 0.5$ to $\$ 1.8$ million annually per state. Overweight loads could be reduced by $5 \%$ leading to a savings of $\$ 5.6$ million annually. Operating costs of a weigh station could be reduced up to $\$ 169,000$, with credentials checking adding $\$ 4.3-\$ 8.6$ million and automated safety inspections adding $\$ 156,000-\$ 781,000$ in savings due to avoided accidents annually per state. A full implementation of services examined in the Crescent project would yield a benefit/cost ratio of 4.8 for state government over a 20-year period. Less complete implementations range in benefit/cost ratio from 0 up to $12: 1$ for the government. The COVE Study ${ }^{97}$ estimates a benefit/cost ratio to the government of 7.2 for electronic clearance, 7.9 for one-stop/no-stop shopping, and 5.4 for automated roadside inspections.

\subsubsection{Predicted Cost Reduction Benefits of CVO}

An extensive benefit to cost analysis of CVO user services effects on regulatory compliance cost of motor carriers predicted a range of benefits. The study segmented the motor carrier industry into small firms (110 power units), medium-sized firms (11-99 power units), and large firms (100 or more power units) and analyzed each user service from the perspective of each market segment. The benefit/cost ratio for commercial vehicle administrative processes range from 19.8:1 to 1.0:1. For electronic screening the benefit to cost ratio ranges from 6.5:1 to 1.9:1. The benefit to cost ratio for automated roadside safety inspection rarged from 1.3:1 to 1.4:1. The benefit/cost ratio for on-board safety monitoring ranged from $0.49: 1$ to $0.02: 1$. For hazardous materials incident response, the benefit/cost ratio ranged from $2.5: 1$ to $0.3: 1^{98}$.

Motor carriers are currently involved with development of additional fleet equipage related to electronic tags, enhanced communications, and potential CVO architecture standards. A study of real-time diversion of truckload carriers predicted an additional productivity improvement of $6 \%{ }^{99}$. Currently, the individual companies are equipping their own fleets with custom systems that provide them with a competitive advantage, but may or may not fit with eventual standards.

\footnotetext{
96 The Crescent Project: An Evaluation of an Element of the HELP Program, The Crescent Evaluation Team, Executive Summary and Appendix A, February 1994.

${ }^{97}$ Study of Commercial Vehicle Operations and Institutional Barriers, Appendix F, Booz, Allen \& Hamilton, McLean, VA, Noyember 1994.

98 "Assessment of Intelligent Transportation Systems/Commercial Vehicle Operations Users Services: ITS/CVO Qualitative Benefit/Cost Analysis - Executive Summary," American Trucking Associations Foundation, Inc., Alexandria, VA, 1996.

${ }^{99}$ Regan, A., et al., Improving Efficiency of Commercial Vehicle Operations Using Real-Time Information: Potential Uses and

Assignment Strategies, 74 ${ }^{\text {th }}$ Transportation Research Board Annual Meeting, Transportation Research Record 1493, January 1995.
} 


\subsection{Cost Reduction Benefits of Integrated Systems}

Integrated systems have the potential to lower cost by sharing infrastructure, staff, and equipment cost among a number of services and organizations.

\subsubsection{Predicted Cost Reduction Benefits of Integrated Systems}

Analysis performed for the USDOT ITS Joint Program Office indicated that incorporation of the full metropolitan ITS infrastructure into a regional transportation improvement plan could reduce the cost of infrastructure expansion by approximately half. This analysis was based on published data regarding VMT growth, infrastructure component benefits, and FHWA cost estimates ${ }^{100}$.

${ }^{100}$ McGurrin, M. F., and Shank, D. E., "ITS versus New Roads: A Study of Cost-Effectiveness," in ITS World, July August 1997. 


\section{SECTION 6}

\section{CUSTOMER SATISFACTION}

Customer satisfaction indicates the degree to which transportation consumers are accommodated by ITS service offerings. Although satisfaction is difficult to measure directly, measures related to satisfaction can be observed including amount of travel in various modes, mode options, and the quality of service as well as the volume of complaints and/or compliments received by service providers.

\subsection{Customer Satisfaction Benefits of ATIS}

Traveler information systems can improve customer (i.e. traveler) satisfaction by reducing stress associated with navigation and travel time estimation. Road and transit network information reduce uncertainty in travel times, bus schedules and adherence status, travel options, and transportation network conditions. Information provided on alternate routes and modes gives the traveler additional travel options.

\subsubsection{Measured Customer Satisfaction Benefits of ATIS}

The Puget Sound Help Me (PuSHMe) Mayday System allowed a driver to immediately send a response center a notification and location of incidents along with the need for any assistance. Of those drivers equipped with voice communications, $95 \%$ felt more secure while $70 \%$ of those without voice communications said that they were more secure with the system installed ${ }^{101}$.

The Genesis project, in Minneapolis delivered incident information via alphanumeric pagers. A majority of Genesis users (65\%) reported using the service daily and $88 \%$ reported using the service once or more per week. Of users who participated in the test, only $2 \%$ dropped out of the project during operation due to dissatisfaction with the service. An additional indication that users found the service valuable is that users discovered over half of the incidents affecting their travel via Genesis compared to discovering $15 \%$ of incidents via radio and TV. When users became aware of incidents via Genesis, they chose alternate routes for travel in $42 \%$ of the situations ${ }^{102}$.

One indication of reduced travel stress is the availability of information. Of rental users of TravTek, $38 \%$ found the device helpful in finding specific destinations in unfamiliar territory as did $63 \%$ of local drivers ${ }^{103}$. In the Pathfinder project, users perceived that their trips were less stressful and that they were saving time, even in situations where the time savings were insignificant. Drivers were also more comfortable in diverting with Pathfinder, as indicated by a $40 \%$ increase in diversion ${ }^{104}$.

\footnotetext{
101 Haselkorn, M., et al., "Evaluation of PuSHMe Mayday System," Final Report, June 19, 1997.

102 Wetherby, B., et al., "System Effectiveness Test," final report, June 10, 1997.

${ }^{103}$ Inman, V., et. al., "TravTek Evaluation: Rental and Local User Study," FHWA-RD-96-028, Federal Highway Administration, March 1996.

104 Pathfinder Evaluation Report, Prepared for California Department of Transportation, JHK \& Associates, Pasadena, CA, February 1993.
} 


\subsubsection{Anecdotal Customer Satisfaction Benefits of ATIS}

Pre-trip traveler information is also popular, although measures of reduced stress are difficult to obtain. The Los Angeles Smart Traveler project has deployed a small number of information kiosks in locations such as office lobbies and shopping plazas ${ }^{105}$. The number of daily accesses range from 20 to 100 in a 20 -hour day, with the lowest volume in offices and the greatest in busy pedestrian areas. The most frequent request was for a freeway map with $83 \%$ of users requesting this information. Over half of the accesses included requests for MTA bus and train information. Users, primarily upper middle class in the test area, were overwhelmingly positive in response to a survey.

The TravLink test in the Minneapolis area distributed PC and video text terminals to 315 users and made available transit route and schedule information, including schedule adherence information, as well as traffic incidents and construction information ${ }^{106}$. For the month of July 1995, users logged on to the system a total of 1660 times, an average of slightly more than one access per participant per week. One third of the accesses to the system requested bus schedule adherence; another $31 \%$ examined bus schedules. Additionally, three downtown kiosks offering similar information averaged a total of 71 accesses per weekday between January and July of 1995; real-time traffic data were more frequently requested than bus schedule adherence.

An automated transit information system implemented by the Rochester-Genesee Regional Transportation Authority resulted in an increase in calling volume of $80 \%^{107}$, while a system installed by New Jersey Transit reduced caller wait time from an average of 85 seconds to 27 seconds and reduced caller hang-up rate from $10 \%$ to $3 \%$ while increased the total number of callers ${ }^{108}$. The Boston SmarTraveler has experienced 138\% increase in usage from October 1994 to October 1995 to a total of 244,182 calls monthly, partly due to a partnership with a local cellular telephone service provider, according to a SmartRoute Systems memorandum entitled SmarTraveler Update dated November 6 , 1995.

TravTek users perceived that their driving was safer. Based on survey data, users felt less nervous and confused and more confident, attentive, and safe, with local users being significantly more positive than renters. Users also felt that the use of TravTek did not interfere with their driving task. While users who were interacting with TravTek immediately before a near accident were more likely to feel that they had contributed to the close call, users were no more likely to be involved in close calls than were nonusers ${ }^{109}$.

\footnotetext{
${ }^{105}$ Giuliano, G., et al., "Los Angeles Smart Traveler Information Kiosks: A Preliminary Report," 74" Transportation Research Board Annual Meeting. Transportation Research Record 1516, January 1995.

100 Remer, M., Atherton, T., and Gardner, W., ITS Benefits, Evaluation and Costs: Results and Lessons from the Minnesota Guidestar Travlink Operational Test, Draft, November 1995.

107 USDOT, Federal Transit Administration, APTS Benefits, November 1995.

108 "NJ Transit's Customer Information Speeded Up by New System," Passenger Transport, January 24, 1994.

109 Inman, V., et. al.., "TravTek Evaluation: Rental and Local User Study," FHWA-RD-96-028, Federal Highway Administration, March 1996.
} 


\subsection{Customer Satisfaction Benefits of ATMS}

Traffic management systems are expected to reduce traveler stress by smoothing the flow of traffic and reducing the variability of travel times.

\subsubsection{Measured Customer Satisfaction Benefits of ATMS}

Traffic signal system improvements are able to reduce the number of vehicle stops. Quoting studies mentioned earlier, ATSAC reported $41 \%$ reduction in vehicle stops ${ }^{110}$. SCOOT in Toronto resulted in a $22 \%$ decrease in stops ${ }^{111}$ compared to a "best effort" fixed timing plan. The Abilene report indicates no change in the number of stops ${ }^{112}$.

\subsection{Customer Satisfaction Benefits of APTS}

Advanced public transportation systems are expected to reduce stress by improving the security of the patron, providing information about the trip, increasing the convenience of purchasing passage, and reducing variation from schedule.

\subsubsection{Measured Customer Satisfaction Benefits of APTS}

The Winston-Salem Transit Authority in Winston-Salem, North Carolina, evaluated effects of a computeraided dispatch and scheduling (CADS) system on the operation of a 17 bus fleet ${ }^{113}$. While the client list grew from 1,000 to 2,000 over a 6-month period and vehicle miles per passenger trip grew $5 \%$, operating expenses dropped $2 \%$ per passenger trip and $9 \%$ per vehicle mile. These productivity improvements occurred at the same time as service improvements including institution of same day reservations, which grew to account for $10 \%$ of trips, and a decrease in passenger wait time of over $50 \%$.

\subsubsection{Anecdotal Customer Satisfaction Benefits of APTS}

For the transit riding public, security is a crucial issue. Every day there are numerous emergency situations in every major city involving passenger and operator safety. The deployment of automatic vehicle location (AVL) systems coupled with modern computer-aided dispatch (CAD) as part of transit management systems has had a dramatic effect on the response to emergencies. The AVL/CAD systems now being deployed have two key features which contribute to passenger safety. First, these systems have a silent alarm capability where the driver can alert the dispatch center of a problem. When this alarm is activated, the vehicle in trouble is highlighted on the dispatcher's console for immediate response. The dispatcher can activate a covert microphone on the bus and listen to the nature of the problem without alerting the perpetrators of passengers. The dispatcher can then alert the appropriate emergency service. A number of transit agencies have reported a dramatic reduction in response time. The fact that the dispatcher can pinpoint the vehicle at all times, and is able to advise the police of the nature of the problem has produced a reduction in response time from over ten minutes to less than two minutes ${ }^{114}$. At least one dispatcher in Denver believes that this capability has literally saved the lives of some passengers.

\footnotetext{
${ }^{110}$ City of Los Angeles Department of Transportation," Automated Traffic Surveiliance and Control (ATSAC) Evaluation Study," June 1994.

${ }^{111}$ Siemens Automotive, USA, "SCOOT in Toronto," Traffic Technology International, Spring 1995.

112 Orcutt Associates, "Evaluation Study, Buffalo Gap Road, Abilene Signal System," prepared for the City of Abilene, Texas, 1994.

${ }^{113}$ Stone, J., "Winston-Salem Mobility Management: An Example of APTS Benefits, " NC State University, Interim Report, 1995.

114 Jones, W., ITS Technologies in Public Transit: Deployment and Benefits, USDOT ITS Joint Program Office, November 1995.
} 
Electronic fare payment tests are ongoing in both bus and rail systems which address customer convenience and security. In California, tests comparing various card technologies have found RF proximity cards to be high in reliability. A test in the Marseilles, France, metropolitan area is comparing RF and IR technologies that would allow each patron to use a card of his or her choice (credit card, debit card, monthly pass, etc.) for transportation payment, while processing a transaction in less than a second ${ }^{115}$.

The Phoenix transit operators have used electronic fare payment techniques since $1991^{116}$. The Arizona state legislature passed an air quality bill in the late 1980s. Maricopa County, the county encompassing Phoenix, in turn passed a travel reduction ordinance that required each employer in the Phoenix area with over 100 employees to reduce single-occupancy commuting trips by $5 \%$ in two years. To assist in data collection needed in this program as well as to reduce operational problems, the City of Phoenix Public Transport System led development of the Bus Card Plus system to read magnetically encoded plastic passes. Employers were then billed monthly for transit use by their employees.

The first public use of the Phoenix system was in April 1991 by employees of Valley National Bank. Currently, 190 companies participate with a total of 35,000 cards in use. Express routes report $90 \%$ of fares are paid by bus pass cards. Since employers are billed only for transit usage rather than purchasing monthly passes, costs to them are decreasing by up to one third. Starting in May of 1995, VISA and MasterCard have also been accepted. During the four months between May and September 1995, processing fees totaled under $7 \%$ of revenue generated and without major problems.

\subsection{Customer Satisfaction Benefits of CVO}

Customer satisfaction improvements to regulators relate to safety, cost saving, and improved service to commercial vehicle operators in the form of reduced time and cost for inspections and credentials acquisition and safe commercial vehicles.

\subsubsection{Measured Customer Satisfaction Benefits of CVO}

Use of advanced vehicle monitoring and communications technologies by motor carriers have demonstrated considerable improvements in customer service and driver retention ${ }^{117}$. Schneider of Green Bay Wisconsin, reports a $20 \%$ increase in loaded miles and that the elimination of driver check-in telephone calls saves approximately two hours per day resulting in a driver salary increase of $\$ 50$ per week with a primary benefit of improved customer service. Trans-Westem Ltd. of Lerner, Colorado, credits their fleet management system for improved driver relations, noting that drivers are able to drive 50 to 100 additional miles per day and driver turn-over has decreased from $100 \%$ to $30 \%$. North American Van Lines of Fort Wayne, Indiana reports $16.9 \%$ additional shipments, $5.7 \%$ fewer deadhead miles, and $3.8 \%$ fewer cancellations.

\footnotetext{
${ }^{115}$ Mathieu, J., "Multiservices/Multiproviders Remote Ticketing on the Marseille Metropolitan Area," Proceedings of the Second World Congress on intelligent Transport Systems, November 1995.

${ }^{118}$ Schwenk, J., "Using Credit Cards To Pay Bus Fares in Phoenix," The Volpe Center, DOT-TSC-FTA-96-01, 1996.

${ }^{117}$ Hallowell, S., and Morlok, E., " Estimating Cost Savings From Advanced Vehicle Monitoring and Telecommunication Systems in Intercity Irregular Route Trucking," Department of Systems, University of Pennsylvania, Philadelphia, PA, January 1992
} 


\subsubsection{Predicted Customer Satisfaction Benefits of CVO}

Although Commercial Vehicle drivers differ significantly in their views about specific CVO services, a large majority view the implementation of some or all of the services favorably. In a 1995 survey of 1583 commercial vehicle drivers, $46 \%$ of the drivers viewed all applicable CVO senvices favorably, while $12 \%$ viewed none of the services favorably. The remaining $42 \%$ viewed some, but not all of the services favorably ${ }^{118}$.

\subsection{Customer Satisfaction Benefits of Integrated Systems}

One method to measure customer satisfaction of integrated systems is to determine the number of those who use information and their perceptions of how well other systems cooperate together.

\subsubsection{Measured Customer Satisfaction Benefits of Integrated Systems}

Before and after surveys of the San Antonio TransGuide system were used to capture the effects of the system on travelers. Surveys indicated an improvement from $40 \%$ to $86 \%$ of travelers that believe methods for notifying motorists and managing congestion are efficient after the installation of the first phase of the system. Surveys also showed an improvement from $45 \%$ to $71 \%$ of people using alternative routes during incident conditions believed they saved time due to accurate information. There is also evidence of improved driver confidence in the system. Before studies showed $33 \%$ of travelers who received instructions followed them during incident conditions. After the implementation of the system, $80 \%$ of travelers receiving instructions follow them. Also, $88 \%$ of travelers surveyed feel messages are "very easy" to understand"

\footnotetext{
${ }^{118}$ Penn + Shoen Associates, "Driver Acceptance of Commercial Vehicie Operations (CVO) Technology in the Motor Carrier Environment: Executive Summary," Federal Highway Administration, DTFH61-94-C-00182, undated.

${ }^{119}$ Henk, R. H. "Before-and-After Analysis of the San Antonio TransGuide System Phase I," $76^{\text {th }}$ Annual Meeting, Transportation Research Board, Washington DC, January 1997.
} 


\section{SECTION 7}

\section{Emissions and Fuel Consumption Benefits of ITS}

Environmental benefits from a given project can only be estimated by analysis and simulation in most situations. The problems related to regional measurement include small impact of individual projects and large numbers of exogenous variables including weather, contributions from non-mobile sources or other regions, and the time evolving nature of ozone pollution.

Several studies, including one from Illinois Department of Transportation ${ }^{120}$ and another from the National Research Council ${ }^{121}$, report that $60 \%$ of the mobile source pollution arises from "gross polluters" comprising only $10 \%$ of the vehicles. Two operational tests are under development that test concepts to identify these vehicles and bring down their pollution levels. The voluntary emissions compliance test near Denver is in the calibration stage. The second test is the Ada County, Idaho travel demand management emission detection program. This remote emissions monitoring technology has been used previously, but the overall impact of such a device is not yet known.

\subsection{Emissions and Fuel Consumption Benefits of ATIS}

Providing information about incidents, travel time, and other roadway information, ATIS can reduce traveler delay by allowing more informed alternative route or mode selection. Vehicle emissions and fuel consumption are effected by reducing travel time and delay.

\subsubsection{Predicted Emissions and Fuel Consumption Benefits of ATIS}

Surveys performed in the Seattle, Washington area and Boston, Massachusetts areas indicate that when provided with better traveler information, there is a nearly even split between travelers who change route of travel and travelers who change time of travel, with an additional $5 \%-10 \%^{122}$ changing travel mode based on traveler information.

Assuming that $30 \%$ of the 96,000 daily callers projected for 1999 change travel plans according to this breakdown, the impact of SmarTraveler in Boston on emissions has been estimated using the MOBILE5a model. On a daily basis, this adjustment of travel behavior nets an estimated reduction of $498 \mathrm{~kg}$ of volatile organic compounds, $25 \mathrm{~kg}$ of NOx, and $5032 \mathrm{~kg}$ of CO representing reductions of $25 \%, 1.5 \%$, and $33 \%$ respectively of these pollutants from travelers changing travel plans. While this represents significant reductions for participating travelers, only 28,800 daily trips are expected to be affected in a metropolitan area with 2.9 million registered drivers.

Simulations based on TravTek experience yield similar, but less optimistic, results. Based on analysis of a market penetration of $100 \%$, hydrocarbons would be reduced by $16 \%$ and $\mathrm{CO}$ emissions would be reduced by $7 \%$. However NOx emissions increase by $5 \%$ due to increases in vehicle speeds ${ }^{123}$

\footnotetext{
${ }^{120}$ Environmental Planning and Economics, Inc., "Cleaning the Air, Choosing the Future: Reducing Highway Vehicle Emissions in the Chicago Non-Attainment Area," submitted to the Illinois Department of Environmental and Natural Resources, Springfield, Illinois, 1992.

${ }^{121}$ National Research Council, "Rethinking the Ozone Problem in Urban and Regional Air Pollution," National Academy Press, 1991.

122 Tech Environmental, Inc., "Air Quality Benefit Study of the SmarTraveler Advanced Traveler Information Service," July 1993.

${ }^{123}$ Van Aerde, M., and Rakha, H., "TravTek Evaluation Modeling Study," Preliminary final report, FHWA-RD-95-090, Federal

Highway Administration, January 1996.
} 


\subsection{Emissions and Fuel Consumption Benefits of ATMS}

Advanced Traffic Management Systems can effect emissions, and fuel consumption by smoothing traffic flow, decreasing the number of stops, and improving average speeds of facilities.

\subsubsection{Predicted Emissions and Fuel Consumption Benefits of ATMS}

One case where direct measurement of environmental impact is practical is a highly localized measure such as air quality surrounding a particularly snarled intersection or other point of interest. An example of local air quality benefit is the reduction of emissions using signal system optimization in the "Five Points" area of Las Vegas ${ }^{124}$. Studied alternatives included signal optimizations and geometric changes to the intersection. Simulation results of the alternatives indicated that $\mathrm{CO}$ emissions could be reduced from $9.8 \%$ to $15.8 \%$.

Two programs funded by the Congestion Mitigation and Air Quality Improvement Program (CMAQ) have produced estimated results in air quality improvement ${ }^{125}$. Since August 1992 the San Francisco, freeway service patrol has assisted more than 90,000 drivers. It has decreased air poliution and reduced fuel consumption by helping to reduce the effects of incident caused congestion, start-and-stop travel and vehicle idling. Estimates indicate a reduction in $32 \mathrm{~kg} /$ day of hydrocarbons, $322 \mathrm{~kg} /$ day of CO emissions, and NOx is reduced by $798 \mathrm{~kg} / \mathrm{day}$. The Houston TranStar Management Center helps to reduce hydrocarbons by $91 \mathrm{~kg} /$ day by reducing incident detection, and response time.

The Travel Demand Management Emissions Detection project in Ada County (Boise) Idaho, examined the feasibility of using remote sensing technology to monitor vehicle emissions. The system could provide enough data to potentially eliminate the need for $90 \%$ of clean vehicles to undergo idle emissions testing. State cost savings could potentially range from $\$ 0.28$ to $\$ 2.19$ per registered vehicle over existing idle emissions testing procedures ${ }^{126}$.

By improving the response time, incident management systems can help to reduce emissions. The effect of improved response times on emissions was examined for the San Antonio TransGuide System using the FREFLO freeway simulation model. An average 700 vehicle hours of delay saved and a resulting fuel consumption reduction of 9,880 liters for a major incident was predicted. This translates to an annual cost savings of $\$ 1.65$ million $^{127}$.

The Pike Pass ETC program on the Oklahoma Turnpike started operation on 1 January 1991. As of June $1994,250,000$ passes had been issued, of which over $90 \%(226,000)$ were still active, accounting for $35 \%$ of the turnpike association's revenue. Using a protocol prepared from the Northeast States for Coordinated Air Use Management (NESCAUM), the Clean Air Action Corp., ${ }^{128}$ estimated toll booth emissions based on dynamometer tests and toll road observation at Muskogee Turnpike in Oklahoma, Asbury Plaza on the Garden State Parkway in New Jersey, and Western Plaza on the Massachusetts

\footnotetext{
${ }^{124}$ Reduction in Localized Carbon Monoxide Emissions, Draft, Submitted to the Clark County Health District by Barton-Aschman Associates, Inc., November 1994.

125 "Innovations in Transportation and Air Quality: Twelve Exemplary Projects," US department of Transportation, Publication number FHWA-PD-96-016, 1996.

${ }^{128}$ Bowman, C. M., et al., "\#2 - Emission Monitoring of All Ind. Eval. Test Plan Report Vehicles in Ada County," final report, April 1996.

${ }^{127}$ Henk, R. H. et al, "Before-and After Analysis of the San Antonio TransGuide System Phase 1," $76^{\text {th }}$ Annual meeting

Transportation Research Board, Washington, DC, Paper No. 971027, January 1997.

${ }^{128}$ Clean Air Action Corp., "Proposed General Protocol for Determination of Emission Reduction Credits Created by Implementing an Electronic Pike Pass System on a Tollway, "Study for the Northeast States for Coordinated Air Use management, December, 1993.
} 
Turnpike. This report takes the experiences gained with the Pike Pass project and applies them to the other two freeways. The report projects significant reduction in tons of pollutants for the 260 day commuter case. The overall percent change is dependent upon frequency of toll plazas. Per mile of impacted operation, the average emissions reductions are $72 \%$ for carbon monoxide, $83 \%$ for hydrocarbons, and $45 \%$ for oxides of nitrogen. The report uses 0.55 miles as the distance involved in the average barrier toll transaction.

Traffic signal systems continue to be upgraded for a number of reasons, primarily for traffic flow and system maintenance reasons. The improved flow and reduced delays also have a generally positive impact on emissions and fuel consumption at current traffic levels. Several system retimings and equipment upgrades have included emission evaluations. Among documented results Los Angeles, California reported $13 \%$ decrease in fuel consumption, $14 \%$ decrease in emissions ${ }^{129}$ The City of Abilene report ${ }^{130}$ indicates overall impacts on emissions of $6 \%$ decrease in fuel consumption, $10 \%$ decrease in HC, and $13 \%$ decrease in $\mathrm{CO}$, while nitrous oxide increased by $4 \%$. The SCOOT implementation in Toronto showed a decrease in fuel consumption of $6 \%$, a decrease in carbon monoxide emission of $5 \%$, and a decrease in hydrocarbon emissions of $4 \%$ compared to "best effort" fixed timing plan ${ }^{131}$.

According to analysis in considering expansion of the Detroit freeway management center ${ }^{132}$, delay under incident conditions would be reduced by about $40 \%$, resulting annually in a reduction of 41.3 million gallons of fuel used (42\%) and reducing carbon monoxide emissions by 122,000 tons, hydrocarbon emissions by 1400 tons, and oxides of nitrogen emissions by 1200 tons. These estimates assume that the freeway management system would not change vehicle miles traveled.

\subsection{Emissions and Fuel Consumption Benefits of CVO}

\section{7..3.1 Predicted Emissions and Fuel Consumption Benefits of CVO}

The Advantage 1-75 multi-state project is attempting to minimize the number of weigh-station stops between Florida and Ontario, Canada for transponder-equipped trucks. Preclearance systems have been demonstrated to result in fuel savings to commercial vehicles of between 0.05 and 0.18 gallons per avoided stop, not including fuel savings due to reduced queues. On average two to three stops have been eliminated for equipped vehicles ${ }^{133}$.

\footnotetext{
${ }^{129}$ City of Los Angeles Department of Transportation, "Automated Traffic Surveillance and Control (ATSAC) Evaluation Study," June 1994.

${ }^{330}$ Orcutt Associates, "Evaluation Study, Buffalo Gap Road, Abilene Signal System," prepared for the City of Abilene, Texas, 1994.

131 Siemens Automotive, USA, "SCOOT in Toronto," Traffic Technology International, Spring 1995.

132 Early Deployment of ATMS/ATIS for Metropolitan Detroit, prepared for Michigan DOT by Rockwell International, Dunn

Engineering, and Hubbel, Roth \& Clark, February 1994.

${ }^{133}$ McCall, B., et al., Minutes of the 1-75 Evaluation Task Force Meeting, August 11, 1997.
} 


\section{SECTION 8}

\section{BIBLIOGRAPHY}

"Advanced Traveler Information Kiosk Project: Summary Report - Focus Groups," Catherine Ross and Associates, Inc., undated.

AHS Precursor Analyses, Activity Area A, Urban and Rural AHS Analysis, Battelle, BRW, and Transportation Research Center, 1994.

Air Quality Benefit Study of the SmarTraveler Advanced Traveler Information Service, Tech Environmental, Inc., July 1993.

"Assessment of Intelligent Transportation Systems/Commercial Vehicle Operations Users Services: ITS/CVO Qualitative Benefit/Cost Analysis - Executive Summary," American Trucking Associations Foundation, Inc., Alexandria, VA, 1996.

"Assessment of ITS Benefits - Results from the Field," ITS America Sixth Annual Meeting, April 1996.

"Assessment of ITS Benefits -Early Results," US Department of Transportation, FHWA-JPO-96001 ,August 1995.

ATA Foundation, Inc., "A Survey of the Use of Six Computing and Communications Technologies in Urban Trucking Operations," Alexandria, VA, 1992.

Benefits of the Texas Traffic Light Synchronization Grant Program I; Volume I, TxDOT/TTI Report \# 02581, Texas Department of Transportation, Austin, Texas, October 1992.

Booz Allen \& Hamilton,"1996 Olympic and Paraolympic Event Study," Final Report, May 1997.

Bowman, C. M., et al., "\#2 - Emission Monitoring of All Ind. Eval. Test Plan Report Vehicles in Ada County," final report, April 1996.

Brodsky H. and A. S. Hakkert, "Highway Fatal Accidents and Accessibility of Emergency Medical Services," Soc. Si. Med., Vol. 17 No 11, p 731-740, 1983.

Broeders, W.P.B., "RDS/TMC as Traffic Management Tool and Commercial Product," Proceedings of the Second World Congress on Intelligent Transportation Systems, Yokohama, Japan, November 1995.

"Building the ITI: Putting the National Architecture into Action," Federal Highway Administration, FHWAJPO-96-011, April 1996.

Casey, R. et. al., Advanced Public Transportation Systems: The State of the Art - Update '96, USDOT Federal Transit Administration, January 1996.

Casey, R., "The Benefits of ITS Technologies for Rural Transit," The Volpe Center, presented at the Rural ITS Conference, September 1996.

Casey, R., and Labell, L., "Advanced Public Transportation Systems Deployment in the United States,: USDOT Federal Transit Administration, August 1996.

Center for Transportation Research and Education, "Automated Mileage and Stateline Crossing Operational Test Evaluation Summary," Final Report, Federal Highway Administration, May 1996. 
City of Los Angeles Department of Transportation, "Automated Traffic Surveillance and Control (ATSAC) Evaluation Study," June 1994.

Clean Air Action Corp., "Proposed General Protocol for Determination of Emission Reduction Credits Created by Implementing an Electronic Pike Pass System on a Tollway," Study for the Northeast States for Coordinated Air Use management, December, 1993.

COMSIS Corporation, "CHART Incident Response Evaluation Final Report," Silver Spring, MD, May 1996.

Cuciti P., and B Janson., "Incident Management via Courtesy Patrol: Evaluation of a Pilot Program in Colorado," $74^{\text {th }}$ annual Meeting of the Transportation Research Board, Washington DC, Transportation Research Record, 1995.

Dinning, M., "Benefits of Smart Cards in Transit," The Volpe Center September 1995.

Early Deployment of ATMS/ATIS for Metropolitan Detroit, prepared for Michigan DOT by Rockwell International, Dunn Engineering, and Hubbel, Roth \& Clark, February 1994.

Environmental Planning and Economics, Inc., "Cleaning the Air, Choosing the Future: Reducing Highway Vehicle Emissions in the Chicago Non-Attainment Area," submitted to the Illinois Department of Environmental and Natural Resources, Springfield, Illinois, 1992.

"Estimation of Benefits of Houston TranStar," Prepared by Parsons Transportation Group in cooperation with Texas Transportation Institute, February 7, 1997.

Evanco, W., "The Impact of Rapid Incident Detection on Freeway Accident Fatalities," Mitretek Systems, Inc., WN96W0000071, June 1996.

Evanco, W., "The Impact on Fatal Involvements of Commercial Vehicle Operation ITS Services," Mitretek Systems, Inc., January 1997.

Farwell, R., "Evaluation of Omnilink Demand Driven Transit Operations: Flex-Route Services," SG Associates, Annandale, Virginia, presented at the European Transport Forum, 1996.

Giugno, M., Milwaukee County Transit System, July 1995 Status Report.

Giuliano, G., et al., "Los Angeles Smart Traveler Information Kiosks: A Preliminary Report," $74^{\text {th }}$ Transportation Research Board Annual Meeting, Transportation Research Record 1516, January 1995.

Glassco, R, et al, "Studies of Potential Intelligent Transportation System Benefits Using Traffic Simulation Modeling," Mitretek Systems, MP96W0000101, June 1996.

Glassco, $R$, et al., "Studies of Potential Intelligent Transportation System Benefits Using Traffic Simulation Modeling: Volume 2," Mitretek Systems, MTR 1997-31, June 1997.

Goeddel, D., "Benefits Assessment of Advanced Public Transportation Systems (APTS)", prepared for Federal Transit Administration by Volpe National Transportation Systems Center, July 1996.

Government Performance and Results Act of 1993, Public Law 103-62, 103 Congress, August 3, 1993.

"GPS Aids in Oklahoma Bus Crash," Earth Observation Magazine, April 1996. 
Hallowell, S., and Morlok, E., "Estimating Cost Savings From Advanced Vehicle Monitoring and Telecommunication Systems in Intercity Irregular Route Trucking," Department of Systems, University of Pennsylvania, Philadelphia, PA, January 1992

Harris, J. and Sands, M., "Speed Camera Advances," Traffic Technology International, Spring 1995.

Haselkorn, M., et al., "Evaluation of PuSHMe Mayday System," Final Report, June 19, 1997.

Henk, R. H. et al, "Before-and After Analysis of the San Antonio TransGuide System Phase I," $76^{\text {th }}$ Annual meeting Transportation Research Board, Washington, DC, Paper No. 971027, January 1997.

Henk, R. H. et al, "Before-and-After Analysis of the San Antonio TransGuide system," paper submitted for the Third World Congress on Intelligent Transport Systems, July 1996.

Henry, K. and Meyhan, O., "6 Year FLOW Evaluation," Washington State DOT, District 1, January 1989.

Inman, V. et al., "TravTek Evaluation Orlando Test Network Study," FHWA-RD-95-162, Federal Highway Administration, January 1996.

Inman, V., et al, "TravTek Evaluation Yoked Driver Study", FHWA-RD-94-139, Federal Highway Administration, October 1995.

Inman, V., et. al., "TravTek Evaluation: Rental and Local User Study," FHWA-RD-96-028, Federal Highway Administration, March 1996.

Inman, V., et. al., "TravTek Evaluation: Orlando Test Network Study," FHWA-RD-95-162, Federal Highway Administration, January 1996.

"Innovations in Transportation and Air Quality: Twelve Exemplary Projects," US department of Transportation, Publication number FHWA-PD-96-016, 1996.

"Intelligent Transportation Infrastructure Benefits: Expected and Experienced," US Department of Transportation, FHWA-JPO-96-008, January 1996.

Intelligent Transportation Systems impact Assessment Framework: Final Report, Volpe National Transportation Systems Center, September 1995.

"Intelligent Transportation Systems (ITS) Projects," US Department of Transportation, January 1996.

"Introduction to Commercial Vehicle Information Systems and Networks," prepared for Federal Highway Administration by the Johns Hopkins University Applied Physics Laboratory, Preliminary, January 1996.

"ITS Architecture: Mission Definition," prepared for Federal Highway Administration by the Joint Architecture Team of Loral Federal Systems and Rockwell International, June 1996.

Jones, W., ITS Technologies in Public Transit: Deployment and Benefits, USDOT ITS Joint Program Office, November 1995.

Khattak, A., Kanafani, A., and Le Colletter, E., "Stated and Reported Route Diversion Behavior: Implications on the Benefits of ATIS," University of California - Berkely, UCB-ITS-PRR-94-13, 1994.

Kloos,W., et al., "Bus Priority at Traffic Signals in Portland: The Powell Boulevard Pilot Project," ITE Compendium of Technical Papers, July 1994. 
Krukar, M. and Evert, K., Integrated Tactical Enforcement Network (Automated Enforcement Facilities in Oregon), Presented at the National Traffic Data Acquisition Technologies Conference, Austin, TX 17-20, August 1990.

Lennon L., "Tappan Zee Bridge E-Z Pass System Traffic and Environmental Studies," Compendium of Technical Papers, 64 ${ }^{\text {th }}$ ITE Annual Meeting, Institute of Transportation Engineers, 1994.

Mathieu, J., "Multiservices/Multiproviders Remote Ticketing on the Marseille Metropolitan Area," Proceedings of the Second World Congress on Intelligent Transport Systems, November 1995.

Maze, TH., et al,. "Automated Mileage and Stateline Crossing Operation Test Part 1 - Evaluation Summary," May 1, 1996.

McCall, B., et al., Minutes of the 1-75 Evaluation Task Force Meeting, August 11, 1997.

McGowan, P. and Irwin, P., "TransGuide Transportation Guidance System: Technology in Motion," Texas DOT, November 1995.

McGurrin, M. F., and Shank, D. E., "ITS versus New Roads: A Study of Cost-Effectiveness," in ITS World, July August 1997.

Meyer, M., ed., A Toolbox for Alleviating Traffic Congestion, Institute of Transportation Engineers, Washington, DC, 1989.

Minnesota Department of Transportation, "Highway Helper Summary Report - Twin Cities Metro Area," Report \# TMC 07450-0394, July 1994.

National Highway Traffic Safety Administration, "Traffic Safety Facts 1994," DOT-HS-808-292, August 1995.

National Research Council, "Rethinking the Ozone Problem in Urban and Regional Air Pollution," National Academy Press, 1991.

National Transportation Statistics 1997, USDOT Bureau of Transportation Statistics, U.S. Government Printing Office, Washington, DC, December 1996.

"NJ Transit's Customer Information Speeded Up by New System," Passenger Transport, January 24, 1994.

Orcutt Associates, "Evaluation Study, Buffalo Gap Road, Abilene Signal System," prepared for the City of Abilene, Texas, 1994.

"Partners in Motion, 494 Transportation Corridor: ICTM Project, Interim Report \#1," Prepared for ICTM Evaluation Committee by HNTB Corporation, undated.

Pathfinder Evaluation Report, Prepared for California Department of Transportation, JHK \& Associates, Pasadena, CA, February 1993.

Penn + Shoen Associates, "Driver Acceptance of Commercial Vehicle Operations (CVO) Technology in the Motor Carrier Environment: Executive Summary," Federal Highway Administration, DTFH61-94-C00182 , undated.

"Photo Enforcement Proves Very Effective," in Urban Transportation Monitor, Vol. 9, No. 5, March $17,1995$. 
Pilant, L., "Automated Vehicle Location," The Police Chief, September 1995.

"Pike Pass Facts," Oklahoma Turnpike Commission flyer, 1995

"Precursor Systems Analyses of Automated Highway Systems: Volume Four - Lateral and Longitudinal Control Final Report," prepared by University of Southern California Center for Advanced Transportation Technologies under subcontract to Raytheon Company for Federal Highway Administration, February 1995.

Reduction in Localized Carbon Monoxide Emissions, Draft, Submitted to the Clark County Health District by Barton-Aschman Associates, Inc., November 1994.

Regan, A., et al., Improving Efficiency of Commercial Vehicle Operations Using Real-Time Information: Potential Uses and Assignment Strategies, $74^{\text {th }}$ Transportation Research Board Annual Meeting, Transportation Research Record 1493, January 1995.

Remer, M., Atherton, T., and Gardner, W., ITS Benefits, Evaluation and Costs: Results and Lessons from the Minnesota Guidestar Travlink Operational Test, Draft, November 1995.

Renforth, James D., Director - Safety Services of Greyhound Lines, Inc., letter to Paul Bouchard, President, VORAD Safety Systems, February 1994.

"Review of ITS Benefits: Emerging Successes" United States Department of Transportation, FHWA-JPO97-001

Ride Solutions, "Operational Strategies for Rural Transportation," Florida Coordinated Transportation System, undated

Robinson, J. and Piotrowicz, G., "Ramp Metering Status in North America, 1995 Update," Federal Highway Administration, June 1995.

Schofer, J. et al., "Formal Evaluation of the Targeted Deployment," Vol. II, Appendix J, Northwestern University Transportation Center, July 1996.

Schwenk, J., "Using Credit Cards To Pay Bus Fares in Phoenix," The Volpe Center, DOT-TSC-FTA-9601, 1996.

Siemens Automotive, USA, "SCOOT in Toronto," Traffic Technology International, Spring 1995.

Smith, S. and Perez, C., "Evaluation of INFORM - Lessons Learned and Application to Other Systems," Conference Paper Presented at 71' TRB, January 1992.

Stevens, W. et al., "Summary and Assessment of Findings From the Precursor Analysis of Automated Highway System," The MITRE Corporation, WN95W0000124, October 1995.

Stone, J., "Winston-Salem Mobility Management: An Example of APTS Benefits, "NC State University, 1995.

Study of Commercial Vehicle Operations and Institutional Barriers, Appendix F, Booz, Allen \& Hamilton, McLean, VA, November 1994. 
Study of Institutional Impacts of New Technology Applications: St. Clair and Detroit Rivers Highway Border Crossings, Marshall Macklin Monaghan Limited with KPMG, JHK, \& Constance Consultants, May 1994.

"Stuttgart STORMS Ahead," Intelligent Transport Systems, Issue No. 2, Kent, UK Autumn 1995.

Sullivan, E.C., and Hsu, C.I., "Accident Rates Along Congested Freeways: Final Report," Research Report UCB-ITS-RR-88-6, Institute of Transportation Studies, University of California, Berkeley, CA, 1988.

Taylor, B and Bergan, A., "Words of Warning," in ITS: intelligent transport systems, Issue number 10, May/June 1997

Tech Environmental, Inc., "Air Quality Benefit Study of the SmarTraveler Advanced Traveler Information Service," July 1993.

The Crescent Project: An Evaluation of an Element of the HELP Program, The Crescent Evaluation Team, Executive Summary and Appendix A, February 1994.

"Tracking Patrol cars in California,", in ITS: intelligent transport systems, June 1996.

"Transportation: Driving a Thriving Economy," American Association of State Highway and Transportation Officials and the National Governors' Association, May 1997.

"Under Detection," in ITS: intelligent transport systems, Issue number 10, May/June 1997.

USDOT, Federal Transit Administration, APTS Benefits, November 1995.

Van Aerde, M., and Rakha, H., "TravTek Evaluation: Modeling Study," FHWA-RD-95-090, Federal Highway Administration, March 1996.

"Variable Speed Limits Reduce Accidents Significantly in the UK," in The Urban Transportation Monitor, March 14, 1997.

Wetherby, B., et al., "System Effectiveness Test," final report, June 10, 1997. 


\section{APPENDIX A}

\section{RESULTS FROM FIELD OPERATIONAL TESTS}

The U.S. DOT has funded 84 Field Operational Tests of technologies and operational concepts related to Intelligent Transportation Systems. Although some of these tests were started in the early part of the 1990 s, most began later in the decade. Moreover, it has often taken much time for the institutional arrangements between stakeholders to become agreed upon. Hence, although there has been knowledge of the operational test activities for many years, it has been only recently that an extensive amount of evaluation results have been produced. Evaluation results that have been published earlier than Spring 1996 are included in the main body of the current report, e.g., Pathfinder and TravTek.

This Appendix provides a summary of the evaluation results that have become available since Spring 1996. These results fall into two categories, preliminary results for operational tests that are still ongoing, and final results for tests that have been completed in the last year. For these evaluations, an extensive body of literature is being produced. Several of these are listed in the footnotes referenced in this appendix. The appendix, then, serves three purposes: to identify those tests which have produced new results in the last year, provide summaries of the major findings for each, and identify the reference sources for further analysis of the evaluation results.

A list of the operational tests that have provided new evaluation results, and their (scheduled) completion dates is provided in table A-1. Three Operational Tests, ADVANCE in suburban Chicago, TRANSGUIDE in San Antonio, and Automated Mileage and State Crossing Ops Test (AMASCOT), have produced final evaluation reports since Spring 1996. However their substantive results were previously reported, and hence are included in the body of the current report, rather than in this Appendix.

It should be noted in Table A-1 that all Operational Tests with Completion Dates listed as 9/97 or earlier have been completed with final evaluation reports submitted. 
Table A-1

Operational Tests that Produced Evaluation Results Since Spring 1996

\begin{tabular}{|l|c|}
\hline \multicolumn{1}{|c|}{ Operational Test } & $\begin{array}{c}\text { (Scheduled) } \\
\text { Completion Date }\end{array}$ \\
\hline Transit APTS Systems & $8 / 96$ \\
\hline TravLink (Minneapolis) & \\
\hline Highway ATMS/ATIS Systems & $1 / 97$ \\
\hline ADVANCE (Chicago) & $1 / 97$ \\
\hline TRANSGUIDE (San Antonio) & $9 / 97$ \\
\hline Puget Sound Help Me (PuSHMe) Mayday System & $1 / 97$ \\
\hline Multi-Jurisdictional Live Aerial Surveillance & $10 / 97$ \\
\hline Genesis (Minn.) & $10 / 97$ \\
\hline Atlanta & $6 / 97$ \\
\hline Smart Call Box (San Diego area) & $4 / 96$ \\
\hline Travel Demand Management Emission Detection (TDM-ED) (Idaho) & $5 / 97$ \\
\hline Capital (Washington DC area) & $12 / 97$ \\
\hline Spread-Spectrum Radio Traffic Interconnect (RTI) (Los Angeles) & $3 / 98$ \\
\hline Fast-Trac (Oakland Co. Mich.) & $5 / 98$ \\
\hline Trilogy (Minnesota) & $12 / 98$ \\
\hline $\begin{array}{l}\text { Advanced Rural Transportation Information and Coordination (ARTIC) } \\
\text { (Minnesota) }\end{array}$ & \\
\hline & \\
\hline Highway CVO Systems & $11 / 97$ \\
\hline Automated Mileage and State Crossing Ops Test (AMASCOT) & $7 / 97$ \\
\hline Advantage I-75 & $12 / 97$ \\
\hline Wisconsin/Minnesota Out of Service & $1 / 98$ \\
\hline Electronic One Stop Shopping (EOSS) & \\
\hline Operation Respond & \\
\hline
\end{tabular}

There are also several operational tests which are still underway, and have either not yet become operational, or not yet produced evaluation results. In addition, some of the tests listed in table A-1 have not yet produced final evaluation results. Several of the tests which should have useful evaluation results in the near future are listed in table A-2. These results will be reported in future updates of this benefits review as they become available. 
Table A-2

Operational Tests Scheduled to Produce Evaluation Results in Near Future

\begin{tabular}{|l|c|}
\hline \multicolumn{1}{|c|}{ Operational Test } & $\begin{array}{c}\text { Scheduled } \\
\text { Completion Date }\end{array}$ \\
\hline Transit APTS Systems & $1 / 98$ \\
\hline Dallas Smart Vehicie & $3 / 98$ \\
\hline CTA Smart Bus (Chicago) & $4 / 98$ \\
\hline Santa Clara County Smart Paratransit & $7 / 98$ \\
\hline Houston Smart Commuter & \\
\hline & \\
\hline Highway ATMS/ATIS Systems & $10 / 97$ \\
\hline Transmit (Transcom) & $10 / 97$ \\
\hline Genesis & $12 / 97$ \\
\hline Spread-Spectrum Radio Traffic Interconnect (RTI) (Los Angeles) & $12 / 97$ \\
\hline Seattle Wide-Area Information for Travelers (SWIFT) & $2 / 98$ \\
\hline North Seattle ATMS & $3 / 98$ \\
\hline Adaptive Traffic Control System (Anaheim, CA) & $4 / 98$ \\
\hline Direct (Detroit) & $5 / 98$ \\
\hline Trilogy (Minnesota) & $6 / 98$ \\
\hline Integrated Ramp Metering/Adaptive Signal Control (Irvine, CA) & $6 / 98$ \\
\hline Mobile Communications System (Orange Co. CA) & \\
\hline & \\
\hline Highway CVO Systems & $11 / 97$ \\
\hline Advantage I-75 (multi-state) & $12 / 97$ \\
\hline Electronic One Stop Shopping (EOSS) & $1 / 98$ \\
\hline Operation Respond & \\
\hline
\end{tabular}

\section{A1 TRANSIT SYSTEMS}

\section{A1.1 TravLink}

This test was carried out on a 12 mile long corridor in Minneapolis. It provided kiosks and computer terminals at various sites so that real time traffic and transit schedule information could be available to travelers. The project ran from 1992 to 1996.

Transit users indicated they were willing to pay between $\$ 2$ and $\$ 5$ per month for real-time transit information. The TravLink system was demonstrated to improve the collection of schedule adherence data. ${ }^{1}$

1 Cambridge Systematics, Operational Test Evaluation Report, Ch. 4, 8/1/96. 


\section{A2 HIGHWAY SYSTEMS (ATMSIATIS)}

\section{A2.1 Puget Sound Help Me (PuSHMe) Mayday System}

This project, carried out in the Puget Sound area of Washington state, assessed the requirements for basing a regional "mayday" system on in-vehicle cellular telephones which would allow a driver to immediately send to a response center a notification of an incident, its location, and any need for assistance. The project ran from 1994 to 1997.

This cellular emergency notification system was shown to be reliable. Most police dispatchers found the system-provided information useful in insuring the dispatch of the appropriate response equipment. ${ }^{2}$

Response times to incidents are likely to improve because the system reduces the time from incident to incident detection to less than 2 minutes for equipped vehicles. The vast majority (95\%) of drivers of vehicles equipped with operator voice communications capability felt more secure with the system installed. A strong majority ( $70 \%$ ) of drivers of vehicles not equipped with operator voice communications capability said they would be more secure with the system installed. ${ }^{3}$

In-vehicle emergency response systems, when bundled with other in-vehicle communications services, were shown to be economically viable for private service providers. ${ }^{4}$

\section{A2.2 Multi-Jurisdictional Live Aerial Video Surveillance}

This test provided live color video transmission from a gyro-stabilized camera mounted on helicopters or fixed-wing aircraft for observing and evaluating major highway incidents. The video was transmitted to police and state highway traffic management centers, and mobile command centers at incident sites. Communications technologies included microwave, CATV, and coaxial cable. The project ran from 1991 to 1995 in Fairfax County examining the use of helicopters, and a separate test was run until 1997 in Montgomery County Maryland, evaluating aircraft.

Aerial video has been demonstrated to enhance effective real-time incident management, and was shown to be particularly effective at identifying secondary congestion and accidents. Aerial video has demonstrated its usefulness to decision makers during large special events. Aerial video allows for rapid identification of problems associated with roadway changes, and facilitates faster and more effective solutions. ${ }^{5}$

Haselkorn, M., et al., Evaluation of PuSHMe Mayday System Final Draft, Ch.2, 6/19/97.

Haselkorn, M., et al., Evaluation of PuSHMe Mayday System Final Draft, Ch. 3, 6/19/97.

Haselkorn, M., et al., Evaluation of PuSHMe Mayday System Final Draft, Ch. 4, 6/19/97.

Demetsky, M., et al., Evaluation of Live Aerial Video for Traffic Management, Evaluation of Aerial Video, 7/1/94. 


\section{A2.3 Genesis}

This ATIS test examined the capability of urban travelers to use pagers and personal hand-held communications devices to obtain transit and traffic information. Travelers obtained information about route and mode alternatives. Approximately 450 pagers and 45 hand-held devices with pager cards were used. Genesis is part of the Minnesota Guidestar program, and builds on the availability of real-time traffic data. The project ran from 1992 to 1997.

Travelers were very enthusiastic about receiving up-to-the-minute traffic information - 65 percent of respondents used the devices/information on a daily basis. Fifty-two percent of the users found real-time traffic information to be useful. Forty-two percent of the users reported taking an alternate route in response to information provided to them. ${ }^{6}$

Users who participated in focus groups were unanimous in indicating the system was most useful for pretrip planning, and that using them while driving over-complicated the driving task. Users perceived that the information helped them avoid congestion and improve travel time. ${ }^{7}$

\section{A2.4 Atlanta}

Atlanta added several ITS capabilities in the period just prior to the 1996 Olympic Games, to assist in moving visitors as well as vehicles in an extremely crowded area. These public sector improvements worked in concert with the Atlanta Traveler Information Showcase, to demonstrate that ITS technologies can greatly improve incident management. In addition, improved inter-agency coordination was developed based on the capabilities of the regional ATMS. This led to resource sharing that reduced the cost of managing event traffic. ${ }^{8}$ The operational tests in Atlanta will be completed by the end of 1997.

Between the first week of the Olympic Games, and the Paralympic Games (approximately 4 weeks), several improvements were observed in the performance of Georgia DOT operators in the TMC. ${ }^{9}$

- Mean time between first report of an incident and incident verification was reduced from 4.2 minutes to 1.1 minutes $(74 \%)$.

- Mean time between incident verification and automated generation of incident response was reduced from 9.5 minutes to 4.7 minutes (50\%).

- Mean time between incident verification and clearance of traffic lanes was reduced from 40.5 minutes to 24.9 minutes (38\%).

- Maximum time between first report of an incident and incident verification was reduced from 35 minutes to 3 minutes (91\%).

- Maximum time between incident verification and automated generation of incident response was reduced from 39 minutes to 9 minutes $(77 \%)$.

- Maximum time between incident verification and clearance of traffic lanes was reduced from 6 hours 15 minutes to 1 hour 28 minutes (60\%).

\footnotetext{
Wetherby, B., et al., System Effectiveness Test, Ch.4, 6/10/97.

Ibid.

Booz Allen \& Hamilton, 1996 Olympic and Paralympic Event Study, Sections 3.3, 3.4, 3.5, 5/2/97.

Ibid.
} 


\section{A2.5 Smart Call Box}

This test, which was carried out on freeways in the San Diego area, added an interface between some of the telephone call boxes instalied on California freeways and a traffic management system. The project tested the feasibility of collecting traffic census data; collecting traffic counts, flows, and speeds; reporting information from roadside weather information systems; controlling CMSs; and controlling roadside CCTVs. The project ran from 1993 to 1997.

Smart call boxes can be used to control field devices, eliminating the need for trenching for communications lines, and installation of power supplies. Smart call box systems can be cost effective compared with the use of hardwire telephone systems, provided they have sufficient functionality, and reasonable maintenance costs. At individual sites, the cost effectiveness of smart call box systems will depend on access distances to the conventional phone system..$^{10}$ The range of capital cost savings which could be achieved as a result of using smart call boxes to control several field devices was as follows: ${ }^{11}$

- Traffic Census $\$ 1,450$ to $\$ 103,100$

- Incident Detection $\$ 7,365$ to $\$ 80,700$

- Weather $\$ 27,500$ to $\$ 103,100$

- CCTV Surveillance $\$ 1450$ to $\$ 33,350$

\section{A2.6 Travel Demand Management Emissions Detection (TDM-ED) - Ada County}

This project examined the feasibility of using remote sensing technology to monitor vehicle emissions. In particular, active infra-red emissions detection on the roadside was used to detect the relative contributions of emissions by different classes of vehicles. The project ran from 1994 to 1996 in Ada County (Boise) Idaho.

The remote emissions sensor was found reliable and appropriate as an augmentation to idle emissions testing. The system could provide enough data to potentially eliminate the need for 90 percent of clean vehicles, which pass equipped sites at least three times, to undergo idle emissions testing. ${ }^{12}$ The remote sensing system that was used exhibited high availability $(0.98)$, and the license plate recognition system was able to recognize 66 percent of all license plates for which an image was captured. ${ }^{13}$

The majority of survey respondents supported remote emissions testing and did not perceive it as an invasion of privacy. ${ }^{14}$

State cost savings could potentially range from $\$ 0.28$ to $\$ 2.19$ per registered vehicle over existing idle emissions testing procedures. ${ }^{15}$

10 Banks, J. H., Smart Call Box Field Operational Test Evaluation: Draft Executive Summary, 3/6/97.

11 Banks, J. H., Smart Call Box Field Operational Test Evaluation: Draft Cost, 3/6/97.

12 Bowman, C. M., et al., Ind. Eval Test Plan Report \#2 - Emission Monitoring at All Ind. Eval Test Plan Report Vehicles in Ada County, Ch. 1,4.3, 4/1/96.

13 Bowman, C. M., et al., Ind. Eval Test Plan Report \#1 - Origin and Destination Survey and Em. Monitoring at External Stations, Executive Summary, 1.0, 4/1/96.

14 Bowman, C. M., et al., \#2 - Emission Monitoring of All Ind. Eval Test Plan Report Vehicles in Ada County, Executive Summary, 2.0, 4/1/96.

15 Bowman, C. M.,et al., \#2 - Emission Monitoring of All Ind. Eval Test Plan Report Vehicles in Ada County, Executive Summary, 1.4, 4/1/96. 


\section{A2.7 CAPITAL}

This test evaluated the capability of the existing cellular telephone infrastructure for both area-wide surveillance and communications. Several technical aspects of the service were investigated, including the procedure for geolocation estimates, the method of traffic data processing, correctness of the transmitted information, and service costs. Also evaluated were public acceptance, and the value of the information to fleet vehicles. The project ran from 1993 to 1997.

Although cellular geolocation was demonstrated to be able to locate vehicles with a required precision, the technology that was tested did not have the capability to determine vehicle speeds, or the rate of increase of congestion due to incidents. ${ }^{16}$

\section{A:2.8 Spread Spectrum Radio Traffic Interconnect (RTI)}

This test examined wireless communication as a alternative to hard-wire technology for connectivity to local traffic signals. The test used a network of spread spectrum radios to provide communication interconnects to a portion of the Los Angeles ATSAC signal system. The test examined the use of the technology in a variety of geographies, and its ability to provide large scale fast (once per second) communications. The project runs from 1991 to 1997.

The initial deployment of 20 spread spectrum radios as an alternative to hardwire interconnection of traffic signals was found to be suitable for traffic control and monitoring applications. The average throughput of the system was found to be 90 percent, i.e. 90 percent of the time, once-per-second responses from intersections were received at the central computer. Wireless communication was demonstrated as a possible low-cost alternative to hard-wire technology for connecting to traffic signals.

Several avenues were identified to improve overall system performance, as part of a larger deployment involving nearly 100 signalized intersections.

\section{A2.9 Advanced Rural Transportation Information and Coordination (ARTIC)}

ARTIC is part of Minnesota's Guidestar program. It coordinates communications among several public agencies (highway, transit, and state patrol) by establishing a centralized communications site. It exchanges information on emergency vehicle status. The project runs from 1994 to 1998 , and examines improvements in response times to accidents and emergencies.

Results, so far, are anecdotal. Consolidation of communications from various rural public agencies is demonstrating reduced accident/incident response times, and is positively contributing to efficient use of limited resources to improve safety.

16 Transportation Studies Center, Univ. of MD Operational Test and Evaluation Program, Ch. 5, 7, 5/1/97. 


\section{A3 HIGHWAY SYSTEMS (CVO)}

\section{A3.1 Advantage l-75}

This project is a multi-state partnership to facilitate transponder-equipped and properly documented trucks to travel along $1-75$ with minimal stopping at weigh stations. $1-75$ runs from Florida through the mid-west into Ontario. Electronic clearances will be based on truck size and weight measurements taken upstream and on computerized checking, within each state, of operating credentials. Each state retains its statutory authority for motor carrier regulation. The project runs from 1991 through the autumn of 1997.

Modeling and simulation with the data from weigh-station data collection are estimating that there is significant potential for improved weigh station operations. Electronic clearance for commercial vehicles will forestall huge weigh station expansion and addition costs. Preclearance systems have been demonstrated to result in fuel savings to commercial vehicles of between 0.05 and 0.18 gallons per avoided stop, not including fuel savings due to reduced queues. On average, two or three required stops would be eliminated for a vehicle traveling from Florida to Ontario. ${ }^{17}$

\section{A3.2 Electronic One-Stop Shopping Operational Tests}

Investigations were carried out by different organizational entities in three separate geographic areas to test different approaches to one-stop, multi-state electronic purchases of credentials. In all, 14 states were involved, with HELP, Inc. playing a role in the western states. Different locations, such as motor carrier facilities, permitting services, truck stops, and state agency facilities were examined. Credentials included permits for registration, fuel taxes, and vehicle over-size. Different delivery mechanisms were examined. The primary purpose of the tests was to evaluate improvements in state and motor carrier productivity. The project runs from 1995 to autumn 1997.

Commercial vehicle electronic credential projects have demonstrated the ability to reduce the time required to obtain credentials. In some cases from six to eight weeks to 15 minutes. They have demonstrated the ability to reduce travel required to obtain credentials, often eliminating it entirely. ${ }^{18}$

Commercial vehicle electronic credential projects have demonstrated that the motor carrier industry is highly favorable in seeing this type of system deployed. ${ }^{19}$

\section{A3.3 Advantage 1-75; One-Stop Shopping; Out-of-Service Verification (Wisconsin/Minnesota)}

These three different operational tests have produced very similar anecdotal results. The first two are described in sections 3.1 and 3.2 of the Appendix. The Wisconsin/Minnesota Out of Service test provides automatic, real-time out of service verification at the roadside. It uses video identification of trucks together with an out of service database to determine whether a vehicle is in violation. The test uses AVI tags and video imaging analysis.

Out-of-service, one-stop shopping and preclearance systems have increased the coordination between agencies across state lines and improved procedures for data sharing. ${ }^{20}$

17 McCall, B., et al., Minutes of $1-75$ Evaluation Task Force Meeting, 8/11/97.

18 Western Highway Institute (WHI), Final Evaluation Report, Quantitative Findings, 7/1/97.

19 Western Highway Institute (WHI), Final Evaluation Report, Qualitative Findings, 7/1/97.

20 R. L. Smith, R. L., Huang, W., Automatic Out-of-Service verification Operational Test Evaluation, Ch. 5, 6/1/97. 


\section{A3.4 Operation RESPOND}

This project tests the ability to develop and utilize an electronic link between participating carriers and 911 operators during their initial response to hazardous materials accidents. The project was expanded beyond the initial geographic areas to include Mexican and Canadian border crossing areas. The provided information will enable emergency response units to have real-time access to hazmat information across North America, which can be used to facilitate timely assessment of situations, and determine appropriate initial actions. The project ran from 1995 to 1997.

Hazardous Materials projects have demonstrated the ability to significantly reduce incident response time and to improve response strategy selection. Cost savings, based on more efficient use of hazmat teams responding to routine incidents, have been estimated at a value of $\$ 150$ to $\$ 2100$ per incident. Where applicable, potential savings in reducing unjustifiable evacuations are estimated at $\$ 8000$ per incident, and avoidable highway/railroad closings are estimated at $\$ 4150$ per incident. Actual field simulations have shown that the time required to obtain information needed to make response decisions can be reduced from 53 minutes to 37 minutes (30\%).

\section{A3.5 Trilogy}

This ATIS test provided traffic data to drivers through two different technologies using FM radio subcarriers. Area-wide and route-specific en-route traffic advisories were provided. The different approaches were evaluated with respect to the improvement in travel efficiency. The project, which is part of Minnesota's Guidestar Program, started in 1994, and runs through 1998.

Although this project tests the provision of traffic data to all drivers, early results only provide information about fleet drivers. Professional drivers in urban areas are realizing "significant cost savings" from using in-vehicle traffic information systems. ${ }^{21}$

21 HNTB, Market-Line Research, Trilogy Interim Report, Executive Summary, 5/1/97. 


\section{A4.0 BIBLIOGRAPHY OF APPENDIX A}

Banks, J. H., Smart Call Box Field Operational Test Evaluation: Draft Executive Summary, 3/6/97.

Banks, J. H., Smart Call Box Field Operational Test Evaluation: Draft Cost, 3/6/97.

Booz Allen \& Hamilton, 1996 Olympic and Paralympic Event Study, Sections 3.3, 3.4, 3.5, 5/2/97.

Bowman, C. M., et al., \#2 - Emission Monitoring of All Ind. Eval Test Plan Report Vehicles in Ada County, Executive Summary, 2.0, 4/1/96.

Bowman, C. M., et al., Ind. Eval Test Plan Report \#1 - Origin and Destination Survey and Em. Monitoring at External Stations, Executive Summary, 1.0, 4/1/96.

Bowman, C. M., et al., Ind. Eval Test Plan Report \#2 - Emission Monitoring at All Ind. Eval Test Plan Report Vehicles in Ada County, Ch. 1,4.3, 4/1/96.

Cambridge Systematics, Operational Test Evaluation Report, Ch. 4, 8/1/96.

Demetsky, M., et al., Evaluation of Live Aerial Video for Traffic Management, Evaluation of Aerial Video, 7/1/94.

Haselkorn, M., et al., Evaluation of PuSHMe Mayday System Final Draft, Ch.2, 6/19/97.

HNTB, Market-Line Research, Trilogy Interim Report, Executive Summary, 5/1/97.

McCall, B., et al., Minutes of I-75 Evaluation Task Force Meeting, 8/11/97.

Smith, R. L. and Huang, W., Automatic Out-of-Service verification Operational Test Evaluation, Ch. 5, 6/1/97.

Transportation Studies Center, Univ. of MD Operational Test and Evaluation Program, Ch. 5, 7, 5/1/97.

Western Highway Institute (WHI), Final Evaluation Report, Quantitative Findings, 7/1/97.

Wetherby, B., et al., System Effectiveness Test, Ch.4, 6/10/97. 


\section{APPENDIX B}

\section{BENEFITS ASSESSMENT OF APTS SUMMARY}

The Federal Transit Administration (FTA) is making substantial investments in the deployment and evaluation of advanced technologies through the Advanced Public Transportation Systems (APTS) program. These technologies are being used to improve the convenience, reliability, and safety of public transportation services. This appendix summarizes a report prepared for the Federal Transit Administration's, Office of Mobility Innovation. That report was prepared by the Office of Operations Engineering and Assessment, John A. Volpe National Transportation Systems Center in July 1996.

The Volpe report differs from the main body of the current document in that it attempted to project national level benefits from DOT's APTS program. (The current document is limited to reporting the benefits of individual projects.)

The Volpe report is based on forecasts and reasonable assumptions on the potential future application of technologies within a transit agency. Its benefit estimates were calculated for a ten-year time horizon (1996-2005) for the deployment of the APTS technologies. All benefits were discounted to 1996, and calculated in 1996 dollars

The following paragraphs summarize the benefits reported in the FTA document. The interested reader is encouraged to refer to the document to determine references and assumptions used to develop its results.

The APTS Program involves the application and integration of technologies in the following areas:

- Transit Management Systems

- Automated Traveler Information Systems (ATIS)

- Electronic Fare Payment Systems

- Transportation Demand Management (TDM)

Transit Management Systems utilize Computer Aided Dispatching (CAD) and control technologies; Automated Vehicle Location (AVL) and monitoring; Automatic Passenger Counting; and fleet based communication. These technologies are used in combination to improve the overall planning, scheduling and operations of transit systems.

ATIS includes in-vehicle equipment, as well as equipment utilized by the traveler to obtain information, such as: home computers, wayside information centers, kiosks, telephone systems, and the Internet. These systems provide a wide range of computer and communication technologies that provide transit system users with real-time information to make better informed decisions about mode and route choice.

Electronic Fare Payment Systems include technologies that provide a more convenient and efficient method of collecting fares from transit users. These systems include fare media - ranging from magnetic strip to smart cards - and their associated fare collection and processing systems.

TDM involves techniques that combine technologies to promote an increase in demand for transit by using the existing transportation infrastructure. These techniques include CAD systems for demand responsive transit (DRT), and the coordination of transportation services between transit providers and other transportation agencies.

The Volpe study analyzed the benefits that may accrue in these four application areas, with the exception that they only examined CAD for DRT rather than the entire area of TDM. 
Table B1 summarizes the projected annual benefits in these four areas, plus the total, for 265 APTS system deployments that are currently operational, under implementation, or planned for implementation over the next 10 years. Both high and low estimates were made. These benefits are expressed in 1996 discounted dollars.

Table B1: Total National APTS System Benefits

\begin{tabular}{|c|c|c|c|c|c|}
\hline & $\begin{array}{c}\text { Transit } \\
\text { Management } \\
\text { Systems }\end{array}$ & $\begin{array}{c}\text { Traveler } \\
\text { Information } \\
\text { Systems }\end{array}$ & $\begin{array}{c}\text { Electronic } \\
\text { Fare Payment } \\
\text { Systems } \\
\end{array}$ & $\begin{array}{c}\text { Transit } \\
\text { DRT-CAD } \\
\text { Systems } \\
\end{array}$ & Total \\
\hline $\begin{array}{l}\text { APTS } \\
\text { Deployments } \\
\text { (Considered) }\end{array}$ & 73 & 72 & 43 & 77 & 265 \\
\hline $\begin{array}{r}\text { Low Estimates (in } \\
\text { Total Benefits } \\
\text { Annualized }\end{array}$ & $\begin{array}{r}\text { illions of disc } \\
\$ 1,718.8 \\
\$ 244.7\end{array}$ & $\begin{array}{r}\text { unted } 19960 \\
\$ 796.0 \\
\$ 113.3\end{array}$ & $\begin{array}{r}\$ 1,279.8 \\
\$ 182.2 \\
\end{array}$ & $\begin{array}{r}\$ 44.7 \\
\$ 6.4 \\
\end{array}$ & $\begin{array}{r}\$ 3,839.3 \\
\$ 546.6 \\
\end{array}$ \\
\hline $\begin{array}{r}\text { High Estimates (in } \\
\text { Total Benefits } \\
\text { Annualized }\end{array}$ & $\begin{array}{r}\text { illions of disc } \\
\$ 3,204.2 \\
\$ 456.2\end{array}$ & $\begin{array}{r}\text { Inted } 1996 \\
\$ 1,592.0 \\
\$ 226.7\end{array}$ & $\begin{array}{r}\text { lars) } \\
\$ 2,559.7 \\
\$ 364.4 \\
\end{array}$ & $\begin{array}{l}\$ 74.5 \\
\$ 10.6\end{array}$ & $\begin{array}{l}\$ 7,430.4 \\
\$ 1,057.9\end{array}$ \\
\hline
\end{tabular}

As shown, the analysis projects total benefits over 10 years from the 265 APTS system deployments within the range from $\$ 3.8$ billion to $\$ 7.4$ billion. On an annualized basis these deployments are projected to fall in the range between $\$ 550$ million and $\$ 1.1$ billion. The distribution of projected APTS benefits shows that approximately $44 \%$ of the total benefits would accrue from transit management system deployments, $34 \%$ from electronic fare payment system application, $21 \%$ from traveler information system deployments, with the remaining $1 \%$ from DRT-CAD system application. The projected total estimated benefits for each of these APTS systems deployments are depicted in figure B1

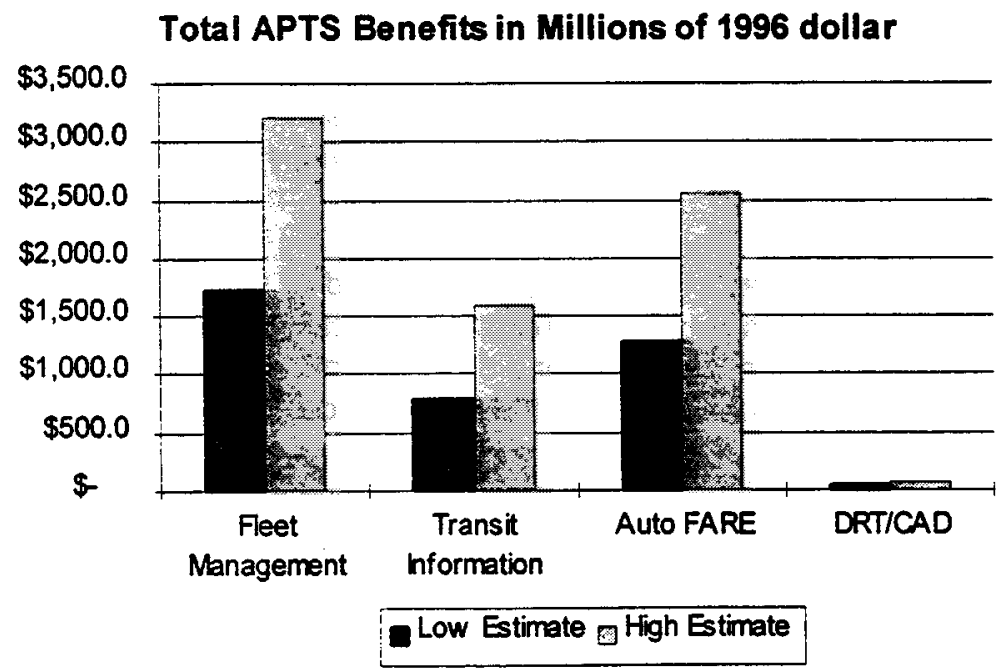

Figure B1: Total APTS System Benefits 


\section{APPENDIX C}

\section{NATIONAL ANALYSES OF ITS BENEFITS}

During the past year, there have been three studies undertaken concerning various aspects of ITS at the national level. Two of these have provided estimations of benefits; the third, instead, has provided estimates of market penetration of ITS products and services. These three studies are reviewed in this Appendix, with the one oriented toward market forecasts being presented first.

A proprietary study was undertaken by SRI Consulting, which was funded by approximately 30 client organizations that paid for the right to obtain and discuss the results. ${ }^{1}$ This study compared the market growth of several ITS products in three market areas - North America, Japan, and Europe -- to the year 2011.

Estimates of market size are important, because they can be combined with estimates of unit benefits (e.g., benefits per vehicle; benefits per mile of freeway; benefits per signalized intersection) to produce estimates of total benefits in a market area. Readers of the current report who want to participate in the SRI project should contact SRI. ${ }^{2}$

The ITS Joint Program Office was one of the paying clients for the SRI study, and obtained many useful insights about the how benefit information might be used by potential ITS implementors, and about the rates at which different products may become operational. No results from that study are presented here, because of their proprietary nature.

A second study at the national level is a benefit/cost analysis of Commercial Vehicle Operations (CVO) by Apogee Research, Inc. for the National Governors Association (NGA). This study was begun in early 1997, and is still being carried out. Some preliminary results have been produced, but these are not publicly available. ${ }^{3}$ Final results will be available in a few months, and will be summarized in a later version of this benefits report.

The third national-level study is the "ITS National Investment and Market Analysis" that was carried out by Apogee Research and Wilbur Smith Associates for ITS America and the U.S. DOT. The study will be called the NIMA study in this appendix. The final report for the NIMA study became available in May 1997.

${ }^{4}$ The study provided cost estimates, as well as benefit estimates, for public sector ITS infrastructure elements in metropolitan areas. These estimates were based on the assumption that Operation Timesaver - the initiative to save travel time in the 75 largest metropolitan areas - would be implemented by the year 2005. The NIMA study investigated the benefits and costs for these 75 areas combined, as well as for an additional 222 metropolitan areas, combined. In addition, the NIMA study made market forecasts for the public and private sector ITS markets, which can be compared with those from SRI (by those that have the SRI report). This appendix is limited to summarizing only the benefit and cost analysis in the NIMA report.

\footnotetext{
' SRI Consulting, Intelligent Transportation Systems, Market Report; Report 2, Part 1, ATMS, ETC, PVTMS, and CVO, September 1996, and Report Three, Part 1, IVNS, ATIS, IDIS, and VSC, March 1997 (Client Private)

${ }^{2}$ Contact Business Intelligent Center, SRI Consulting, 333 Ravenswood Avenue, Menlo Park, CA 94025-2516

${ }^{3}$ Apogee Research Inc., ITS-CVO Cost/Benefit Analysis: State Processes for Commercial Vehicle Operations (In progress)

4 Apogee Research Inc. And Wilbur Smith Associates, ITS National Investment and Market Analysis, Final Report, May 1997; available from ITS America, 400 Virginia Avenue, Suite 800, Washington, DC 20024-2730
} 
The NIMA study reported that between 1996 and 2015, the 75 Operation Timesaver areas would require $\$ 72$ billion of capital and recurring costs to provide nine ITS infrastructure elements. These costs have a discounted present value (in 1996 dollars) of $\$ 24$ billion. These elements produce direct benefits that have a present value of $\$ 212$ billion. All benefits have been converted to monetary terms and discounted to 1996 dollars. The nine ITS infrastructure elements are as follows:

- Freeway Management

- Traffic Signal Control

- Electronic Toll Collection

- Emergency Management

- Incident Management

- Traveler Information

- Advanced Public Transit

- Electronic Fare Payment

- Rail Grade Crossing

It can be seen that these nine elements are similar to the ITS components that are considered in the body of the current report. NIMA's benefit and cost estimates yield a benefitcost ratio for these 75 areas of about 8.8. The study similarly made benefit and cost estimates for 222 other large areas that yielded a $\mathrm{B} / \mathrm{C}$ ratio for them of 2.0 . For all 297 metro areas, the $\mathrm{B} / \mathrm{C}$ ratio was 5.7

The NIMA report presented benefit estimates for six major benefit areas, namely:

- Time Savings

- Accident Savings

- Operating Cost Savings

- Agency Cost Savings

- Air Pollution and Energy Use

- Induced Demand, estimated as Consumer Surplus

Again, these are similar to the benefit areas in the body of this report. One difference between NIMA and the present report is that the current report uses consumer satisfaction as a benefit area, with results usually based on traveler surveys. NIMA, on the other hand, translates consumer satisfaction into "consumer surplus" which is an increase in "utility" or satisfaction, over and above what is paid for. This increased consumer utility may translate into additional or longer trips, and is then often called "induced demand". The consumer surplus is translated into a monetary value.

For all 297 metro areas, the NEMA study estimated the following distribution of benefits:

Basic Metropolitan ITS Infrastructure Benefits (1996 - 2015)

\begin{tabular}{|l|l|}
\hline Benefit Measure & Percent Savings \\
\hline Accident Savings & $42 \%$ \\
Time Savings & $41 \%$ \\
Operating Cost Savings & $6 \%$ \\
Emissions and Fuel Reduction & $6 \%$ \\
Agency Cost Savings & $5 \%$ \\
Consumer Surplus & $<1 \%$ \\
\hline
\end{tabular}

The report pointed out that over 80 percent of the benefits came from just two benefit areas. It also stated that "unlike traditional highway capacity investments, safety benefits of ITS investments are equally as important as those derived from congestion reduction". 
The NIMA study had to start with estimates of changes in these various benefit areas, such as reductions in travel time or accidents, due to the nine ITS elements listed above, and then perform several additional calculations, such as estimations of the percent of roads in an area that are congested, the percent of time each is congested, the monetary value of each of the benefits, and demographic changes over time.

The sources of the estimates of changes due to an ITS element are documented in the NIMA reports. ${ }^{5}$ What is significant to point out is that most of these fundamental estimates came either from earlier versions of the current report, ${ }^{7}$ or from an earlier version of the report summarized in Appendix B in this report. ${ }^{8}$ Some of these basic estimates are shown in the next three tables.

\section{Assumed Changes Due to Traffic Management improvements}

\begin{tabular}{|l|l|l|}
\hline \multicolumn{1}{|c|}{ Improvement } & \multicolumn{1}{c|}{ Freeways } & \multicolumn{1}{c|}{ Other Principle Arterials } \\
\hline Increase in throughput & $15 \%$ & $10 \%$ \\
\hline Time savings in non-congested situations & - & $6 \%$ \\
\hline Accident rate reduction & $15 \%$ & $9 \%$ \\
\hline Accident clear time reduction & 20 minutes & 15 minutes \\
\hline Incident notification time reduction & 10 minutes & 7.5 minutes \\
\hline Added VMT due to improved service & $10 \%$ & $5 \%$ \\
\hline
\end{tabular}

\section{Assumed Changes Due to Transit Improvements}

\begin{tabular}{|l|l|}
\hline Improvement & \\
\hline Time savings & $15 \%$ \\
\hline Operating cost savings & $9 \%$ \\
\hline Fatalities reduction & $10 \%$ \\
\hline Additional trips & $10 \%$ \\
\hline
\end{tabular}

\section{Assumed Changes Due to Electronic Fare Payment}

\begin{tabular}{|l|l|}
\hline Improvement & \\
\hline Revenue increase & $12 \%$ \\
\hline Fare evasion reduction & $4 \%$ \\
\hline Annual administrative cost savings & $\$ 1$ million to $\$ 5$ million \\
\hline
\end{tabular}

\footnotetext{
Ibid.

"Apogee Research Inc. And Wilbur Smith Associates, ITS National Investment and Market Analysis, Technical Working Paper: Task E Estimation of Direct Benefits of ITS Deployment May 1997

${ }^{7}$ ITI Benefits: Expected and Experienced, January 1996; Review of ITS Benefits: Emerging Successes, September 1996

${ }^{8}$ Benefits Assessment of Advanced Public Transit Systems (APTS), July 1996
} 


\section{Bibliography Appendix C}

Apogee Research Inc. And Wilbur Smith Associates, ITS National Investment and Market Analysis, Final Report, May 1997; available from ITS America, 400 Virginia Avenue, Suite 800, Washington, DC 200242730

Apogee Research Inc. And Wilbur Smith Associates, ITS National Investment and Market Analysis, Technical Working Paper: Task E - Estimation of Direct Benefits of ITS Deployment, May 1997

Apogee Research Inc., ITS-CVO Cost/Benefit Analysis: State Processes for Commercial Vehicle Operations (In progress)

Benefits Assessment of Advanced Public Transit Systems (APTS), July 1996

Contact Business Intelligent Center, SRI Consulting, 333 Ravenswood Avenue, Menlo Park, CA 940252516

ITI Benefits: Expected and Experienced, January 1996; Review of ITS Benefits: Emerging Successes, September 1996

SRI Consulting, Intelligent Transportation Systems, Market Report; Report 2, Part 1, ATMS, ETC, PVTMS, and CVO, September 1996, and Report Three, Part 1, IVNS, ATIS, IDIS, and VSC, March 1997 (Client Private) 


Publication Number: FHWA-JPO-98-002 12/97(1.5M)EW 